\title{
Data Mining em Grandes Redes: Superfícies de Coesão sobre Base Multidimensionalmente Escalonada
}

\author{
Francisco José Espósito Aranha Filho
}

\author{
Dissertação Apresentada ao \\ Instituto de Matemática e Estatística da \\ Universidade de São Paulo para \\ Obtenção do Grau de Mestre em Estatística
}

Área de Concentração: Estatística

Orientadora: Profa. Dra. Lúcia Pereira Barroso

São Paulo, Fevereiro de 2003. 
Data Mining em Grandes Redes:

Superfícies de Coesão sobre Base Multidimensionalmente Escalonada

Este exemplar corresponde à redação da dissertação após a incorporação de sugestões da comissão julgadora.

São Paulo, maio de 2003.

Banca Examinadora:

Profa. Dra. Lúcia Pereira Barroso (Orientadora) - IME - USP

Prof. Dr. Dalton Francisco de Andrade - UFSC

Prof. Dr. Norberto Antônio Torres - FGV-EAESP 


\section{Resumo}

Tendo como motivação o desenvolvimento de uma representação gráfica de redes com grande número de vértices, útil para aplicações de Filtro Colaborativo, este trabalho propõe a utilização de superfícies de coesão sobre uma base temática multidimensionalmente escalonada. Para isso, utiliza uma combinação de Escalonamento Multidimensional Clássico e Análise de Procrustes, em algoritmo iterativo que encaminha soluções parciais, depois combinadas numa solução global. Aplicado a um exemplo de transações de empréstimo de livros pela Biblioteca Karl A. Boedecker, o algoritmo proposto produz saídas interpretáveis e coerentes tematicamente, e apresenta um stress menor que a solução por Escalonamento Clássico.

\section{Palavras-Chave}

Análise de Procrustes; Análise de Redes; Escalonamento Multidimensional; Data Mining; Link Analysis; Cooperação Indireta; Distância Temática; Filtro Colaborativo; Teoria dos Grafos. 


\section{Abstract}

In this dissertation, a graphical representation of large networks based on the use of cohesion surfaces over a multidimensionally scaled thematic base is proposed as a tool for Collaborative Filtering. For its development Classic Multidimensional Scaling and Procrustes Analysis are combined in an iterative algorithm, which consolidates partial solutions into an overall continuous representation. Tested on a set of book lending trasactions at the Karl A. Boedecker Library, the algorithm produces an output that is thematically interpretable and consistent, with a stress measure smaller than Classic MDS solutions.

\section{Key-Words}

Collaborative Filtering; Data Mining; Graph Theory; Indirect Cooperation; Link Analysis; Multidimensional Scaling; Procrustes Analysis. 


\section{Agradecimentos}

Gostaria de registrar meus agradecimentos:

- à Profa. Lúcia Barroso pela orientação, apoio e confiança;

- aos Profs. Norberto Torres e Dalton de Andrade pelas valiosas críticas e sugestões;

- aos auxiliares de pesquisa Alfredo Roberto Jr, Priscila Rosa e Sandro Venezuela, cujo suporte foi decisivo na realização da pesquisa;

- ao NPP - Núcleo de Pesquisas e Publicações da FGV-EAESP, pelo apoio financeiro para a realização do projeto. 
Data Mining em Grandes Redes:

Superfícies de Coesão sobre Base Multidimensionalmente Escalonada

\section{Sumário}

RESUMO …...................................................................................................................... II

PALAVRAS-CHAVE …….................................................................................................................... II

ABSTRACT .......................................................................................................................................III

KEY-WORDS ..............................................................................................................................III

AGRADECIMENTOS......................................................................................................................IV

PRIMEIRA PARTE: INFORMAÇÕES PRELIMINARES...................................................1

1. ORGANIZAÇÃO DO TRABALHO ………………………………………………………....

2. INTRODUÇÃ̂

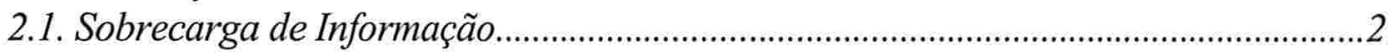

2.2. Respostas Tecnológicas à Sobrecarga de Dados ......................................................

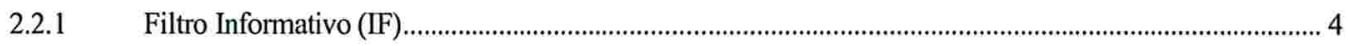

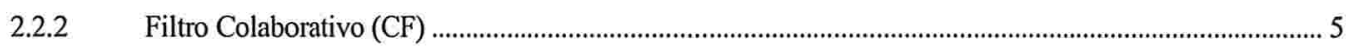

3. PESQUISAS ANTERIORES....................................................................................7

3.1. Projeto 1: Colaboração Indireta na Biblioteca Karl A. Boedecker (ARANHA, 2001a)

3.2. Projeto 2: Análise de Redes no Sistema de Recomendações (ARANHA, 2001b) .......8

4. OBJETIVO DESTE TRABALHO …………………………………………………..... 10

4.1. Superficie de Coesão sobre Base Multidimensionalmente Escalonada ................... 10

4.2. Criação de um Algoritmo Escalável para a Implementação da Nova Estratégia... 12

SEGUNDA PARTE: DEFINIÇÕES E TÉCNICAS ESTATÍSTICAS ............................... 13

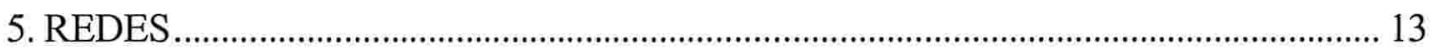

5.1. Definições e Notação...................................................................................... 13

5.2. Análise de Redes Sociais (Social Network Analysis) ................................................. 14

5.3. Problemas Clássicos e Contemporâneos com Estrutura de Rede............................. 15 
5.3.1 Difusão de Inovações ....................................................................................................................... 15

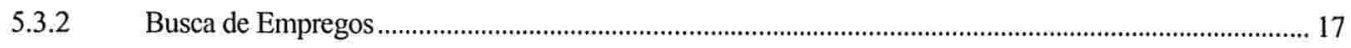

5.3.3 Internet ...................................................................................................................................... 17

5.3.4 Cooperação Indireta: Clientes de Uma Livraria Virtual ............................................................................ 18

6. ESCALONAMENTO MULTIDIMENSIONAL (MULTIDIMENSIONAL SCALING -

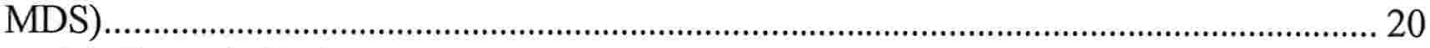

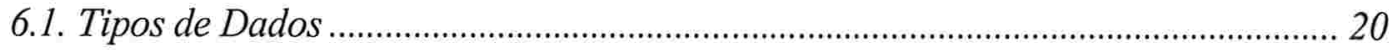

6.1.1 Escala de Medida.......................................................................................................................... 20

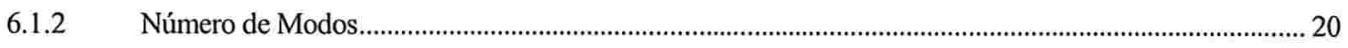

6.1.3 Número de Direções................................................................................................................. 20

6.2. Modelos de Escalonamento Multidimensional ........................................................ 21

6.2.1 Escalonamento Clássico........................................................................................................................ 21

6.2.2 Escalonamento Métrico por Mínimos Quadrados ............................................................................... 21

6.2.3 Escalonamento Não-Métrico ......................................................................................................... 22

6.2.4 Análise Procrustes ........................................................................................................................ 22

6.2.5 Outros Modelos ................................................................................................................................ 22

7. ALGUNS DETALHES SOBRE MDS CLÁSSICO E PROCRUSTES ........................ 23

7.1. MDS Clássico ........................................................................................................... 23

7.1.1 Implementação da Função cmdscale no R.............................................................................................. 24

7.2. Procrustes .......................................................................................................... 25

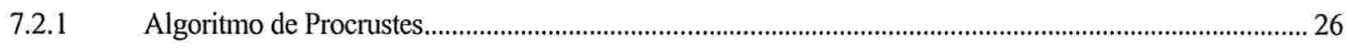

TERCEIRA PARTE: FORMULAÇÃO DO PROBLEMA E ENCAMINHAMENTOS

8. TRÊS ARQUIVOS COM DADOS PARA EXEMPLO .................................................... 27

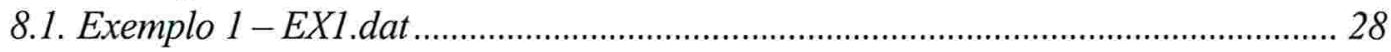

8.2. Resumo Comparativo dos Três Arquivos de Exemplos .............................................. 30

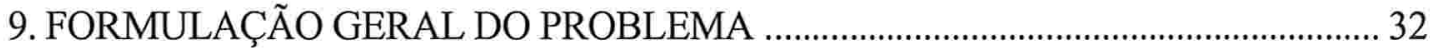

9.1. Pré-Processamento da Lista de Transações .............................................................. 32

9.2. Redes Bimodais e Redes Monomodais ...................................................................... 34

9.3. Cálculo e Armazenamento das Distâncias Temáticas................................................ 36

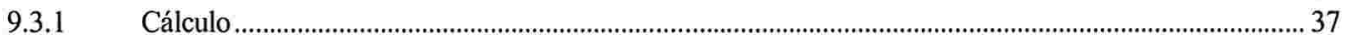

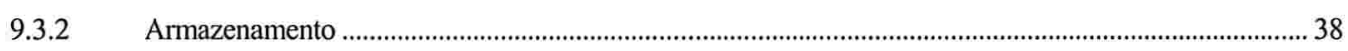

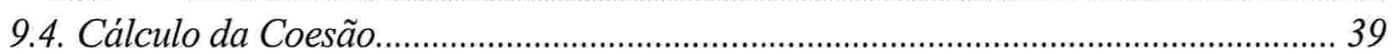

9.5. Representação da Rede Em Espaço Temático ........................................................ 39

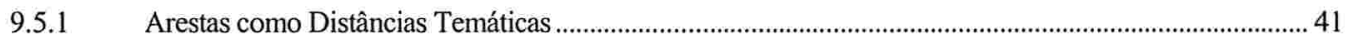

9.6. Substituição de Arestas por Superficie de Coesão................................................. 45 
10. BASE ESCALONADA

10.1. Quebrando o Problema em Partes Hierarquizadas (Agrupando de Baixo para Cima) 50

10.2. Coleta das Listas de Arestas .................................................................................. 52

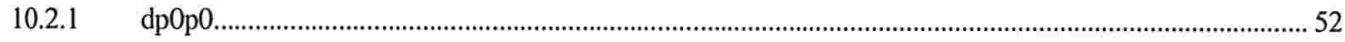

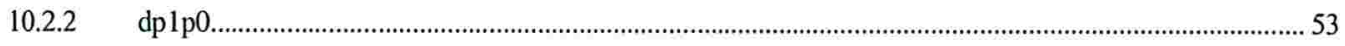

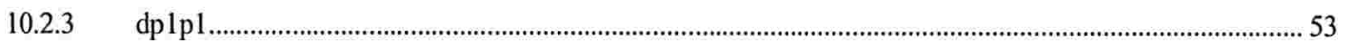

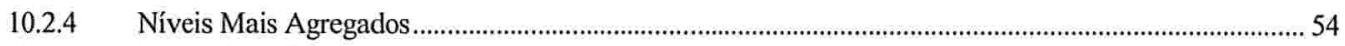

10.3. Escalonando (de Cima para Baixo) ....................................................................... 54

10.3.1 Configuração do Último Nivel (Nível Mais Elevado)............................................................................. 54

10.3.2 Triangulando e Encontrando Soluções Parciais............................................................................... 55

10.3.3 Juntando as Soluções Parciais................................................................................................................ 61

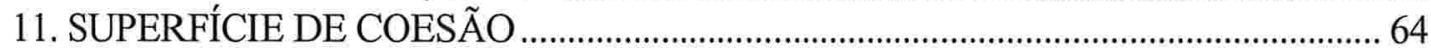

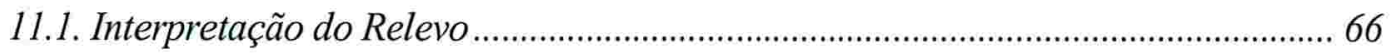

11.2. Estratégia de Implementação da Representação Gráfica ........................................ 69

12. PARTICULARIDADES DO PROBLEMA DE COOPERAÇÃO INDIRETA ........... 71

12.1. Matriz de Adjacência Escassa ............................................................................... 71

12.2. Matriz de Distâncias Temáticas Escassa ........................................................... 72

12.3. Distribuição das Distâncias Temáticas.................................................................. 72

12.3.1 Matriz D de Distâncias Temáticas..................................................................................................... 72

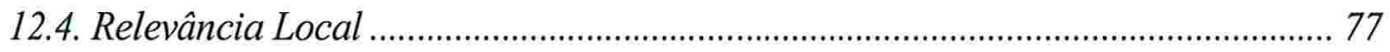

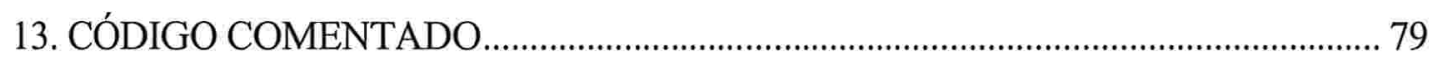

13.1. R

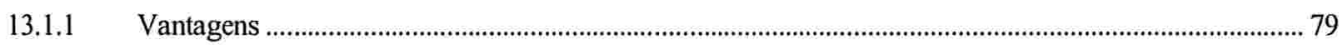

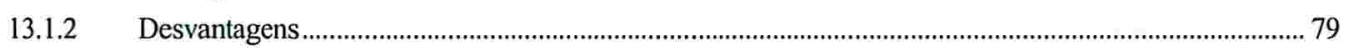

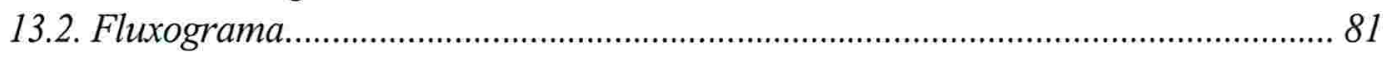

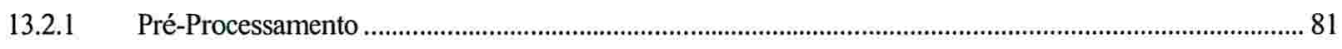

13.2.2 Lista Vizinhos e Distância Temática ............................................................................................................... 81

$13.2 .3 \quad$ "Sobe"

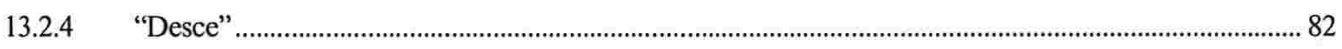

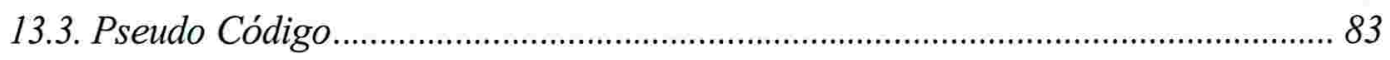

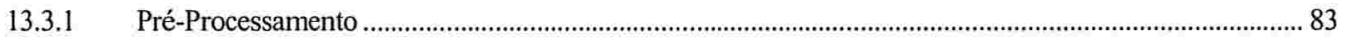

13.3.2 Lista Vizinhos e Distância Temática ........................................................................................... 83

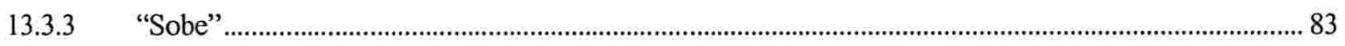

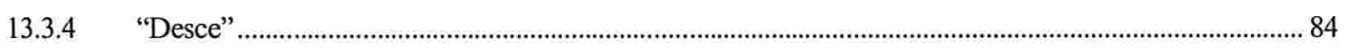

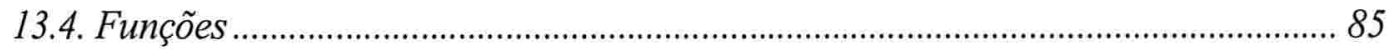


14. COMPARAÇÃO DE DUAS SOLUÇÕES: MDS CLÁSSICO E ALGORITMO PROPOSTO.

14.1. Para a Aplicação, o MDS Clássico Não É Boa Referência .................................... 86

14.1.1 MDS Clássico Fornece Solução Praticamente Arbitrária ....................................................................... 87

14.1.2 Algoritmo Proposto Produz Stress Menor Onde Interessa................................................................. 88

QUARTA PARTE: FECHAMENTO ...................................................................................... 91

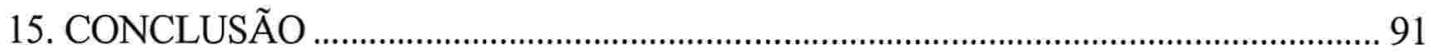

15.1. Data Mining: Problemas e Soluções na Representação de Redes ......................... 91

16. CONTRIBUIÇÕES DO TRABALHO ......................................................................... 92

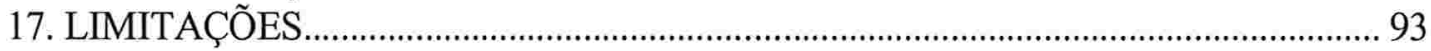

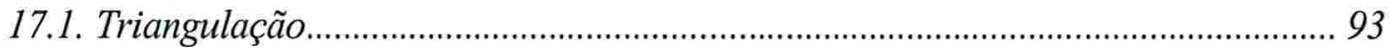

17.2. Informática, Interface …………………………………………………….... 93

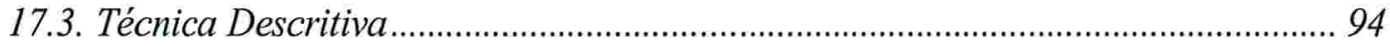

17.4. Isolamento da Base de Dados........................................................................... 94

17.5. Desconexão de Interface Gráfica ......................................................................... 94

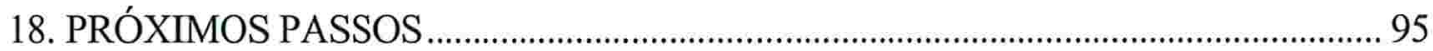

18.1. Aperfeiçoamentos Planejados........................................................................... 95

18.1.1 Triangulação - Remoção de Bug Conhecido e Aproveitamento de Redundância ................................... 95

18.1.2 Iteração no Cálculo da Distância Temática............................................................................................... 95

18.1.3 Aperfeiçoamento do Ajuste por Procrustes......................................................................................... 95

18.1.4 Ajuste Fino: Uma Janela Voadora.....................................................................................................95

18.1.5 Stress Deve ser Indiferente a Distorções de $\delta_{\mathrm{ij}}=1$ para $\mathrm{d}_{\mathrm{ij}}>1$............................................................. 96

18.2. Idéia Novas para Interpretação dos Resultados ................................................. 96

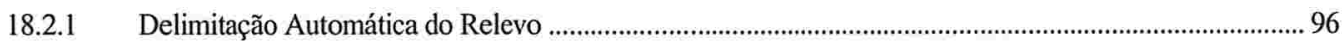

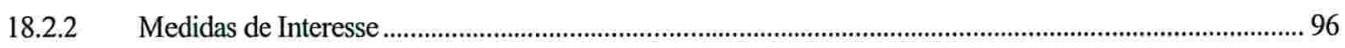

18.2.3 Identificação de "Conectores" ................................................................................................................... 96

19. ANEXO : LISTAGEM DAS FUNÇÕES IMPLEMENTADAS EM R ……………….. 97

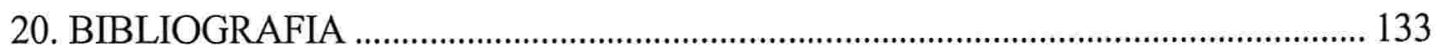

ÍNDICE REMISSIVO.................................................................................................................. 138 


\section{Figuras}

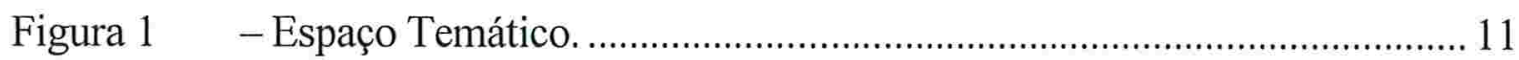

Figura 2 - Relevo de Subgrupos Especializados................................................ 12

Figura 3 - Interface Principal do Sistema de Recomendações da Amazon.com... 19

Figura 4 - Representação Gráfica da Rede do Exemplo 1. ...................................... 29

Figura 5 -Exemplo de Remoção de Cílio …………………………………………....... 33

Figura 6 - Fluxograma do Pré-Processamento ………………………………....... 34

Figura 7 - Matrizes de Adjacência A e $\mathrm{A}^{2}$ do Exemplo 1, .....................................35

Figura 8 - Representação Gráfica da Rede de Usuários do Exemplo 1.................36

Figura 9 -Diversas Representações de um Grafo de Ordem 10 e Tamanho 15 ... 41

Figura 10 - Rede do Exemplo 1 em Espaço Temático (sem Legenda de Pontos)... 42

Figura 11 - Rede do Exemplo 1 em Espaço Temático (com Legenda de Pontos).. 43

Figura 12 - Rede do Exemplo 2 em Espaço Temático (sem Legenda de Pontos).. 44

Figura 13 -Rede do Exemplo 2 em Espaço Temático (com Legenda de Pontos).. 45

Figura 14 - Superfície de Coesão do Exemplo 1. ......................................................... 47

Figura 15 - Superfície de Coesão do Exemplo 2 2 ....................................................... 48

Figura 16 - Alocação de Vértices a Grupos e Criação de Representantes................50

Figura 17 - Redução do Número de Vértices em Iterações Sucessivas..................... 51

Figura 18 - Arquivo de Exemplo 2: Vértices da Rede ...............................................52

Figura 19 - Centróides de Nível 1 do Exemplo 2, com Rótulos de Vértices............55

Figura 20 - Triangulação dos Vértices do Nível 1 do Exemplo 2..............................58

Figura 21 - Configuração no Triângulo 1 do Exemplo 2 .............................................. 61

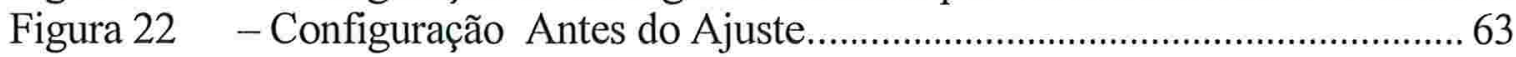

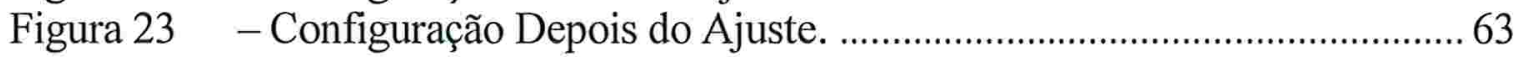

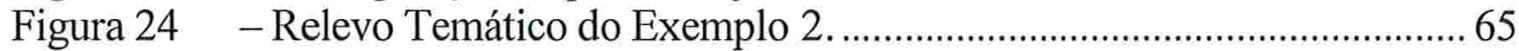

Figura 25 - Legenda dos Vértices da Rede do Exemplo 2........................................ 66

Figura 26 - Retícula sobre os Vértices do Exemplo 2............................................ 70

Figura 27 - Histograma das Distâncias Temáticas entre Usuários do Exemplo 1..73

Figura 28 - Histograma das Distâncias Temáticas do Exemplo 2 ………………..... 75

Figura 29 - Histograma das Distâncias Temáticas do Exemplo 3. ............................. 77

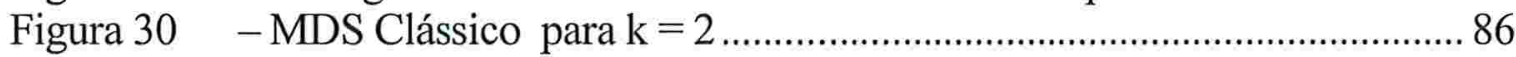

Figura 31 - Algoritmo Proposto........................................................................ 86

Figura 32 - Scree-plot dos Componentes do Exemplo 2 2...................................... 88

Figura 33 - Distribuição do Stress .......................................................................... 89 


\section{Tabelas}

Tabela 1 - Principais Características das Técnicas de IR, IF e CF ............................... 4

Tabela 2 - Resumo Comparativo dos Arquivos de Exemplos....................................... 30

Tabela 3-Distâncias do Primeiro "Triângulo" .................................................................. 59

Tabela 4-Configuração Processada no Triângulo 1 do Exemplo 2 ............................... 60

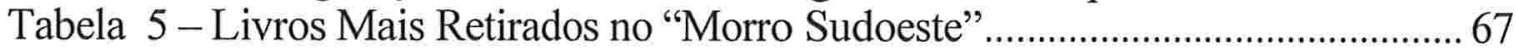

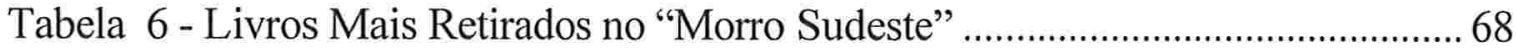

Tabela 7 - Livros Mais Retirados no "Morro Norte" ...................................................... 69

\section{Saídas}

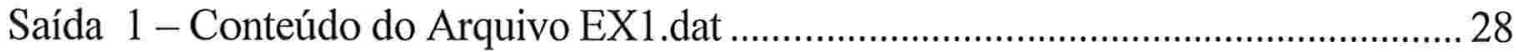

Saída 2 - Arquivo EX1.dat Pré-Processado .................................................................... 29

Saída 3 - Matriz de Adjacência do Exemplo 1.................................................................. 30

Saída 4 - Lista de Vizinhos dos Nós de Usuários no Exemplo 1.................................. 37

Saída 5-Distâncias Temáticas entre Usuários do Exemplo 1..................................... 38

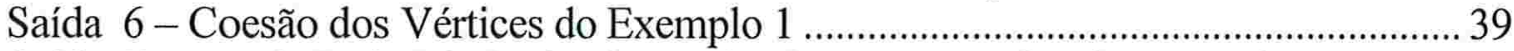

Saída 7 - Matriz D de Distâncias (Temáticas) entre Usuários do Exemplo 1 1............. 72

Saída 8 - Distâncias Temáticas entre Nós de Usuários do Exemplo 2 ......................... 74

Saída 9 - Distâncias Temáticas entre Nós de Usuários do Exemplo 3 ......................... 76 


\section{Primeira Parte: Informações Preliminares}

\section{ORGANIZAÇÃO DO TRABALHO}

$\mathrm{O}$ presente trabalho está organizado em quatro partes. Na primeira, apresentamos o problema do ponto de vista da aplicação e do contexto em que ele surgiu; na segunda, fixamos notação e algumas definições e revisamos sucintamente duas técnicas estatísticas (MDS Clássico e Procrustes Analysis) utilizadas na solução.

Em seguida, na terceira parte encaminhamos a solução computacional; e na quarta, apresentamos nossas conclusões, limitações do trabalho e possíveis desdobramentos. 


\section{INTRODUÇÃO}

Com o avanço da informática e das telecomunicações, o volume de informações disponíveis sobre todos os aspectos da atividade humana, e em todos os ramos da ciência, passou a crescer a taxas vertiginosas:

"Nos últimos trinta anos, produziu-se um volume de informações novas maior do que [o volume produzido] nos cinco mil anos precedentes. Cerca de mil livros são publicados no mundo por dia, e o total do conhecimento impresso duplica a cada oito anos." (LARGE, 1984)

\subsection{Sobrecarga de Informação}

$\mathrm{O}$ aumento da capacidade de se analisarem estes dados não é proporcional ao crescimento da oferta. A possibilidade de acesso dos usuários aos dados é limitada, quando não por outros motivos, ao menos pela finitude do tempo disponível para examiná-los; assim, a maior parte do conteúdo disponível permanece sem utilização, e mesmo quando as informações chegam a ser escrutinadas, encontram uma capacidade humana de absorção e entendimento também restrita. Uma estimativa eloqüente indica, por exemplo, que o leitor contemporâneo de um jornal de qualidade recebe mais informação em um único domingo do que um cidadão vivendo na Inglaterra do século XVII recebia ao longo de toda a sua vida (WURMAN, 1991). No mesmo período a expectativa de vida de um inglês passou de cerca de 45 para cerca de 80 anos.

Como resposta ao desafio apresentado pela sobrecarga de dados, o ser humano aplica suas habilidades cognitivas, lingüísticas e sociais no desenvolvimento de estratégias para fazer avaliações rápidas de relevância e escopo: cotidianamente, por exemplo, julgam-se livros pela capa, artigos pelo abstract e filmes pelo trailer. Os jornais de domingo são lidos apenas muito "na diagonal". Em Marketing, sabe-se que, como parte do processo decisório de compra de produtos, o consumidor envolve-se numa coleta de informações limitada e seletiva, apoiando sua decisão final em uma fração pequena do total de informações disponíveis (NEWMAN e STAELIN, 1972; MIDGLEY, 1983; BEATTY e SMITH, 1987). Estas são todas estratégias racionais, em que se troca eficácia por eficiência, a taxas amplamente vantajosas. Ademais, 
diversas formas de inteligência artificial têm sido desenvolvidas e utilizadas no tratamento destes dados.

\subsection{Respostas Tecnológicas à Sobrecarga de Dados}

Há três tipos de tecnologia usualmente empregados para minorar os efeitos da sobrecarga de dados (GOOD, SCHAFER e OUTROS, 1999), cada um focalizado num conjunto distinto de aspectos do problema. A Recuperação de Informação (IR, Information Retrieval) atende interesses efêmeros, respondendo a consultas ad hoc, do tipo "quantos clientes compraram sabão em pó em nossas lojas da zona sul nos últimos três meses?" O Filtro Informativo (IF, Information Filtering) trata de tarefas ligadas à classificação de novos fluxos de conteúdo em categorias pré-definidas ("Sobre qual assunto versa este novo livro do acervo?") e ligadas à comparação do ajuste destes conteúdos ao perfil de interesse dos usuários ou consumidores ("Quem se interessa por livros deste assunto?"). Finalmente, o Filtro Colaborativo (CF, Collaborative Filtering) dedica-se a produzir indicadores da relevância localizada de itens de informação, com base na análise da manipulação destes itens por grupos de usuários com interesses especializados ("Que usuários tomam emprestados muitos livros em comum? Apresentemos a cada um no grupo os livros não consultados por ele, mas presente no acervo do grupo". A Tabela 1, a seguir, resume as principais características destas três técnicas; nas subseções 2.2.1 e 2.2 .2 as técnicas são discutidas (com exceção das características da IR, que não são de interesse neste trabalho). 
Tabela 1 - Principais Características das Técnicas de IR, IF e CF

\begin{tabular}{|c|c|c|c|}
\hline Técnica & $\begin{array}{l}\text { Participação do } \\
\text { Usuário }\end{array}$ & $\begin{array}{c}\text { Principais } \\
\text { Procedimentos }\end{array}$ & $\begin{array}{c}\text { Traços } \\
\text { Distintivos }\end{array}$ \\
\hline $\begin{array}{c}\text { Information } \\
\text { Retrieval (IR) }\end{array}$ & $\begin{array}{c}\text { Ativa, na } \\
\text { formulação das } \\
\text { consultas }\end{array}$ & $\begin{array}{c}\text { Indexação de } \\
\text { documentos } \\
\text { segundo várias } \\
\text { chaves }\end{array}$ & $\begin{array}{l}\text { Não captura } \\
\text { preferências do } \\
\text { usuário }\end{array}$ \\
\hline $\begin{array}{l}\text { Information } \\
\text { Filtering (IF) }\end{array}$ & $\begin{array}{c}\text { Geralmente ativa, } \\
\text { na criação de } \\
\text { perfil de } \\
\text { interesses ou } \\
\text { necessidades }\end{array}$ & $\begin{array}{c}\text { Análise e } \\
\text { classificação de } \\
\text { conteúdos; } \\
\text { comparação do } \\
\text { perfil do conteúdo } \\
\text { com o perfil do } \\
\text { usuário }\end{array}$ & $\begin{array}{l}\text { O número de } \\
\text { usuários é } \\
\text { irrelevante; eficaz } \\
\text { na circulação de } \\
\text { novos itens de } \\
\text { informação; } \\
\text { ineficaz na } \\
\text { diversificação do } \\
\text { conteúdo sugerido }\end{array}$ \\
\hline $\begin{array}{c}\text { Collaborative } \\
\text { Filtering (CF) }\end{array}$ & $\begin{array}{l}\text { Passiva, os } \\
\text { usuários do } \\
\text { sistema não } \\
\text { precisam fornecer } \\
\text { inputs; o sistema, } \\
\text { encarrega-se de } \\
\text { obter os inputs a } \\
\text { partir da } \\
\text { observação do } \\
\text { comportamento } \\
\text { dos usuários }\end{array}$ & $\begin{array}{c}\text { Análise e } \\
\text { classificação do } \\
\text { comportamento } \\
\text { dos usuários; } \\
\text { consolidação de } \\
\text { listas de itens com } \\
\text { relevância local }\end{array}$ & $\begin{array}{l}\text { Exige um número } \\
\text { grande de } \\
\text { usuários; não } \\
\text { analisa o } \\
\text { conteúdo dos } \\
\text { itens; lento na } \\
\text { circulação de } \\
\text { novos itens de } \\
\text { informação; } \\
\text { eficaz na } \\
\text { diversificação de } \\
\text { conteúdos }\end{array}$ \\
\hline
\end{tabular}

\subsubsection{Filtro Informativo (IF)}

O IF, também chamado de Filtro de Conteúdo, é uma das técnicas já tradicionais na seleção de informações relevantes dentro de um conjunto volumoso de dados disponíveis (SMYTH e COTTER, 2000). Seu sucesso apoia-se na habilidade de

- representar acuradamente cada item de informação no acervo, com base em um subconjunto de suas características, principalmente seu enquadramento em uma tipologia temática; e de 
- representar o interesse do usuário através de um perfil baseado no mesmo subconjunto de características extraídas dos itens.

Neste contexto, a relevância de um item para um usuário é proporcional à similaridade do perfil do item ao perfil do usuário; os itens selecionados para serem submetidos à atenção do usuário são os mais parecidos com o seu perfil de interesse.

O problema da utilização de Filtros Informativos é justamente a necessidade de se caracterizarem os itens e o interesse dos usuários: esta atividade é complexa, onerosa, e requer conhecimento especializado sobre cada campo do conhecimento humano. Numa biblioteca, por exemplo, a caracterização dos itens corresponde ao processo de classificação, indexação e catalogação dos novos livros ou periódicos. Para usufruir do sistema de IF, o usuário também necessita informar ativamente, e com precisão, o perfil do seu interesse.

Mesmo concluída com sucesso a etapa de caracterização dos itens e do perfil do usuário, as recomendações por meio de IF terão sempre um escopo limitado, uma vez que esta técnica somente seleciona itens em que as duas caracterizações se aproximam. Como o perfil do usuário é explicitamente construído num ponto fixo do tempo (e raramente atualizado), ou inferido com base no registro de escolhas anteriores, um subespaço temático tende a ser reforçado, principalmente no caso de usuários novos para o sistema. Os itens recomendados podem ser relevantes, mas nem de longe correspondem à amplitude total dos interesses do usuário. Por estes motivos, o sistema tampouco permite descobertas serendipitosas (serendipitous), isto é, descobertas que se fazem sem que se procure pelo item encontrado.

\subsubsection{Filtro Colaborativo (CF)}

Em contraposição ao Filtro Informativo, as técnicas de Filtro Colaborativo movem-se para além da experiência de cada usuário isolado: procuram valerse das experiências de grupos de usuários. Em vez de identificar a semelhança entre usuários e itens, busca localizar usuários parecidos entre si. Sendo parecidos os membros de um grupo, o que se descobre pelo monitoramento de seu comportamento no sistema, infere-se que os itens de 
interesse para um membro do grupo também serão de interesse para os demais membros.

A grande vantagem desta estratégia é não ser necessário entrar no mérito do conteúdo dos itens. O grande problema é que itens novos, conhecidos por poucos usuários, demoram a aparecer como sugestões, isto é, novos itens têm um longo período de latência. Assim, por exemplo, um grande fã de Woody Allen teria que esperar até um novo filme deste diretor ter sido assistido por muitos membros de seu grupo, para só então o filme surgir como recomendação. Um sistema de Filtro Informativo detectaria a proximidade de perfis (filme de Woody Allen/gosto por filmes de Woody Allen) imediatamente, fazendo a recomendação independentemente do filme já ter sido muito assistido.

Também fora do domínio da criação de sistemas de recomendação, várias iniciativas de implementação de Filtro Colaborativo foram documentadas recentemente. PAYTON (1998) procurou facilitar o contato entre pessoas com interesses comuns, explicitando seu padrão de navegação na Internet. KAUTZ, SELMAN e SHAH (1997a, 1997b) caracterizaram redes de pesquisadores que mantinham vínculos sociais, analisando a co-ocorrência de nomes em documentos públicos na Internet. SCHWARTZ e WOOD (1993) identificaram colaboradores potenciais pela análise do tráfego de emails em pontos selecionados da rede. SWANSON e SMALHEISER (2000) desenvolveram o software Arrowsmith para identificar relações pouco evidentes entre achados científicos na área de biomédicas.

Caminhando em direção oposta, isto é, perseguindo o objetivo de dificultar a cooperação, foram publicados vários trabalhos na área de detecção de fraudes contra companhias seguradoras e de saúde (CABENA e OUTROS, 1997) combate à lavagem de dinheiro e combate ao crime organizado em geral (JENSEN, 1999; HANN 1998). 


\section{PESQUISAS ANTERIORES}

O problema de pesquisa a ser abordado neste trabalho materializou-se no decorrer de dois projetos de Filtro Colaborativo anteriormente realizados. Para esclarecer-lhe o contexto, convém reportar brevemente os projetos precedentes.

\subsection{Projeto 1: Colaboração Indireta na Biblioteca Karl A. Boedecker (ARANHA, 2001a)}

No esforço de reagir à perda da posição de fornecedor privilegiado de informações, decorrente do avanço de fontes alternativas como a Internet, as bibliotecas precisam reformular seu papel e seus objetivos (CARSON e OUTROS, 1997). Dentre as mudanças necessárias, destacam-se (Stephen Abram, segundo MILLER, 1998):

- o reposicionamento da biblioteca como mapeadora e auditora de conteúdos internos e externos à organização, e não como mera gerenciadora do acervo; e

- a transferência do foco das operações para 0 usuário e seu comportamento; esta mudança se manifesta através do cultivo de relacionamentos pró-ativos e personalizados com os usuários, segundo os princípios do marketing um-a-um (PEPPERS e ROGERS, 1999).

Interessada em investigar as possibilidades concretas de iniciativas imbuídas deste espírito de reformulação, a Biblioteca Karl A. Boedecker (KAB) apoiou, ao longo de 1999, a realização de um projeto piloto de Sistema de Recomendações de títulos aos usuários. A idéia básica era de que o sistema deveria pró-ativamente chamar a atenção do usuário para itens que inferisse serem do seu interesse.

Para o teste do protótipo do sistema foram analisadas 22.500 transações de empréstimo ocorridas entre 01/03 e 19/07/1999 e selecionados 410 usuários entre professores e alunos de pós-graduação para a geração de recomendações. SANTOS (2000) desenhou e implementou o necessário data mart das transações. 
O protótipo resultante do Projeto 1 foi organizado em torno de duas funcionalidades críticas (ARANHA, 2000):

- a identificação de Assuntos Significativos (AS), que são grandes categorias temáticas dos itens do acervo; e

- a formação de Subgrupos Especializados (SGE), de usuários com interesses semelhantes.

Estes dois núcleos funcionais foram implementados, respectivamente, por meio de técnicas de Análise de Cestas (BERRY e LINOFF, 1997 e 2000) e de Análise de Agrupamentos (BUSSAB, MIAZAKI e ANDRADE, 1990; HAIR, TATHAM e OUTROS, 1991; JOHNSON e WICHERN, 2002).

\subsection{Projeto 2: Análise de Redes no Sistema de Recomendações (ARANHA, 2001b)}

No período de abril a dezembro de 2000 , foi realizado um segundo projeto de pesquisa ligado ao Sistema de Recomendações da Biblioteca KAB, com objetivo de substituir as técnicas de Análise de Agrupamentos empregadas no "motor" da funcionalidade de criação dos Subgrupos Especializados por técnicas de Análise de Redes, conforme sugerido na bibliografia de Filtro Colaborativo (por exemplo, em SCHWARTZ e WOOD, 1993).

$\mathrm{Na}$ abordagem por Análise de Redes, a movimentação de consultas ao acervo da biblioteca é representada graficamente por meio de um diagrama de rede, em que livros e usuários são representados por nós (ou vértices) e as transações de empréstimo, por arestas. Alternativamente, a rede pode ser representada por uma matriz de adjacência em que linhas e colunas são nós (livros e usuários), e as arestas (transações de empréstimo) são representadas por números nas caselas da matriz. Por hora, basta saber que vértices e arestas são os objetos por meio dos quais estruturas de dados de interesse na aplicação de Filtro Colaborativo podem ser representados. O leitor não familiarizado com os conceitos de grafo ou rede talvez deseje folhear a seção 5 , onde o tema de redes é tratado em maior detalhe. Ali, a Figura 4, na página 29, traz um exemplo de rede e a Figura 7, na página 35, traz um exemplo de matriz de adjacência. 
No segundo projeto da biblioteca $\mathrm{KAB}$, uma medida de distância temática (ARANHA, 2001b), inicialmente desenvolvida para variáveis dicotômicas, foi generalizada e aplicada a matrizes de co-ocorrências (ARANHA, 2001b), permitindo o aproveitamento de toda a informação disponível sobre o comportamento dos usuários com relação aos itens consultados. O cálculo das distâncias temáticas foi realizado por meio de rotinas escritas no software SPlus, suficientes para o processamento de lotes de até (estimados) 10.000 usuários.

Como resultado das alterações no Sistema de Recomendações, os usuários foram reclassificados em novos Subgrupos Especializados, para os quais Listas-Base e Listas Personalizadas (ARANHA, 2001b) foram geradas segundo o procedimento definido no projeto anterior.

Por um lado, o "motor" da funcionalidade de geração de SGE foi considerado um avanço com relação ao mecanismo anterior, e suficiente para as necessidades da KAB, uma vez que a biblioteca tem cerca de 6.000 usuários ativos. Por outro lado identificou-se na estratégia adotada uma fragilidade: o tamanho máximo do grupo de usuários passível de análise (10.000 usuários) era relativamente pequeno, principalmente quando se consideram os volumes típicos de usuários de aplicações para a Internet. O limite decorria do fato de que a necessidade de arquivo e memória RAM para processamento das rotinas do "motor" de SGE aumentava exponencialmente conforme crescia o número de usuários em análise.

No final de 2000, com o aparecimento da oportunidade de aplicação do Sistema de Recomendações desenvolvido nos Projetos 1 e 2 aos clientes de uma grande livraria virtual brasileira, o limite de processamento foi rapidamente atingido e mostrou-se uma restrição inaceitável em situação real de mercado. O sistema comprovou-se não escalável, tornando inviável sua utilização com os recursos computacionais disponíveis, quando o número de clientes processados se aproximou dos previstos 10.000 usuários. 


\section{OBJETIVO DESTE TRABALHO}

O objetivo deste trabalho é propor e testar uma nova estratégia de utilização de Análise de Redes (AR) como técnica de Filtro Colaborativo, oferecendo alternativas para superar os problemas de explosão combinatória enfrentados na sua aplicação a grafos com elevado número de vértices.

Em particular, pretendemos:

- utilizar medidas caracterizadoras dos nós de uma rede (em termos de conectividade em sua vizinhança e de proximidade temática com outros nós) para criar uma representação contínua da rede (subseção 4.1, a seguir); e

- desenvolver um algoritmo que permita realizar o escalonamento multidimensional de um grande número de vértices, procedimento necessário à implementação da subseção anterior (veja discussão em 4.2, a seguir).

\subsection{Superfície de Coesão sobre Base Multidimensionalmente Escalonada}

O estudo da Teoria dos Grafos (veja seção 5) e a experiência adquirida nas pesquisas descritas na seção 3 , sugerem a conveniência da utilização conjunta de duas medidas de Análise de Redes na implementação do motor do módulo de Subgrupos Especializados (SGE). Estas medidas, definidas com maior detalhe na seção 5, são:

- $\mathrm{d}_{\mathrm{ij}}$, isto é, a distância (temática) entre dois usuários; e

- $\gamma_{\mathrm{i}}$, isto é, a coesão na vizinhança do vértice $i$.

A distância temática $d_{i j}$ será utilizada para posicionar, através de Escalonamento Multidimensional (MDS, veja seção 6), os usuários num plano chamado de "espaço de semelhanças temáticas". Ou seja, a partir do conhecimento da distância entre os vértices, procurar-se-á recompor o "mapa" que revela a sua posição relativa. A Figura 1 exemplifica um espaço temático hipotético para 5 usuários de uma biblioteca, considerando-se como nós da 
rede os usuários e os livros do acervo; e, como arestas, a ocorrência de uma transação de empréstimo, pela qual o usuário num extremo da aresta retirou o livro no outro extremo.

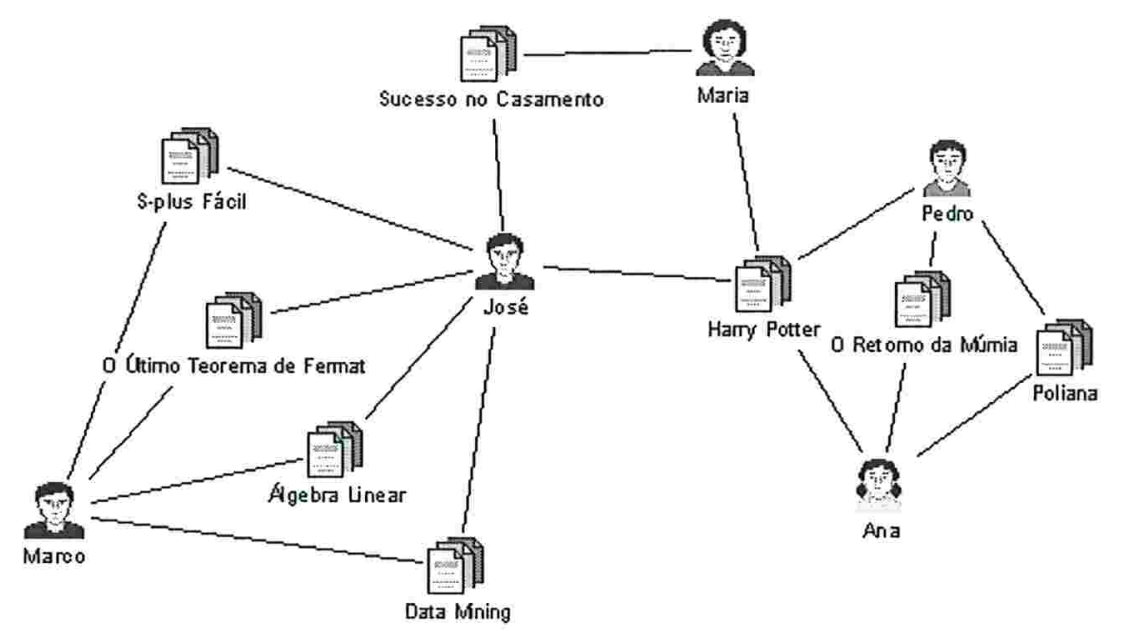

Figura 1 - Espaço Temático.

A outra medida, $\gamma_{i}$ será utilizada para formar uma superfície de coesão sobre a base temática. O exemplo hipotético na Figura 2, a seguir, apresenta uma rede em que somente os usuários de uma biblioteca são representados: a cada nó observado da rede (isto é, a cada usuário em análise, cujas coordenadas no "espaço temático" nesta etapa do algoritmo já serão conhecidas) será associada uma "altura" correspondente ao seu $\gamma_{\mathrm{i}}$. Os pontos do espaço temático para os quais não foram observados vértices terão suas alturas estimadas por interpolação. 


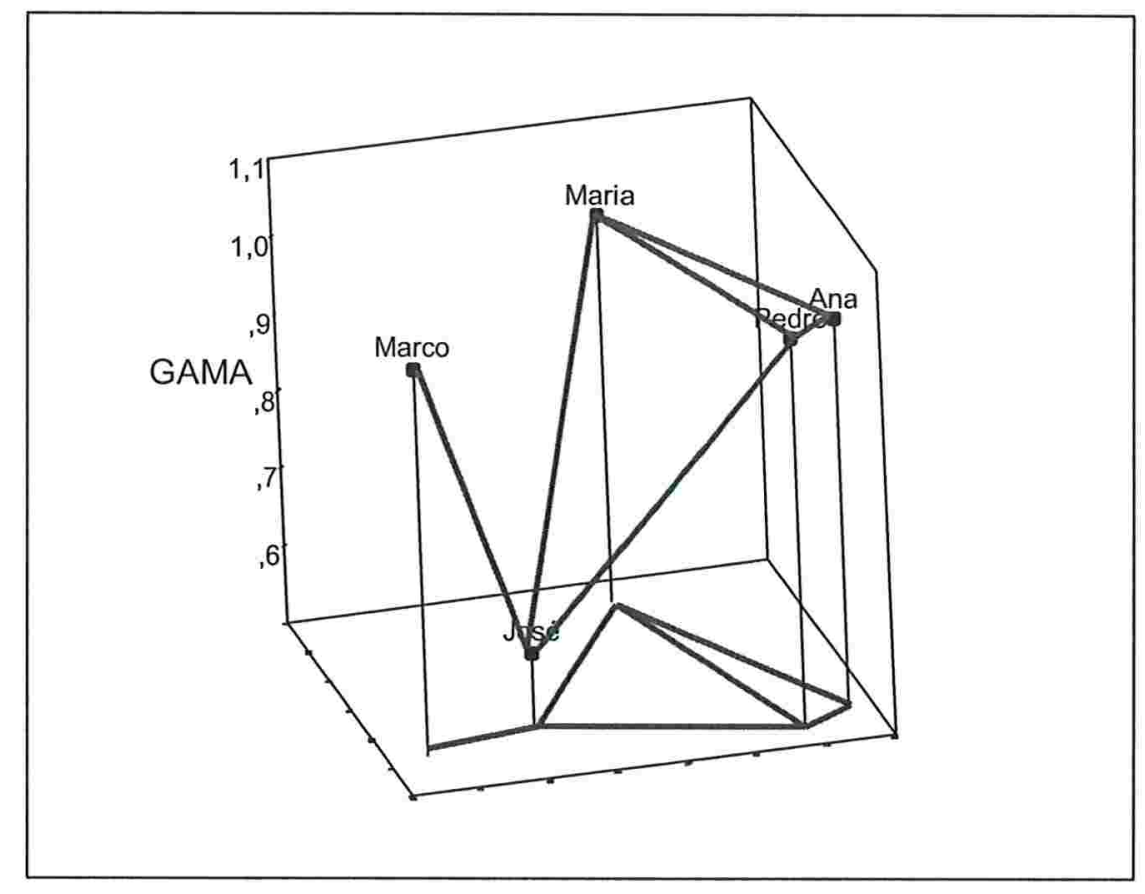

Figura 2 - Relevo de Subgrupos Especializados.

\subsection{Criação de um Algoritmo Escalável para a Implementação da Nova Estratégia}

$\mathrm{O}$ cálculo de $\mathrm{d}_{\mathrm{ij}}$ e da aplicação de MDS caracterizam-se por serem pouco escaláveis, isto é, um aumento no número de nós a serem analisados leva a uma explosão no número de cálculos necessários, tornando-os inviáveis em termos de capacidade computacional e tempo de processamento. Assim, será necessário propor um algoritmo cujo consumo de recursos cresça de forma viável com relação ao aumento do número de usuários a serem analisados.

Para isso, utilizaremos a estratégia de programação de "dividir para conquistar" (veja, por exemplo, AHO, HOPCROFT e ULLMAN, 1974), e particularidades do tipo de rede de interesse para o problema de Filtro Colaborativo (principalmente o fato da matiz de adjacências ser escassa e da distribuição de distâncias ter muita massa à direita - veja subseção 8.2). 


\section{Segunda Parte: Definições e Técnicas Estatísticas}

\section{REDES}

Muitas estruturas do mundo real podem ser representadas por pontos (também chamados nós ou vértices) e linhas (elos ou arestas). Uma abstração matemática destas estruturas leva ao conceito de grafos ou redes. TRUDEAU (1993) e WILSON (1996), entre outros, produziram textos de introdução ao assunto. BOLLOBÁS (1998) apresenta uma excelente síntese da teoria dos grafos, numa abordagem matematicamente mais formal; e em outro trabalho (BOLLOBÁS, 1985), sistematiza a teoria dos grafos aleatórios, inicialmente desenvolvida por Solomonoff e Rapoport em 1951 (BARABASI 2002) e por Erdos e Renyi em oito famosos artigos publicados entre 1959 e 1968 (GRAHAM e NESETRIL, 1997; CLUNG e GRAHAM 1998). BALAKRISHNAN (1997) produziu um resumo da teoria, do qual adaptamos a notação e as definições que se seguem (em BALAKRISHNAN, freqüentemente as definições são mais gerais do que é útil para o problema em análise; nestes casos, foram adotadas definições mais restritivas - e mais simples).

\subsection{Definições e Notação}

Um grafo $G$ consiste em um conjunto $V$ de vértices e uma coleção $E$ de pares (não ordenados e com elementos distintos) de vértices chamados de arestas. Neste trabalho, $V$ e $E$ são considerados finitos. A ordem, \#(V), de um grafo é o seu número de vértices e seu tamanho, \#(E), é o seu número de arestas.

Se os vértices $u$ e $v$ são unidos pela aresta $e$, dizemos que a aresta $e$ incide sobre $u$ e $v$; e que os vértices $u$ e $v$ incidem sobre a aresta $e$.

Dois grafos $G$ e $G^{\prime}$ são considerados idênticos se $V=V^{\prime}$ e $E=E^{\prime}$. E são considerados isomórficos se existe uma correspondência biunívoca $f$ de $V$ em $V$, chamada isomorfismo, tal que exista uma aresta entre $f(u)$ e $f(v)$ em $G$ ' se, e somente se, existir uma aresta entre $u$ e $v$ em $G$. Para todos os efeitos práticos, dois grafos isomórficos podem ser considerados como um mesmo grafo. 
O grafo $H=(W, F)$ é um subgrafo de $G=(V, E)$ se $W$ é subconjunto de $V$ e $F$ é subconjunto de $E$.

Lembrando que a definição adotada de grafo exclui a possibilidade de existência de uma alça fechada (loop), isto é uma aresta cujos dois extremos incidam no mesmo vértice, define-se grau de um vértice como o número de arestas nele incidentes.

Se $G=(V, E)$ é um grafo em que $V=\{1,2, \ldots, \mathrm{n}\}$, a matriz de adjacência $\mathbf{A}$ do grafo é a matriz $n \times n \mathbf{A}=\left[a_{\mathrm{ij}}\right]$, onde $a_{\mathrm{ij}}$, assume o valor 1 se os vértices $i, j$ são ligados por uma aresta (diz-se: são vizinhos, ou são adjacentes); e $a_{\mathrm{ij}}$ assume o valor 0 , caso contrário; como não existem loops, a diagonal de $\mathbf{A}$ é formada por zeros.

Define-se $\Gamma_{v}$, vizinhança do vértice $v$ pertencente a $G$, como o subgrafo de $G$ que contém todos os vértices adjacentes a $v$ e todas as arestas existentes entre estes; note que o próprio $v$ não faz parte de sua vizinhança (WATTS, 1999, pág 31). A coesão da vizinhança de $v$ (chamada de coeficiente de agrupamento, clustering coefficient, por Watts), representada por $\gamma_{v}$, é dada pelo número de arestas existentes na vizinhança dividido pelo número de arestas possíveis na vizinhança, ou seja, a proporção das arestas possíveis que é, de fato, observada (WATTS, 1999, pág.33).

Finalmente, entende-se por $d_{\mathrm{ij}}$, distância (temática) entre dois vértices de $G$, a quantidade 1- $\left[\#\left(\Gamma_{\mathrm{i}} \cap \Gamma_{\mathrm{j}}\right) / \#\left(\Gamma_{\mathrm{i}} \cup \Gamma_{\mathrm{j}}\right)\right]$, conceito adaptado de SCHWARTZ e WOOD (1993).

\subsection{Análise de Redes Sociais (Social Network Analysis)}

As técnicas de Análise de Redes (veja, por exemplo, KNOKE e KUKLINSKY, 1982; WASSERMAN e FAUST, 1994; WASSERMAN e GALASKEWICZ, 1994) caracterizam um objeto de interesse pelas suas relações com os demais objetos em estudo, em vez de os caracterizar por seus atributos individuais. Na área de Ciências Sociais, redes de relacionamentos podem ser especificadas por amizade, dominância, comunicação, etc. (KNOKE e KUKLINSKI, 1982). 
A literatura de Análise de Redes tem grande superposição com a Matemática e a Estatística quando tratam da Teoria dos Grafos. O segmento não coincidente diz respeito às aplicações da Teoria dos Grafos e à sua interpretação, no contexto das Ciências Sociais.

\subsection{Problemas Clássicos e Contemporâneos com Estrutura de Rede}

Inúmeros problemas práticos podem ser representados por meio de redes e endereçados com ferramentas de Teoria dos Grafos ou de Link Analysis. A título de exemplo, destacamos dois problemas clássicos, com papel importante no desenvolvimento teórico dos respectivos campos de conhecimento (difusão de inovações e procura de empregos), e dois problemas contemporâneos, de grande impacto social e econômico (acessibilidade de documentos na Internet e geração de conhecimento por cooperação indireta).

\subsubsection{Difusão de Inovações}

A difusão de inovações (ROGERS, 1995) é um processo de comunicação especial pelo qual idéias, conhecimento e tecnologias percebidas como novas são transmitidos ao longo do tempo entre os membros de um sistema social. Justamente em decorrência da novidade do conteúdo comunicado, o processo de difusão vem associado a um nível de incerteza que é reduzido pelo compartilhamento de informação.

Os canais de comunicação através dos quais mensagens passam de um indivíduo para outro formam uma rede social cuja estrutura tem forte impacto na velocidade e na taxa de adoção da inovação; a intensidade de comunicações homofílicas, isto é, entre nós semelhantes (GRANOVETTER, 1973; ROGERS, 1995) ou coesos, versus a intensidade de comunicações heterofílicas, isto é, entre nós dessemelhantes ou pouco coesos, também impacta fortemente o ritmo e as conseqüências do processo de adoção.

Exemplos de processos de difusão cujos fatores proeminentes de sucesso ou fracasso envolvem características da rede social subjacente são abundantes no clássico trabalho de ROGERS (1995); destacamos os de adoção de: uso de água fervida por moradores de uma vila no Peru; computadores pela alta administração de empresas em Pittsburgh; mecanização agrícola em uma 
comunidade holandesa; novos métodos de ensino de matemática em escolas do condado de Allegheny, Pennsylvania; novo antibiótico por uma comunidade de médicos. Todos eles, e os demais no livro de Rogers, são muito estimulantes de idéias para novas pesquisas.

\subsubsection{Desdobramento Recente: The Tipping Point}

Os modelos de difusão de inovação têm grande semelhança com modelos de disseminação de epidemias. Tanto assim que um dos exemplos apresentados por ROGERS (1995) no capítulo sobre redes de difusão (de inovação) é o caso do "Paciente Zero e Redes Sexuais no Início da Disseminação de AIDS".

GLADWELL (2000), em seu best seller internacional The Tipping Point, faz o caminho inverso e utiliza o modelo epidêmico para analisar o processo pelo qual idéias, modismos e comportamentos sociais disseminam-se por populações, principalmente nos casos em que o "contágio" atinge grandes proporções.

O objetivo de Gladwell é identificar os fatores que, convergindo, fazem um sistema social desequilibrar-se para além do limiar cujo trespasse garante à epidemia massa crítica suficiente para atingir um crescimento exponencial; e também, inversamente, é enumerar os motivos pelos quais a grande maioria das novas idéias, condutas ou produtos "não pegam", isto é, falham no processo de adoção, não atingem o limiar necessário. Neste esforço, destaca a importância de certos nós especiais da rede social; e do contexto fornecido pela rede aos nós individuais. Para consubstanciar sua análise, apresenta, entre outros, os casos da epidemia de sífilis em Baltimore nos anos 90, do programa infantil Vila Sésamo, de uma empresa de alta tecnologia de Delaware e do fim da onda de crimes no metrô de Nova York. Trata-se de um trabalho extremamente provocante e relevante para profissionais envolvidos com comunicação, marketing, ação social, e todas as pessoas que se interessam por propagar produtos ou idéias. 


\subsubsection{Busca de Empregos}

Um bom exemplo do papel de um tipo particular de nó na rede social, chamado por GLADWELL (2000) de "Conector" e caracterizado por apresentar um grau muito elevado, é relatado no tradicional e amplamente citado (ROGERS 1995; WATTS, 1999; BARABASI, 2002) estudo de GRANOVETTER (1973) sobre a forma como profissionais liberais e técnicos, moradores de Newton, subúrbio de Boston, encontram emprego.

Granovetter realizou algumas centenas de entrevistas, detalhando o histórico profissional dos entrevistados. Constatou que $56 \%$ deles encontraram emprego através de um contato pessoal; destes, apenas $17 \%$ encontravam freqüentemente o contato; na maioria dos casos, o contato era apenas superficial e esporádico, caracterizando a "força das ligações fracas" (GRANOVETTER, 1973).

A justificativa para este fenômeno está em que há pouca informação nova a ser compartilhada por pessoas cujos vínculos são estreitos: por circularem no mesmo grupo social, o que uma sabe a outra também sabe. Já pessoas mais distantes, que freqüentam grupos basicamente distintos, têm mais informação nova para trocar.

\subsubsection{Internet}

A Internet já foi considerada a materialização melhor acabada da liberdade de expressão. Qualquer pessoa com acesso a um provedor e recursos econômicos e técnicos modestos pode publicar um documento. Para o bem ou para o mal, uma vez "no ar", uma página de Internet torna-se instantaneamente disponível para o mundo e é difícil de censurar.

Isso não significa, no entanto que ela será lida.

Para ser lida, antes de mais nada, ela deve, evidentemente, poder ser encontrada entre os mais de um bilhão de documentos disponíveis hoje na web (Lawrence e Giles conforme BARABASI, 2002). E para ser encontrada, ela precisa ser "visível". 
Uma boa medida de visibilidade de um documento na Internet é o número de links que apontam para ele. Se todas as páginas da Internet apontassem para a sua página, em pouco tempo todos os internautas a teriam visitado. No entanto, as páginas têm em média seis links, cada um apontando para apenas um documento dentre os um bilhão de documentos existentes. Isso faz com que a probabilidade de um particular documento apontar para a sua página seja próxima de zero (BARABASI, 2002).

Diante dessa problemática, perguntas de pesquisa quanto ao número de documentos e de links disponíveis na Internet; diâmetro da rede; distribuição do grau dos nós; distribuição da coesão e distância temática dos documentos; e discrição da topologia da rede são extremamente relevantes para todos os pesquisadores que se preocupam com a acessibilidade de informação na web.

\subsubsection{Cooperação Indireta: Clientes de Uma Livraria Virtual}

O varejo tem liderado a implementação de Sistemas de Recomendações (com potencial de aplicação em variadas outras áreas de atividade) que ajudam consumidores a encontrar rapidamente itens relevantes dentre o conjunto de produtos e serviços oferecidos. Segundo Jeff Bezos, criador da Amazon.com, o principal motivo pelo qual clientes voltam a uma particular livraria virtual é justamente o grau de ajuda ativa que o site oferece na localização de títulos de interesse para o cliente (RAMO, 1999). A Figura 3 mostra a interface principal do Sistema de Recomendações da Amazon.com. 


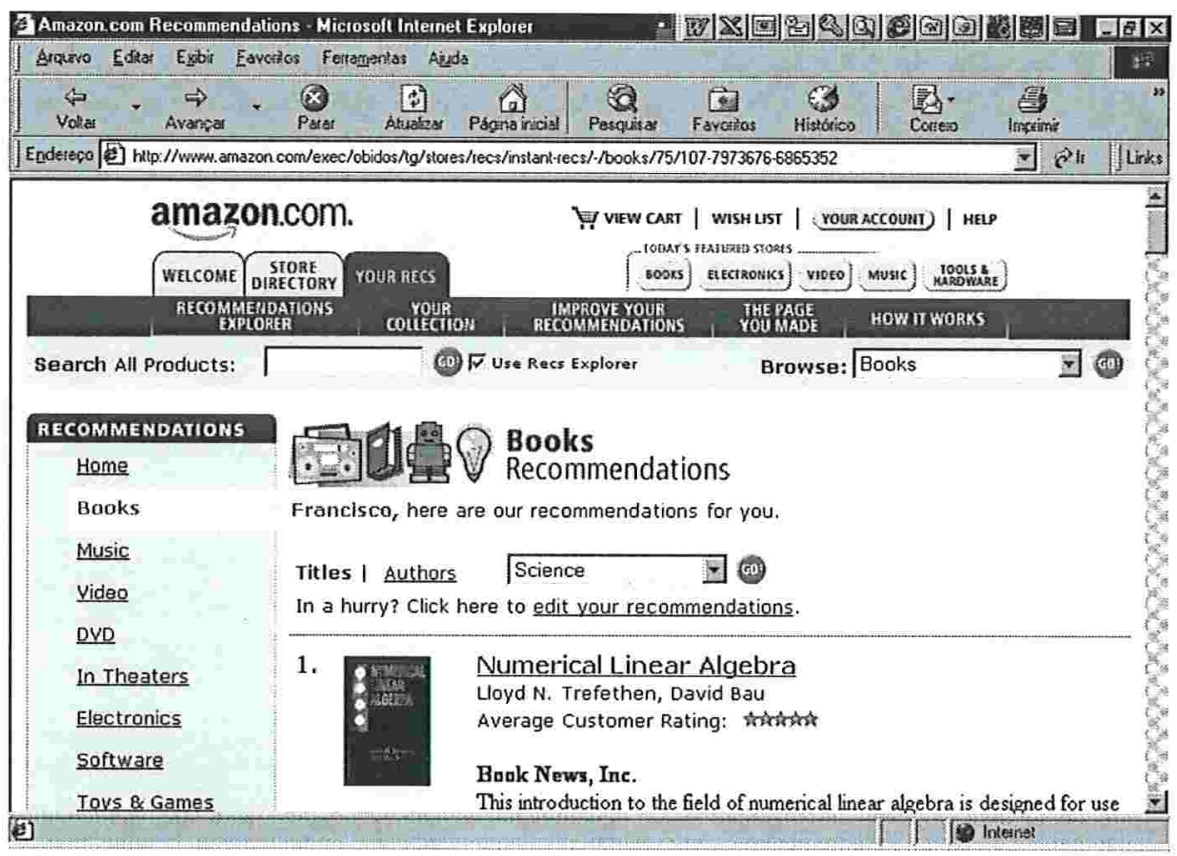

Figura 3 - Interface Principal do Sistema de Recomendações da Amazon.com.

\subsubsection{Outros exemplos de varejo}

$\mathrm{Na}$ área de telecomunicações e na indústria cinematográfica, observam-se mais exemplos impulsionados pela Internet e ligados ao consumo:

- a programação de TVs por assinatura é tão extensa em número de canais e de opções de conteúdo que, freqüentemente, o assinante sequer toma conhecimento da disponibilidade de programas de seu interesse; em conseqüência, começam a prosperar serviços como o Personalized Television (SMYTH e COTTER, 2000), o qual disponibiliza sugestões personalizadas de programas de TV para 20.000 usuários da Inglaterra e da Irlanda;

- na mesma linha, o sistema Movie Lens mantido como ambiente de pesquisa pela Universidade de Minessota, (http://movielens.umn.edu) atualmente oferece sugestões de filmes para cerca de 80.000 usuários, com base em mais de 3 milhões de avaliações individuais. 


\section{ESCALONAMENTO MULTIDIMENSIONAL (MULTIDIMENSIONAL SCALING - MDS)}

Suponha que um conjunto de objetos está sendo analisado e que para cada par de objetos $(r, s)$ há uma medida $\partial_{r s}$ de "dissimilaridade" entre eles. Uma definição estreita de Escalonamento Multidimensional é o conjunto de técnicas utilizadas na busca de um espaço de baixa dimensionalidade, usualmente Euclidiano, no qual os objetos são representados por pontos, numa configuração tal que as distâncias entre os pontos no espaço, $\left\{d_{r s}\right\}$, correspondam, da melhor maneira possível, às dissimilaridades originais, $\left\{\partial_{r s}\right\}$ (COX e COX, 2001).

\subsection{Tipos de Dados}

Vários tipos de dados prestam-se à análise por MDS; no entanto, tipos diferentes exigem/possibilitam o uso de diferentes técnicas e abordagens.

As principais características relevantes para a especificação da técnica adequada são (COX e COX, 2001): escala de medidas, modos e direções (ways).

\subsubsection{Escala de Medida}

Dados podem ser classificados quanto à escala de medida utilizada na sua geração. São quatro: nominal, ordinal, intervalar ou racional.

\subsubsection{Número de Modos}

Cada conjunto de objetos subjacente aos dados é chamado de um modo. Assim as dissimilaridades $\left\{\partial_{r s}\right\}$ entre livros e usuários da biblioteca apresentados no exemplo da Figura 1 caracterizam-se por serem dados de modo dois. Já as dissimilaridades apenas entre usuários apresentados na base da Figura 2, caracterizam-se por serem de modo um.

\subsubsection{Número de Direções}

Cada índice numa medida entre objetos é chamada de direção. Portanto, o $\partial_{r s}$ dos exemplos acima apresenta duas direções. Se cada usuário $i$ avaliasse a 
semelhança entre o conteúdo de pares de livros $(r, s)$, os dados $\partial_{r s, i}$ teriam três dimensões.

\subsection{Modelos de Escalonamento Multidimensional}

Existem vários modelos de MDS (COX e COX, 2001). O ponto de partida é um conjunto de dados medido em escala intervalar, uni-modal e bi-direcional de medidas de dissimilaridade.

\subsubsection{Escalonamento Clássico}

Se as distâncias na configuração forem Euclidianas e

$$
d_{r s}=\partial_{r s} \quad r, s=1, \ldots, n
$$

de tal maneira que as dissimilaridades também são precisamente Euclidianas, então é possível encontrar uma configuração de pontos que garanta a igualdade acima.

O escalonamento clássico trata as dissimilaridades $\left\{\partial_{r s}\right\}$ diretamente como Euclidianas e faz uso da decomposição espectral de uma matriz de dissimilaridades duplamente centrada.

\subsubsection{Escalonamento Métrico por Mínimos Quadrados}

Métodos de escalonamento métrico por Mínimos Quadrados fazem corresponder as distâncias $\left\{d_{r s}\right\}$ a dissimilaridades transformadas $\left\{f\left(\partial_{r s}\right)\right\}$, onde $f$ é uma função monotônica contínua. Uma configuração é procurada de tal maneira que $\left\{d_{r s}\right\}$ se ajuste por Mínimos Quadrados às dissimilaridades transformadas $\left\{f\left(\partial_{r s}\right)\right\}$, por exemplo, minimizando-se a função de perda

$$
\frac{\sum_{r} \sum_{s}\left(d_{r s}-\left(\alpha+\beta \partial_{r s}\right)\right)^{2}}{\sum_{r} \sum_{s} d_{r s}{ }^{2}}
$$

onde $\alpha$ e $\beta$ são constantes que devem ser encontradas. 
O escalonamento clássico e o escalonamento por MQ são exemplos de escalonamentos métricos, onde "métrico" diz respeito ao tipo de transformação das dissimilaridades e não ao tipo de espaço onde se procura a configuração.

\subsubsection{Escalonamento Não-Métrico}

Se a natureza métrica da transformação das dissimilaridades é abandonada, chega-se ao escalonamento não-métrico. A transformação $f$ pode agora ser arbitrária, mas deve obedecer à restrição monotônica, que preserva a ordem das dissimilaridades transformadas:

$$
\partial_{r s}<\partial_{r^{\prime} s^{\prime}} \Rightarrow f\left(\partial_{r s}\right) \leq f\left(\partial_{r^{\prime} s^{\prime}}\right) \quad \text { para todo } 1 \leq r, s, r^{\prime}, s^{\prime} \leq n .
$$

\subsubsection{Análise Procrustes}

Suponha que um escalonamento multidimensional tenha sido realizado em dados de dissimilaridade por meio de dois métodos diferentes, dando origem a duas configurações distintas que representam o mesmo conjunto de objetos. A análise Procrustes dilata, translada, espelha e rotaciona uma das configurações para que os pontos se ajustem, da melhor maneira possível, à outra, permitindo a comparação dos resultados.

\subsubsection{Outros Modelos}

Outros modelos de MDS, como escalonamento unidimensional, biplots, unfolding, análise de correspondência e modelo de diferenças individuais não são de interesse para este trabalho. 


\section{ALGUNS DETALHES SOBRE MDS CLÁSSICO E PROCRUSTES}

A solução encaminhada neste trabalho utiliza repetidas vezes os algoritmos convencionais de MDS clássico e Procrustes. Apresentamos a seguir alguns detalhes de algoritmos para sua implementação.

\subsection{MDS Clássico}

Um algoritmo prático para o cálculo do MDS Clássico é sugerido por COX e COX (2001) como:

a) Obtenha as dissimilaridades $\left\{\partial_{r s}\right\}$.

b) Calcule a matriz $\mathbf{A}=\left\{-\frac{1}{2} \partial_{r s}^{2}\right\}$.

c) Calcule a matriz $\mathbf{B}=\mathbf{H A H}=\left\{a_{r s}-a_{r .}-a_{s s}+a_{.}\right\}$, onde

$\mathbf{H}$ é a matriz centralizadora $\mathbf{I}-n^{-1} \mathbf{1 1}^{\mathrm{T}}$,

I é a matriz identidade,

1 é um vetor coluna de 1 's,

$$
\begin{gathered}
a_{r s}=-\frac{1}{2} \partial_{r s}^{2}, \\
a_{r .}=n^{-1} \sum_{s} a_{r s}, \\
a_{s .}=n^{-1} \sum_{r} a_{r s} \mathrm{e} \\
a_{. .}=n^{-2} \sum_{r} \sum_{s} a_{r s} .
\end{gathered}
$$

d) Calcule de $\mathbf{B}$ os autovalores $\lambda_{1}, \ldots, \lambda_{\mathrm{n}-1}$ e autovetores associados $\mathbf{v}_{1}, \ldots, \mathbf{v}_{\mathbf{n}-1}$, com autovetores normalizados de forma que $\mathbf{v}_{\mathbf{i}}^{\mathrm{T}} \mathbf{v}_{\mathbf{i}}=\lambda_{1}$.

e) Escolha um número $p$ de dimensões apropriado. (No caso deste trabalho o número de dimensões é 2.) 
f) As coordenadas dos $n$ pontos nas $p$ dimensões do espaço Euclidiano são dadas por $x_{\mathrm{ri}}=v_{\mathrm{ir}}(r=1, \ldots, n ; i=1, \ldots, p)$.

\subsubsection{Implementação da Função cmdscale no R}

No ambiente de processamento do $\mathrm{R}$ (veja 13.1), o escalonamento multidimensional clássico está implementado através de uma função disponível na biblioteca mva (multivariate analysis). O código da função é o seguinte:

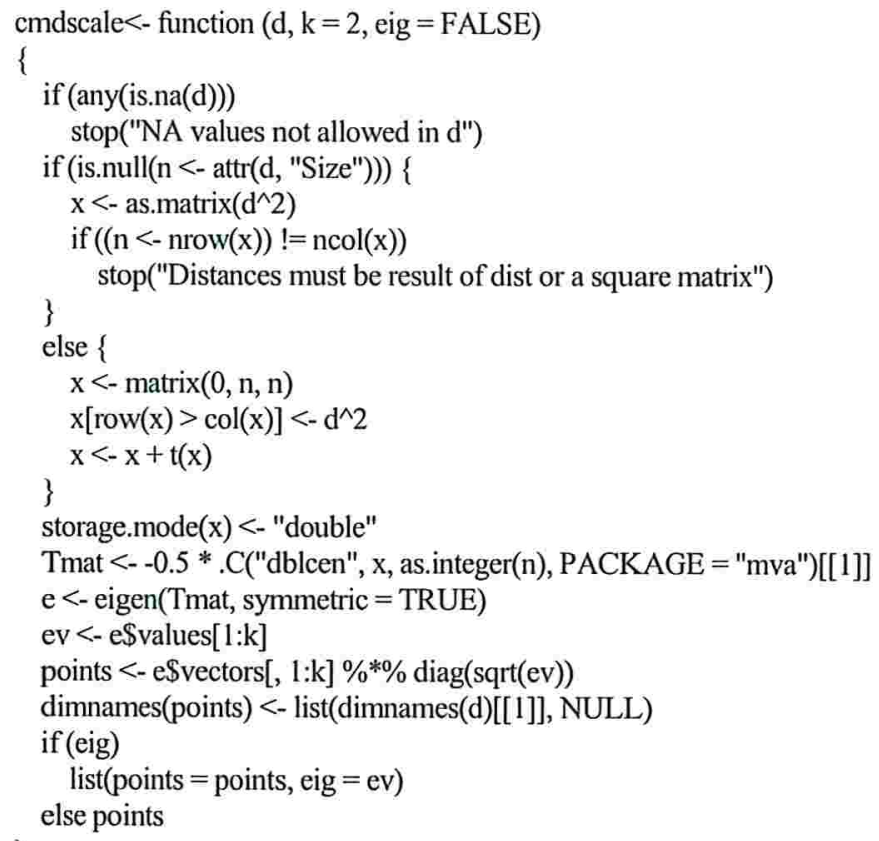

onde

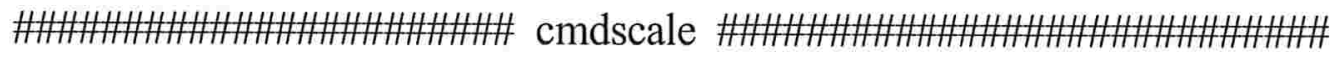

Parâmetros de entrada:

$d \quad=$ matriz de distâncias ou objeto dist de distâncias

$k=$ número de dimensões desejadas para a solução $($ default $=2)$

eig = valor lógico que indica se a decomposição deve ou não constar da saída da função.

Variáveis:

$x$

Tmat

e

ev

points recebe as distâncias ao quadrado; recebe $\mathbf{H A H}$, calculada por meio de uma função implementada em C; recebe a decomposição espectral de Tmat; recebe os autovalores de $e$; recebe as colunas de autovalores relevantes. 
Retorna:

points

contendo as coordenadas procuradas

eig

contendo a decomposição espectral, dependendo do parâmetro

lógico passado para a função.

\subsection{Procrustes}

É comum a necessidade de comparar uma configuração de pontos num espaço Euclidiano com outra configuração que mantém com a primeira um mapeamento um-a-um. Se elas não coincidem, assume-se que o espaço em que uma delas está representada sofreu uma deformação. As técnicas de Análise de Procrustes permitem identificar quais foram as deformações e, "desmanchando-as", fazer coincidir as duas configurações. Permitem, também, calcular uma medida do ajuste após as correções.

A solução teórica (COX e COX, 2001) supõe que uma configuração de $n$ pontos em um espaço Euclidiano $q$-dimensional, com coordenadas dadas pela

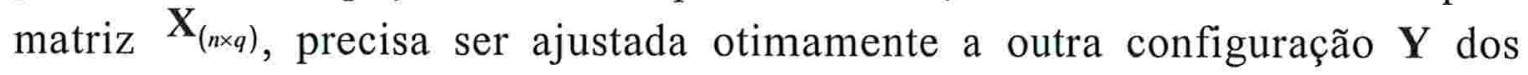
mesmos $n$ pontos em um espaço Euclidiano $p$-dimensional $(p \geq q)$. Assume-se que o $r$-ésimo ponto na primeira configuração pode ser mapeado sobre o $r$ ésimo ponto da segunda.

Inicialmente, $p-q$ colunas de zeros são agregadas à matriz $\mathbf{X}$, de forma a que ambas as matrizes tenham a mesma dimensionalidade.

A soma das distâncias entre os pontos de $\mathbf{X}$ e seus correspondentes em $\mathbf{Y}$ é dada por

$$
R^{2}=\sum_{r=1}^{n}\left(\mathbf{y}_{r}-\mathbf{x}_{r}\right)^{T}\left(\mathbf{y}_{r}-\mathbf{x}_{r}\right)
$$

Sejam os pontos no espaço $\mathbf{X}$ dilatados, transladados, rotacionados e refletidos para novas coordenadas $\mathbf{x}_{r}^{\prime}$ onde

$$
\mathbf{x}_{r}^{\prime}=\rho \mathbf{A}^{T} \mathbf{x}_{r}+\mathbf{b} .
$$


Pode-se demonstrar (COX e COX, 2001) que os movimentos que minimizam $R^{2}$ são

$$
\begin{gathered}
\rho=\operatorname{tr}\left(\mathbf{X}^{T} \mathbf{Y} \mathbf{Y}^{T} \mathbf{X}\right)^{\frac{1}{2}} / \operatorname{tr}\left(\mathbf{X}^{T} \mathbf{X}\right), \\
\mathbf{A}=\left(\mathbf{X}^{T} \mathbf{Y} \mathbf{Y}^{T} \mathbf{X}\right)^{\frac{1}{2}}\left(\mathbf{Y}^{T} \mathbf{X}\right)^{-1}, \mathrm{e} \\
\mathbf{b}=\mathbf{y}_{0}-\rho \mathbf{A}^{T} \mathbf{x}_{0} \quad \text { onde } \quad \mathbf{x}_{0}=\frac{1}{n} \sum_{r=1}^{n} \mathbf{x}_{r} \quad \text { e } \quad \mathbf{y}_{0}=\frac{1}{n} \sum_{r=1}^{n} \mathbf{y}_{0} .
\end{gathered}
$$

Se de interesse, uma medida de qualidade do ajuste, conhecida como estatística de Procrustes, é dada por

$$
R^{2}=1-\left\{\operatorname{tr}\left(\mathbf{X}^{T} \mathbf{Y} \mathbf{Y}^{T} \mathbf{X}\right)^{\frac{1}{2}}\right\}^{2} /\left\{\operatorname{tr}\left(\mathbf{X}^{T} \mathbf{X}\right) \operatorname{tr}\left(\mathbf{Y}^{T} \mathbf{Y}\right)\right\} .
$$

\subsubsection{Algoritmo de Procrustes}

COX e COX (2001) sugerem o seguinte algoritmo para a implementação de uma análise de Procrustes em que uma configuração $\mathbf{Y}$ deve ser ajustada a uma configuração $\mathbf{X}$ :

a) Subtraia o respectivo vetor de médias de cada uma das configurações de forma a que os seus centróides coincidam com a origem;

b) Encontre a matriz $\mathbf{A}=\left(\mathbf{X}^{T} \mathbf{Y} \mathbf{Y}^{T} \mathbf{X}\right)^{\frac{1}{2}}\left(\mathbf{Y}^{T} \mathbf{X}\right)^{-1}$;

c) Encontre $\rho=\operatorname{tr}\left(\mathbf{X}^{T} \mathbf{Y} \mathbf{Y}^{T} \mathbf{X}\right)^{\frac{1}{2}} / \operatorname{tr}\left(\mathbf{X}^{T} \mathbf{X}\right)$; e

d) Calcule $R^{2}=1-\left\{\operatorname{tr}\left(\mathbf{X}^{T} \mathbf{Y} \mathbf{Y}^{T} \mathbf{X}\right)^{\frac{1}{2}}\right\}^{2} /\left\{\operatorname{tr}\left(\mathbf{X}^{T} \mathbf{X}\right) \operatorname{tr}\left(\mathbf{Y}^{T} \mathbf{Y}\right)\right\}$.

A implementação desta função encontra-se na subseção 19.1.18, a seguir. 


\section{Terceira Parte: Formulação do Problema e Encaminhamentos}

Nesta terceira parte do trabalho, apresentamos três arquivos de transações que serão utilizados como exemplos; encaminhamos o problema de representação da rede propondo a utilização de uma Base Temática e a substituição das arestas por uma Superfície de Coesão; finalmente, ressaltamos aspectos do tipo de rede comum nesta categoria de problema de cooperação indireta, que simplificam os algoritmos propostos para o encaminhamento da solução computacional desenvolvida na seção final do bloco.

\section{TRÊS ARQUIVOS COM DADOS PARA EXEMPLO}

Para servir de ilustração na discussão que se segue, uma pequena rede foi criada arbitrariamente e suas arestas registradas no arquivo de exemplo EX1.dat. Em seguida, do arquivo DADOS.dat contendo os dados reais da aplicação foram retirados dois subconjuntos de transações, nomeados EX2.dat e EX3.dat.

Os três arquivos têm, antes do pré-processamento, 19, 1.264 e 4.850 registros, respectivamente. O objetivo ao utilizá-los foi manter os exemplos tão pequenos quanto possível em cada etapa da discussão, pois isto facilita a apresentação de matrizes, cálculos e gráficos ilustrativos dos conceitos estudados; foi também observar como é a tendência de aumento na complexidade do problema do ponto de vista computacional à medida que o número de vértices da rede cresce. 


\subsection{Exemplo 1 - EX1.dat}

O primeiro dos arquivos de exemplo, EX1.dat, tem o conteúdo a seguir.

$\begin{array}{ll}109 & 3 \\ 100 & 1 \\ 108 & 2 \\ 100 & 2 \\ 101 & 1 \\ 108 & 1 \\ 101 & 2 \\ 101 & 1 \\ 107 & 2 \\ 107 & 1 \\ 101 & 5 \\ 102 & 1 \\ 106 & 6 \\ 102 & 3 \\ 106 & 2 \\ 104 & 3 \\ 105 & 3 \\ 104 & 4 \\ 105 & 5\end{array}$

Saída 1 - Conteúdo do Arquivo EX1.dat

Como todos os arquivos de entrada da aplicação, neste trabalho, trata-se, basicamente, de um arquivo contendo duas colunas com nomes (identificadores ou "id"s) de vértices.

Cada linha representa uma aresta, caracterizada pelo nó de usuário (primeira coluna) e pelo nó de livro (segunda coluna).

O primeiro registro poderia, portanto, ser lido da seguinte maneira: "O usuário 109 retirou o livro 3." O segundo registro pode ser lido como: "O usuário 100 retirou o livro 1." E assim por diante.

Depois de devidamente pré-processado (a finalidade e os procedimentos do pré-processamento serão discutidos na subseção 9.1), o arquivo do Exemplo 1 perdeu seis linhas e recebeu nome nas linhas e colunas, ficando com o formato abaixo. 


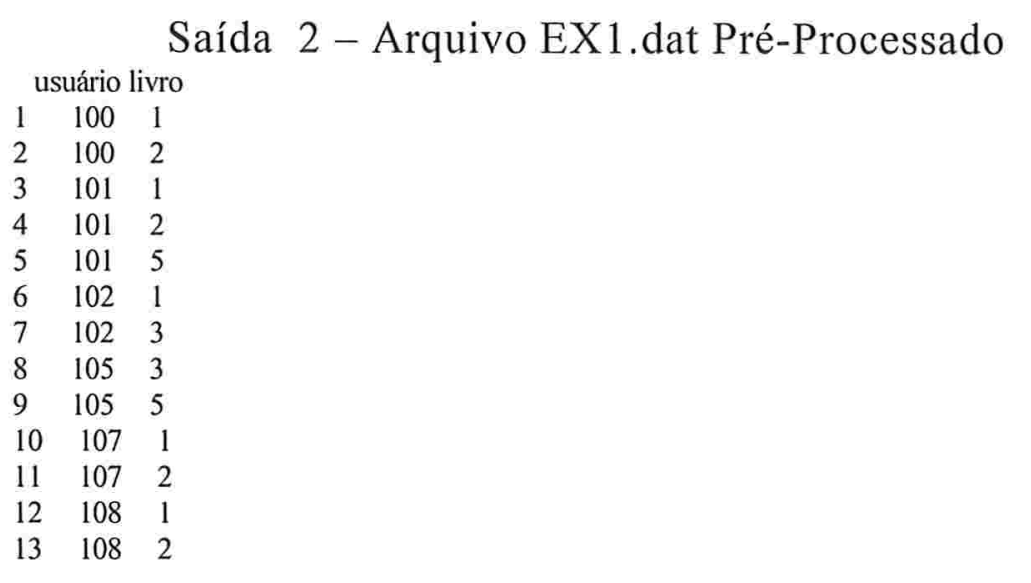

Os nós $\mathrm{V}=\{1,2,3,5,100,101,102,105,107,108\}$ implícitos na lista acima, e as arestas $E=\left\{e_{i}\right\}, i=1, \ldots, 13$, contidas no arquivo formam a rede representada graficamente a seguir. Note que as "transações de empréstimo" do arquivo de entradas formam a "lista de arestas" da rede.

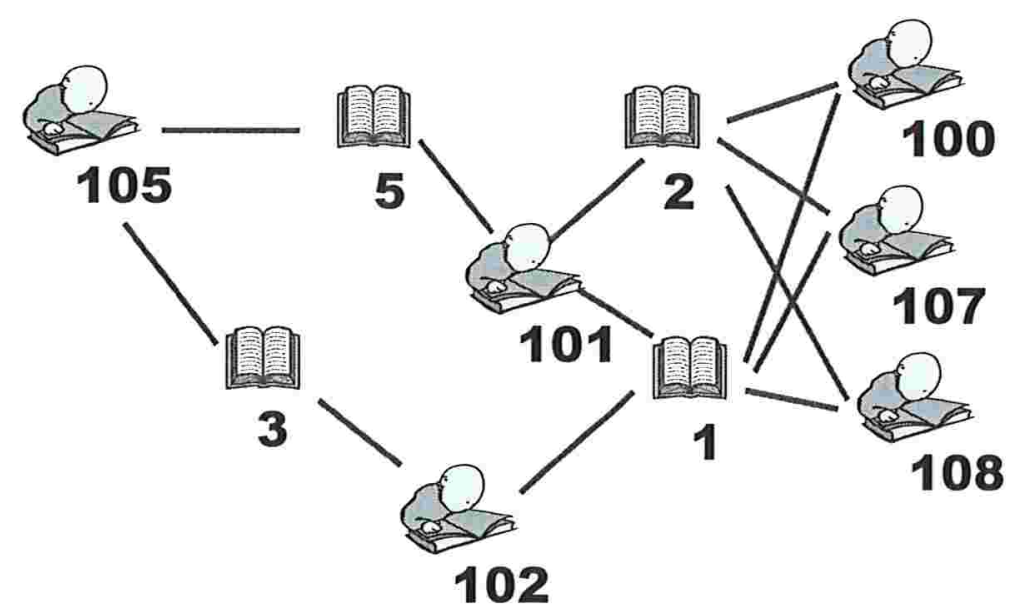

Figura 4 - Representação Gráfica da Rede do Exemplo 1.

A rede pode ser também representada pela matriz de adjacência $\mathbf{A}$, da Saída 3, a seguir. Como as redes de nosso interesse não são orientadas, isto é, a aresta $(i, j)$ é a mesma aresta que $(j, i)$, resulta que a matriz de adjacência é simétrica. Assim, por economia, sempre a representaremos apenas na porção subdiagonal. 
Saída 3 - Matriz de Adjacência do Exemplo 1.

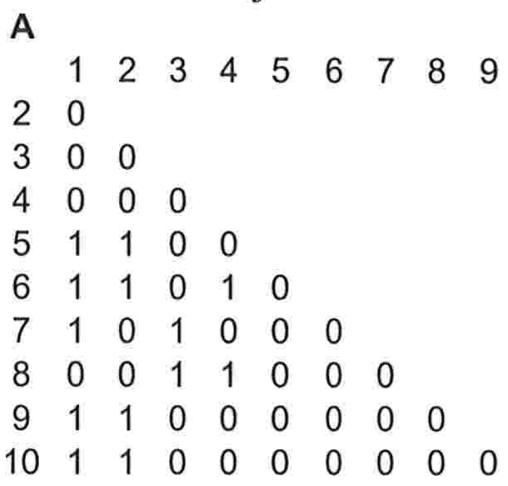

A menos de observação em contrário, as linhas das matrizes de adjacência correspondem aos vértices ordenados crescentemente por id (veja na subseção 13.1.2 comentário sobre a dificuldades trazidas ao algoritmo por conta desta correspondência implícita).

\subsection{Resumo Comparativo dos Três Arquivos de Exemplos}

Os arquivos de exemplo EX2.dat e EX3.dat são análogos, em termos de estrutura, ao arquivo EX1.dat discutido na subseção anterior. Divergem do primeiro porque são conjuntos de transações reais e porque apresentam números diferentes de transações e nós, nos diversos estágios preliminares de processamento, conforme Tabela 2, a seguir.

Tabela 2 - Resumo Comparativo dos Arquivos de Exemplos

\begin{tabular}{|c|c|c|c|c|c|c|c|}
\hline Arquivo & $\begin{array}{c}\text { Número Inicial } \\
\text { de Registros } \\
\text { (TO) }\end{array}$ & $\begin{array}{l}\text { Registos Após } \\
\text { Deduplicação } \\
\text { (TD) }\end{array}$ & $\begin{array}{l}\text { Registros } \\
\text { após } \\
\text { Remoção de } \\
\text { Cílios (TS) }\end{array}$ & $\begin{array}{c}\text { Vértices de } \\
\text { Usuários (TS) }\end{array}$ & $\begin{array}{l}\text { Vértices de } \\
\text { Livros (TS) }\end{array}$ & $\begin{array}{l}\text { Linhas na } \\
\text { Matriz de } \\
\text { Distâncias } \\
\text { Temáticas }\end{array}$ & $\begin{array}{c}\text { Linhas Possíveis } \\
\text { na Matriz de } \\
\text { Distâncias } \\
\text { Temáticas }\end{array}$ \\
\hline & TO & TD & TS & Usuários & Livros & DT-o & $\overline{\text { DT-p }}$ \\
\hline EX1.dat & 19 & 18 & 13 & 6 & 4 & 15 & 15 \\
\hline EX2.dat & 1,264 & 1,089 & 175 & 71 & 66 & 147 & 2,485 \\
\hline EX3.dat & 4,850 & 4,211 & 2,043 & 596 & 702 & 2,445 & 177,310 \\
\hline
\end{tabular}

As explicações sobre conceitos e notação implícitos nas colunas de TO a TS da tabela acima estão na subseção 9.1 a seguir. O número de vértices de usuários (analogamente, livros) corresponde ao número de usuários (livros) distintos existentes na matriz de entrada deduplicada e sem cílios. 
O número de linhas observado na matriz de Distâncias Temáticas (DT-o) corresponde ao número de linhas registrado e acompanhado pelo algoritmo, de um total de caselas de Distâncias Temáticas possíveis (DT-p) na matriz de distâncias. As razões que permitem esta "economia" de recursos e suas implicações estão discutidas na subseção 9.3.2. 


\section{FORMULAÇÃO GERAL DO PROBLEMA}

Nesta seção, explicamos as principais idéias utilizadas na implementação do algoritmo e damos exemplos dos cálculos realizados em cada etapa.

\subsection{Pré-Processamento da Lista de Transações}

Como vimos na subseção 8.1, os dados originais para esta aplicação correspondem a transações que ligam Usuários a Livros, isto é, são transações de empréstimo e por este motivo chamamos a matriz correspondente de TO (Transações Originais). Num caso geral, os dados de entrada correspondem à Lista de Arestas de uma rede bimodal (no sentido definido em 6.1.2).

Como as transações podem estar duplicadas, isto é, um usuário pode haver retirado o mesmo livro várias vezes, e como esta informação não é de interesse no nosso problema, os registros redundantes são descartados e o resultado é armazenado numa matriz batizada de TD (Transações Deduplicadas).

Finalmente, as transações em TD caracterizam uma rede em cuja periferia tipicamente há muitos vértices tenuemente vinculados à rede, isto é, ligados à rede por apenas uma aresta. Também freqüentemente, estes mesmos vértices "quase soltos" encadeiam-se em longos filamentos, como na Figura 5. Estes "filamentos" não têm posição definida no espaço temático; sua inclusão no problema apenas inflaciona a necessidade de recursos computacionais, sem resultar em entendimento adicional da configuração temática. Por este motivo, uma função foi incluída no algoritmo para remover os "cílios" conservando para análise apenas o "núcleo firme" da rede. O resultado é armazenado na matriz TS (Transações Sem Cílios). 


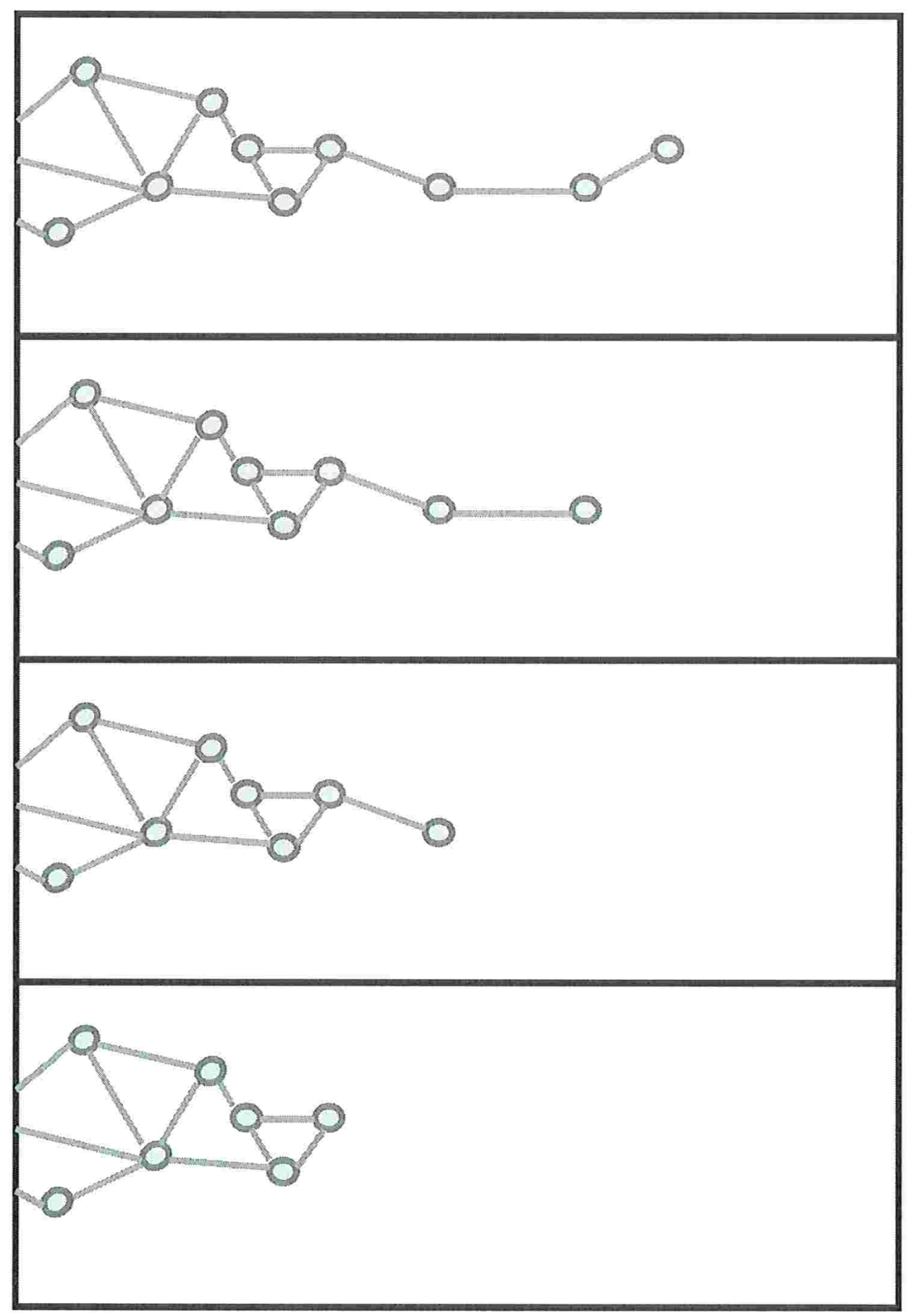

Figura 5 - Exemplo de Remoção de Cílio 
O fluxograma da etapa de Pré-Processamento está incluído na Figura 6.

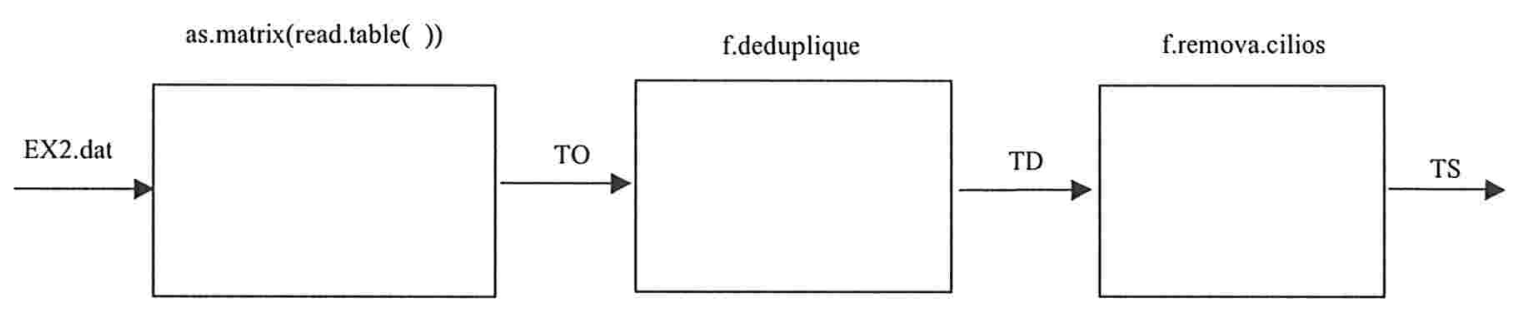

Figura 6 - Fluxograma do Pré-Processamento

\subsection{Redes Bimodais e Redes Monomodais}

Os dados originais da aplicação sob consideração caracterizam-se por serem bimodais, isto é, terem modo 2. Em outras palavras, subjacentes aos dados, há dois tipos de objetos: usuários e livros. No entanto, neste trabalho, estamos principalmente interessados nas relações dos usuários entre si, ou seja, em vários momentos desejamos representar uma rede monomodal (isto é, de modo 1). Felizmente, podemos passar de uma situação a outra por meio de uma operação muito simples: a partir da matriz de adjacência $\mathbf{A}$, construímos a matriz de adjacência em (exatamente) dois passos $\mathbf{A}^{2}$.

A matriz $\mathbf{A}^{2}$ mostra as ligações em (exatamente) dois passos que ocorrem na rede original, isto é, mostra se dois usuários são ligados entre si (através de um livro); e mostra também se dois livros estão ligados entre si (através de um usuário). Este último caso, da ligação entre livros, não é de interesse neste trabalho, mas tem muito interesse mercadológico para sugestões de venda cruzada.

A matriz $\mathbf{A}^{2}$ é, de fato, o quadrado da matriz $\mathbf{A}$, com os valores diferentes de 0 substituídos por 1 (o resultado antes da substituição indica de quantas maneiras diferentes podemos passar de um nó a outro através da rede). Dela, no momento, interessa-nos apenas a partição Usuário-Usuário, conforme a Figura 7. 


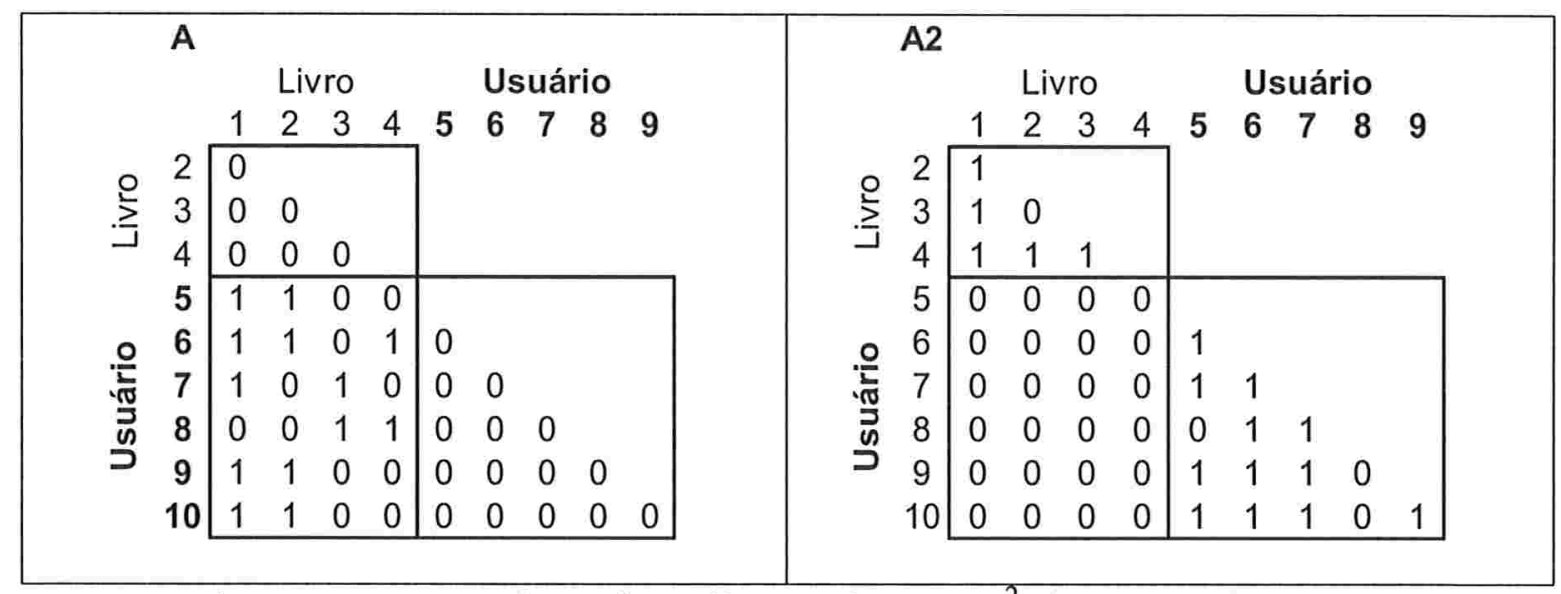

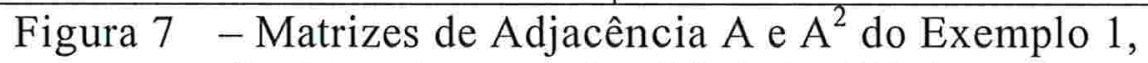
Particionadas segundo o Modo dos Vértices.

Note, na Figura 7, que nas partições Usuário-Usuário e Livro-Livro só contém zeros em A. Nesta altura, as ligações estão todas na partição Usuário-Livro. Isto, evidentemente, decorre de que apenas usuários podem tomar livros emprestados.

Já em $\mathrm{A}^{2}$, a situação se inverte; não há ligações entre usuários e livros, em dois passos. Por meio de exatamente duas arestas, livros ligam-se a livros e usuários a usuários.

A representação gráfica de $\mathrm{A}^{2}$ (na partição Usuário-Usuário) é apresentada na Figura 8, a seguir. 


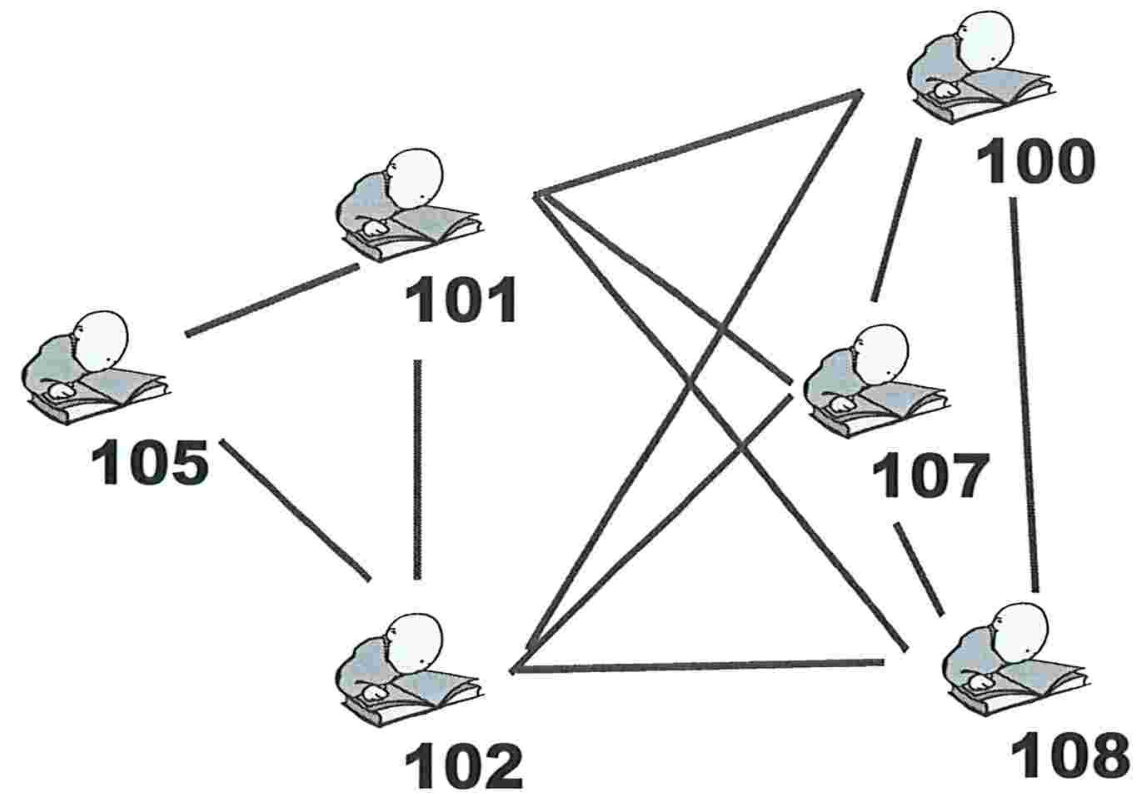

Figura 8 - Representação Gráfica da Rede de Usuários do Exemplo 1.

\subsection{Cálculo e Armazenamento das Distâncias Temáticas}

De posse das informações de usuários, e para evitar a montagem da matriz de adjacência, podemos organizá-las como uma Lista de Vizinhos de cada vértice.

A Lista de Vizinhos (LV) do Exemplo 1 tem a forma apresentada na Saída 4. Ela é divida em dois blocos: Vizinhos em (exatamente) 1 Passo (LV\$V1) e Vizinhos em (exatamente) 2 Passos (LV\$V2). Em LV\$V1, para cada usuário são listados os livros que ele retirou; por exemplo, o usuário com id $=100$ retirou os livros com id $=1$ e 2. Em LV\$V2, para cada usuário são listados os usuários que retiram os mesmos livros que ele. Assim, aprendemos que os usuários 101, 102, 107 e 108 retiraram livros também retirados pelo usuário 100. Confronte a Saída $4 \mathrm{com}$ a Figura 4 e a Figura 8 para confirmar o entendimento da LV. 
Saída 4 - Lista de Vizinhos dos Nós de Usuários no Exemplo 1.

LV \# Lista de Vizinhos

\$V1 \# Vizinhos de Usuários em 1 passo, portanto, Livros

$\$ V 1[[1]] \#$ id $=100$

12

SV1[[2]] \# id $=101$

125

\$V1[[3]] \# id $=102$

13

\$V1[[4]] \# id $=105$

35

\$V1[[5]] \#id $=107$

12

SV1[[6]] \#id $=108$

12

\$V2 \# Vizinhos de Usuários em 2 passos, portanto, Usuários

\$V2[[1]] \# id $=100$

[1] 101102107108

$\$ V 2[[2]] \#$ id $=101$

[1] 100102107108105

SV2[[3]] \# id $=102$

[1] 100101107108105

\$V2[[4]] \# id $=105$

[1] 102101

\$V2[[5]] \# id $=107$

[1] 100101102108

\$V2[[6]] \# id $=108$

[1] 100101102107

\subsubsection{Cálculo}

De posse da Lista de Vizinhos fica fácil calcular a Distância Temática.

Para evitar perda de informação, neste ponto é útil considerar a vizinhança em dois passos (também chamada de vizinhança expandida) de cada vértice. Vejamos, por exemplo, o caso dos vértices 102 e 105.

A vizinhança em exatamente um passo de $v_{102}$ é $\Gamma_{102,1}=\{1,3\}$; e de $v_{105}$ é $\Gamma_{105,1}=\{3,5\}$. 
A vizinhança em exatamente dois passos de $v_{102}$ é $\Gamma_{102,2}=\{100,101,105,107$, $108\}$; e de $v_{105}$ é $\Gamma_{105,2}=\{101,102\}$.

A vizinhança expandida (isto é, em até dois passos) de $v_{102}$ é $\Gamma_{102}=\{1,3,100$, $101,105,107,108\}$; e de $v_{105}$ é $\Gamma_{105}=\{3,5,101,102\}$.

A união entre ambas as vizinhanças expandidas é $\{1,3,5,100,101,102,105$, $107,108\}$, e a intersecção é $\{3,101\}$. Assim, a distância temática entre estes dois nós é

1- $\left[\#\left(\Gamma_{102} \cap \Gamma_{105}\right) / \#\left(\Gamma_{102} \cup \Gamma_{105}\right)\right]=1-[2 / 9]=0.778$.

No caso do Exemplo 1, a lista completa das Distâncias Temáticas é apresentada na Saída 5, a seguir. No exemplo analisado acima, estamos falando do par de vértices $(102,105)$ que, em termos de índices de linhas e colunas da matriz de distâncias é o par $(4,3)$, cuja DT está assinalada em negrito na matriz da Saída 5 .

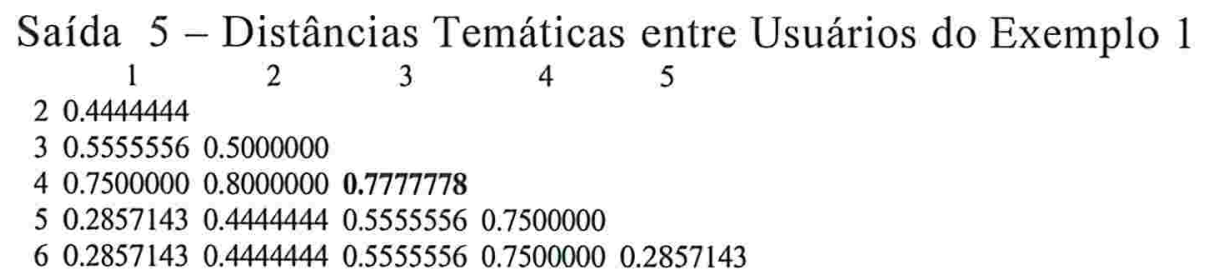

\subsubsection{Armazenamento}

A distância temática é calculável entre todos os pares de nós de uma rede.

Numa rede com baixa densidade de ligações, no entanto, haverá uma grande quantidade de pares de vértices cujas vizinhanças terão intersecção vazia, o que resulta numa Distância Temática igual a 1 - que é o máximo possível. O algoritmo proposto neste trabalho não registra na Lista de Distâncias temáticas os pares de vértices nessa situação. Isto representa uma enorme economia de recursos de armazenamento.

A Tabela 2 mostra que, conforme o número total de vértices passa de 10 para 137 e 1298, a Lista de Distância Temáticas passa respectivamente de 15 para 
481 e 2445 registros, o que corresponde a respectivamente $100 \%, 18 \%$ e $1 \%$ das distâncias existentes.

\subsection{Cálculo da Coesão}

O cálculo da coesão na vizinhança expandida de um vértice é fácil de realizar com base na Lista de Arestas (ou seja, os próprios dados em TS) e da Lista de Vizinhos.

Dado um vértice $i$, digamos o 102, consultamos na LV o tamanho de LV\$V1 e de LV\$V2. O produto destas duas quantidades corresponde ao total de arestas possíveis naquela vizinhança expandida.

Para o cálculo do número de arestas existentes, basta contar em TS (veja a Saída 2, na página 29) as arestas cujos dois extremos (isto é, vértices) pertencem à vizinhança considerada.

No caso do vértice 102 , este cálculo resulta em $5 /(2 * 5)=0$,5. A Saída 6 mostra a coesão dos vértices do Exemplo 1 . O cálculo relativo ao vértice 102 está assinalado em negrito.

\footnotetext{
Saída 6 - Coesão dos Vértices do Exemplo 1 $\$$ Coesao

[1] $0.8750000 \quad 0.5333333 \quad 0.5000000 \quad 0.50000000 .8750000 \quad 0.8750000$
}

\subsection{Representação da Rede Em Espaço Temático}

A representação de uma rede por meio de grafo em um plano é elemento chave de apoio a aplicações em inúmeras áreas do conhecimento (BATTISTA e OUTROS, 1999). Por exemplo:

- engenharia de software - gráficos de fluxo de dados, chamadas de subrotinas, árvores de encadeamento de programas, hierarquias de objetos;

- bancos de dados - relacionamentos entre entidades;

- sistemas de informação - diagramas organizacionais; 
- sistemas de apoio à decisão - redes PERT, árvores de atividade;

- eletrônica - desenho de circuitos;

- inteligência artificial - diagramas de representação de conhecimento;

- biologia - árvores evolutivas;

- química - desenho de moléculas;

- engenharia civil - desenho de plantas; e

- cartografia-desenho de mapas.

Neste trabalho, propomos ampliar a lista acima com a inclusão de uma aplicação da representação de redes num problema de cooperação indireta, relevante para as áreas de marketing e de gerenciamento do conhecimento.

A representação geométrica de gráficos vem sendo estudada por matemáticos há séculos (BATTISTA e OUTROS, 1999). Nos anos 60, começou a ser utilizada no auxílio à compreensão de software. O artigo de Knuth (1963, conforme BATTISTA e OUTROS, 1999) sobre o desenho de fluxogramas foi o primeiro a apresentar um algoritmo de desenho de grafo para efeito de visualização. Em conseqüência do problema ter uma componente combinatorial e geométrica, e devido à diversidade dos campos de aplicação, a pesquisa sobre este assunto tem sido muito diversificada.

O problema de desenhar um grafo de forma a refletir acuradamente sua estrutura é inerentemente mal-definido (SKIENA, 1998). De maneira geral procura-se um algoritmo que mostre a estrutura do gráfico de forma que ela possa ser melhor compreendida e que seja esteticamente agradável. Infelizmente estes critérios demasiado "suaves" não permitem o desenho de um algoritmo otimizante. Segundo eles, é possível fazer representações muito diferentes, cada uma apropriada em um contexto. A Figura 9 traz 3 representações distintas de um grafo de ordem 10 e tamanho 15 . 

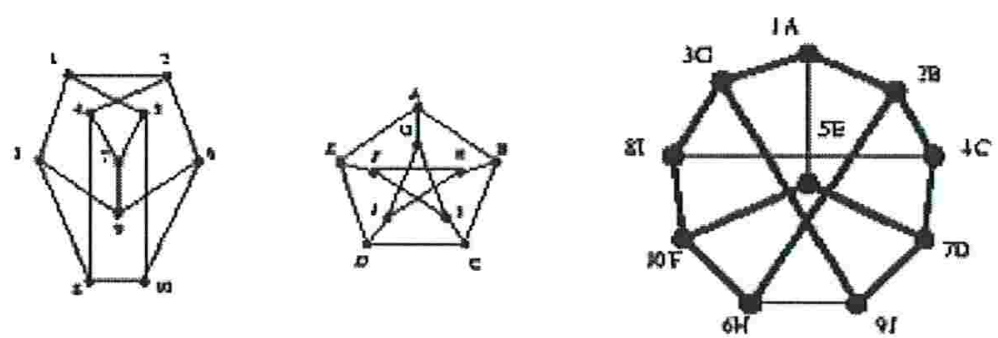

Figura 9 - Diversas Representações de um Grafo de Ordem 10 e Tamanho 15

Por outro lado, critérios mais "duros" e específicos podem ser definidos para medir a "qualidade" de um gráfico:

- cruzamentos: busca-se uma representação com um mínimo de cruzamentos de arestas pois elas dificultam a leitura do grafo;

- área: busca-se uma representação compacta, mas que garanta uma distância mínima entre os nós;

- comprimento das arestas: procura-se evitar arestas longas, pois elas dificultam a leitura do grafo;

- proporções: procura-se respeitar as proporções da mídia utilizada para a saída (papel, tela, etc).

Estes objetivos são mutuamente contraditórios; e a busca de uma solução ótima quase sempre resulta num problema computacionalmente intratável.

\subsubsection{Arestas como Distâncias Temáticas}

Para a representação dos grafos de redes, neste trabalho propomos que as arestas sejam segmentos de reta (isto é, não sejam curvas), e que tenham comprimento proporcional à Distância Temática entre os nós. Os vértices, portanto, estarão em posição coincidentes (distância zero) se tiverem a mesma vizinhança; e estarão a uma distância de 1 , se não tiverem vizinhos comuns.

Esta propriedade implica que o espaço (plano) onde os vértices são representados passa a ser um "espaço temático" no sentido de que usuários com interesses comuns serão desenhados próximos. 
Implica também que a posição relativa dos vértices pode ser encontrada por Escalonamento Multidimensional a partir da Matriz de Distâncias Temáticas calculada para os nós da rede.

A Figura 10 e a Figura 11 representam a rede do Exemplo 1, conforme esta estratégia, respectivamente sem e com legenda de pontos. Note que os vértices 100, 107 e 108 ocupam a mesma posição.

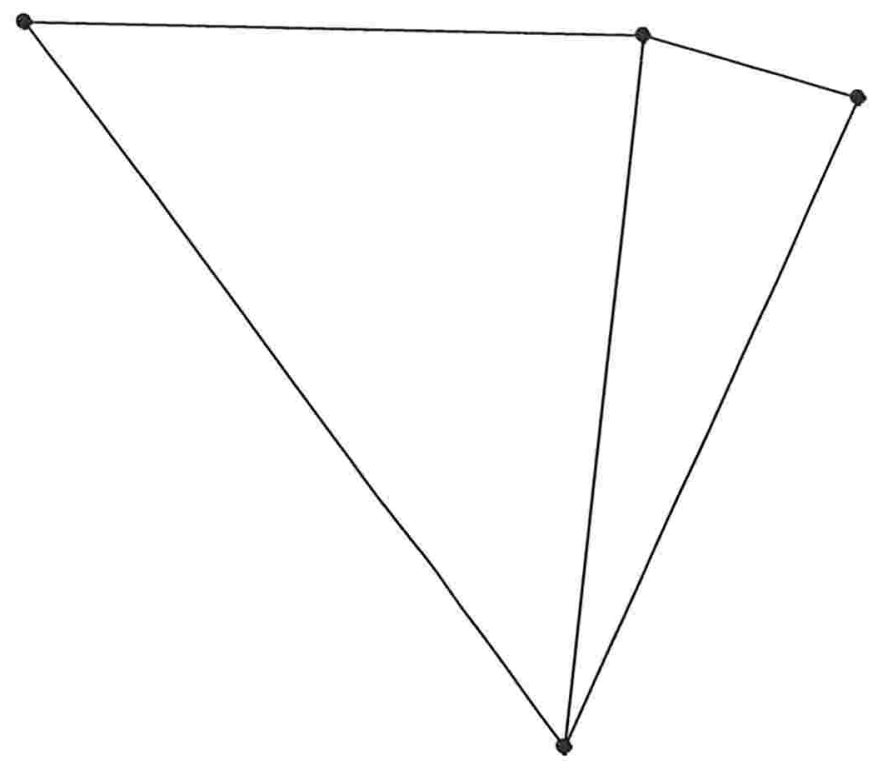

Figura 10 - Rede do Exemplo 1 em Espaço Temático (sem Legenda de Pontos) 


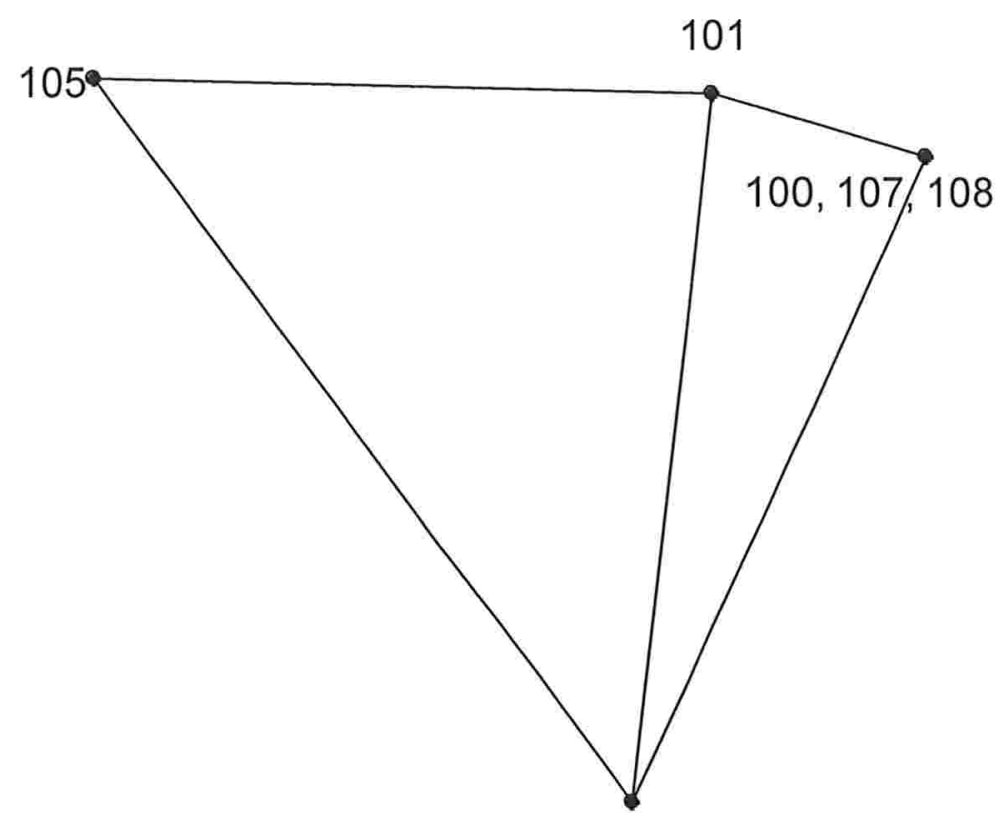

102

Figura 11 - Rede do Exemplo 1 em Espaço Temático (com Legenda de Pontos) 


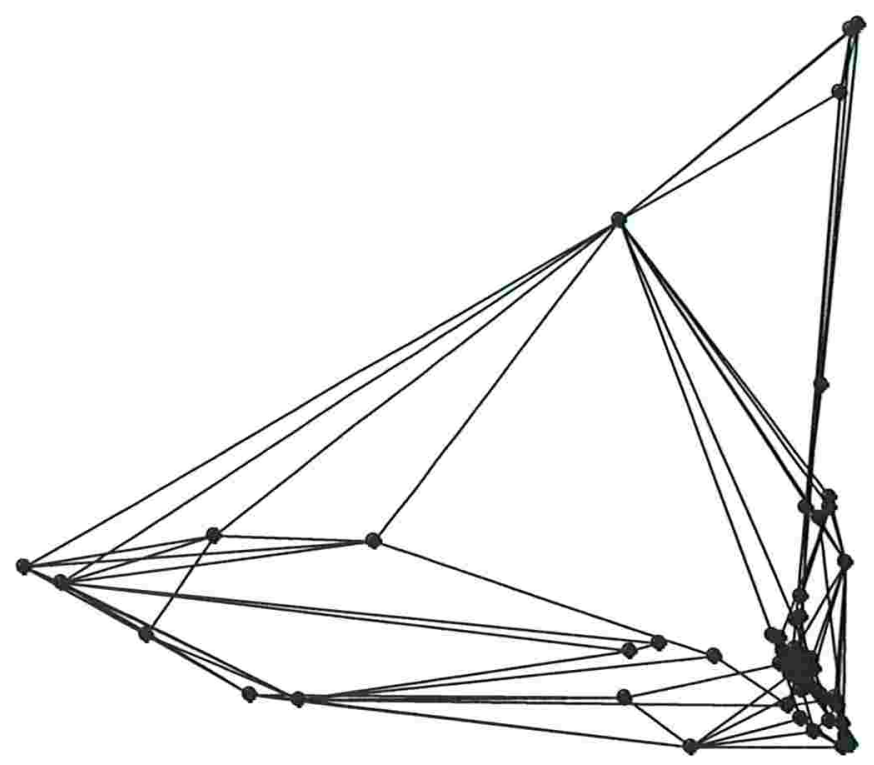

Figura 12 - Rede do Exemplo 2 em Espaço Temático (sem Legenda de Pontos) 


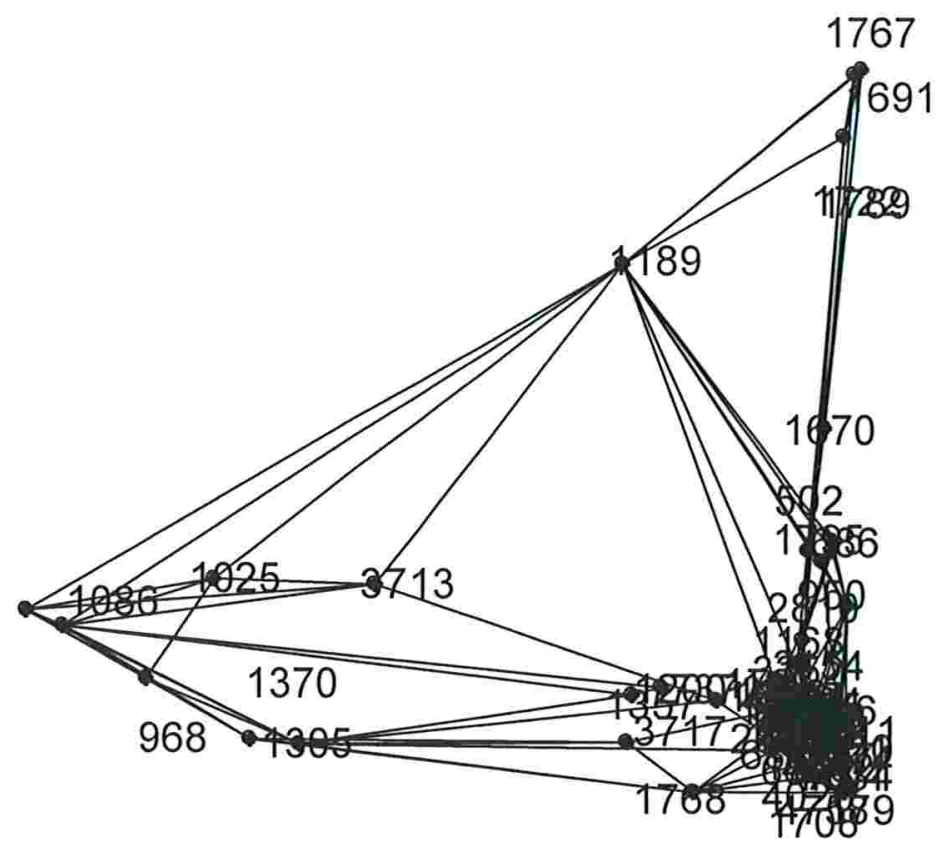

Figura 13 - Rede do Exemplo 2 em Espaço Temático (com Legenda de Pontos)

\subsection{Substituição de Arestas por Superfície de Coesão}

Um dos problemas na representação gráfica de redes diz respeito à resolução da imagem produzida.

Conforme seu número aumenta, vértices e arestas começam a se superpor, dificultando a leitura. Um gráfico completo de 100 vértices, por exemplo, contém aproximadamente 5.000 arestas; num monitor de 1.000 por 1.000 pixels, cerca de 200 pixels poderiam ser alocados por aresta; o desenho tornar-se-ia um borrão. 
Este efeito já pode ser notado ao passarmos do Exemplo 1 (6 vértices) para o Exemplo 2 (73 vértices), como vimos na Figura 10 e na Figura 12. Fica ainda mais agravado quando se deseja identificar os nós, como se nota na Figura 11 e na Figura 13.

Neste trabalho, propomos a estratégia de abandonarmos a representação de arestas individuais em redes grandes, substituindo-as por uma Superfície de Coesão.

Esta superfície é obtida fazendo-se associar às coordenadas de cada vértice (definidas conforme a subseção anterior) uma altura proporcional à coesão no vértice. Os demais pontos são obtidos por interpolação ou pelo ajuste de uma superfície suave aos pontos definidos sobre os nós.

A estratégia faz sentido porque, de um lado, os pontos próximos compartilham a mesma vizinhança; e de outro, porque, se a coesão for alta, os vértices na vizinhança serão muito interligados entre si; se for baixa, eles serão pouco interligados.

Troca-se, assim, precisão na informação por representabilidade.

Num sentido "frouxo", o procedimento corresponde a tratar a rede, uma entidade tipicamente discreta, como uma entidade contínua, isto é, como se em cada ponto da superfície temática existisse (potencialmente) um nó.

A Figura 14 e a Figura 15, a seguir, apresentam a superfície de coesão para os Exemplos 1 e 2 . 


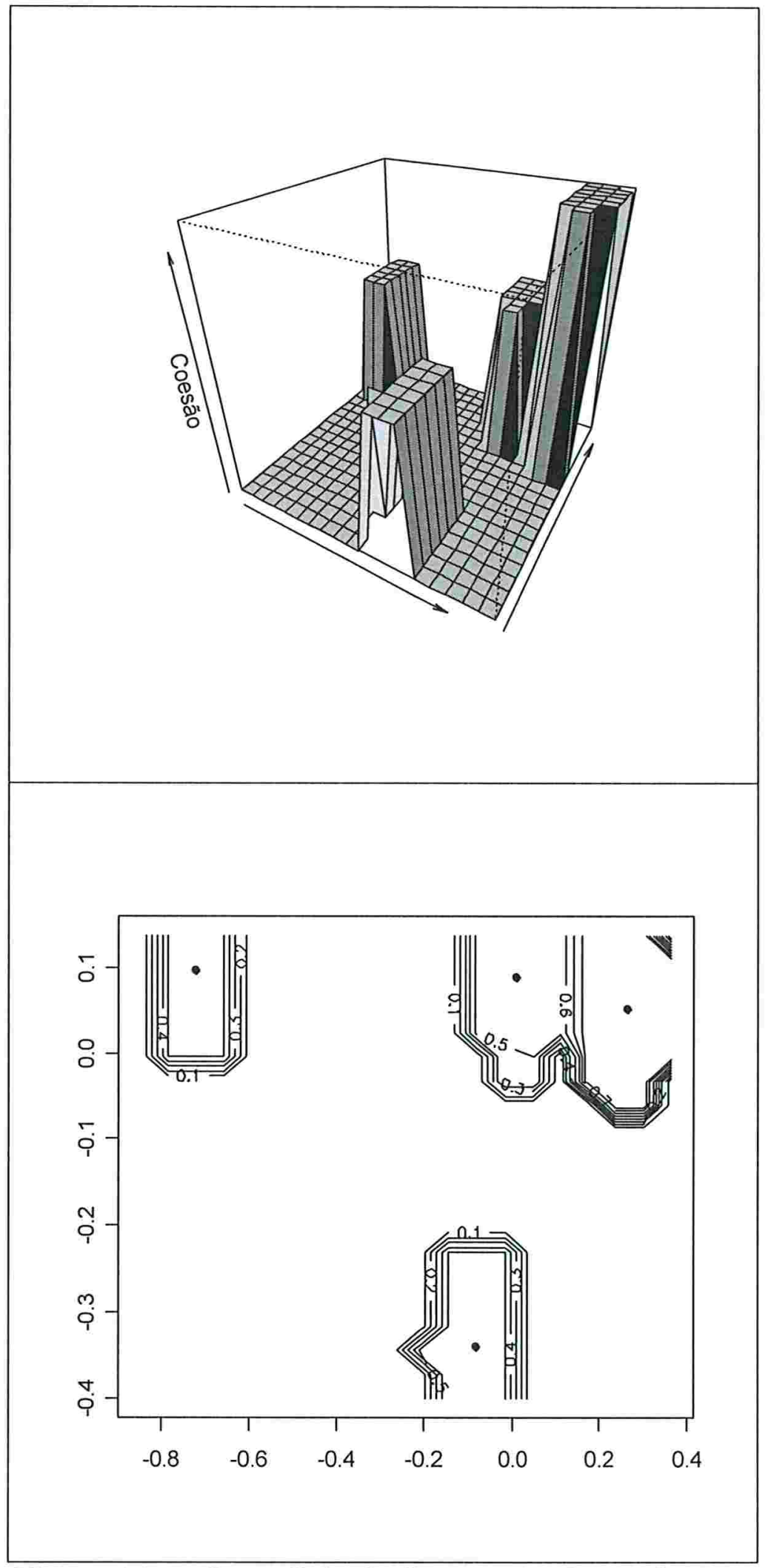

Figura 14 - Superfície de Coesão do Exemplo 1. 


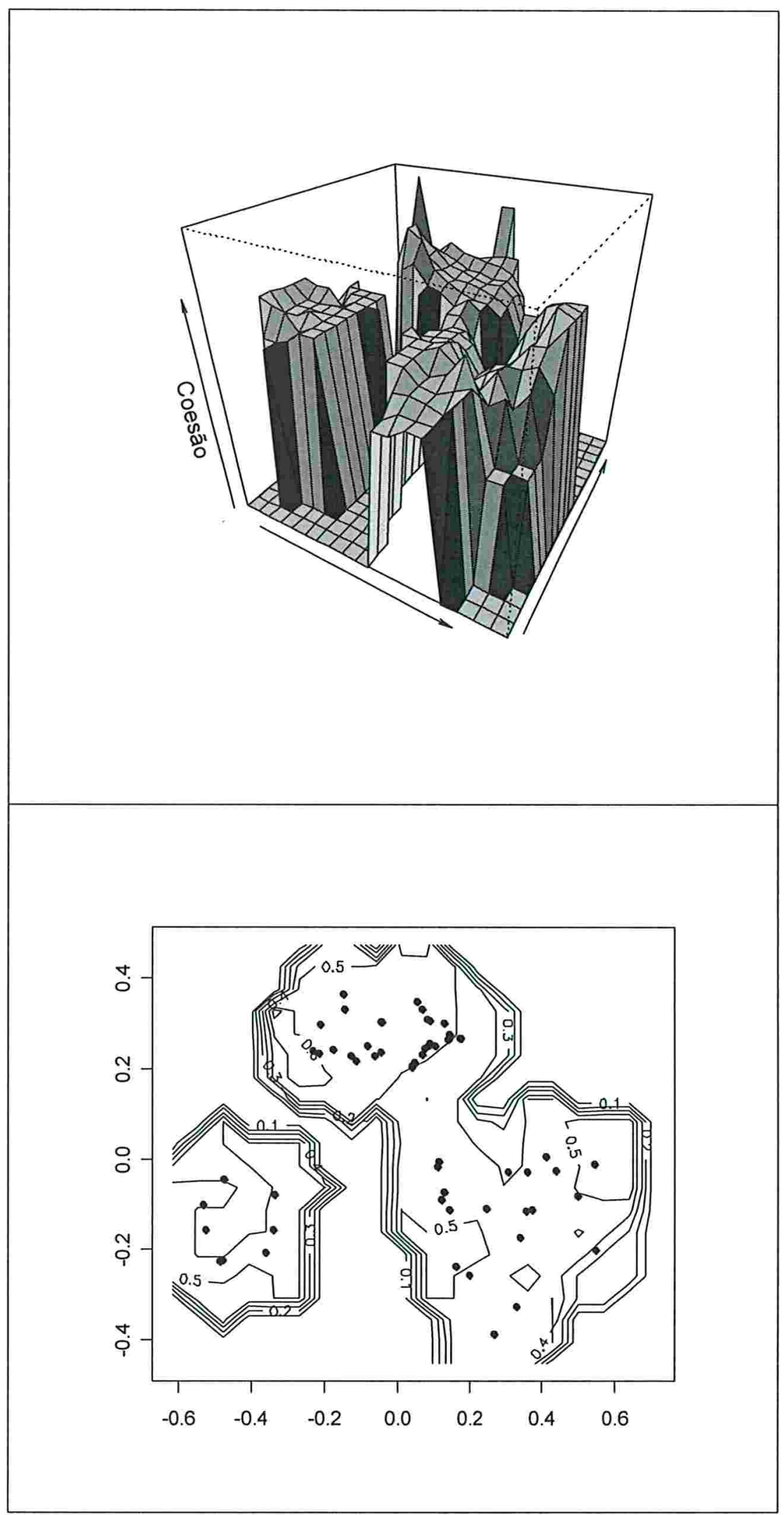

Figura 15 - Superfície de Coesão do Exemplo 2. 


\section{BASE ESCALONADA}

O problema que surge na montagem da base temática (escalonada) para a representação da rede é que os algoritmos tradicionais de escalonamento multidimensional consomem recursos na ordem $\mathrm{O}\left(n^{2}\right)$. No computador com processador Pentium-S, $32 \mathrm{MB}$ de ram e 2 Gyga de disco, em que foi processado este trabalho, já não é possível escalonar diretamente os cerca de 600 nós da rede, por esgotamento da memória: não é possível alocar a matriz de distância para submetê-la à função $c m d s c a l e$.

Uma estratégia para enfrentar o problema envolve a utilização de computadores com capacidade de processamento cada vez maiores. Seria a solução pela força bruta. Um projeto recentemente divulgado (http://www.unt.edu/ir/bigmds/, link válido em 30/01/2003) pretendia adaptar algoritmos de MDS para permitir processamento paralelo a ser realizado por rede de computadores das bibliotecas públicas nos EUA; o resultado do processamento seria projetado na cúpula de um planetário, numa área de $15 \mathrm{~m}$ por $15 \mathrm{~m}$, ou seja, numa tela de $225 \mathrm{~m}^{2}$.

Em nossa abordagem, ao contrário, adotou-se o princípio da economia de recursos computacionais e se optou pela estratégia de "dividir para conquistar" (AHO, HOPCROFT e ULLMAN, 1974), isto é, de dividir o problema em partes menores, encontrar solução para as partes, e então combinar a solução das partes para obter uma solução para o todo.

As principais etapas desenhadas para o escalonamento por partes são:

- subdividir a Lista de Arestas em pequenos conjuntos relativos a pontos (implicitamente) próximos;

- "trocar" cada grupo de pontos por um "representante", formando um conjunto de representantes suficientemente pouco numeroso para ser escalonado; e

- escalonar, na seqüência, os pontos inicialmente substituídos, usando como referência para a junção das soluções parciais os respectivos pontos "representantes", a esta altura já com coordenadas fixadas. 
Vejamos nas subseções a seguir, em maior detalhe, o que isso significa.

\subsection{Quebrando o Problema em Partes Hierarquizadas (Agrupando de Baixo para Cima)}

Com base no princípio de que o agrupamento de vizinhos coesos tem "relevância local" (veja 12.4), foram adotados os seguintes critérios para agrupar os vértices nos subconjuntos de processamento:

- A Lista de Vizinhos foi ordenada por Coesão e Grau, criando-se um índice que permite recuperar a posição original da vizinhança;

- Em cada passo, é considerado o vértice cuja vizinhança é a mais coesa; este vértice e os participantes de sua vizinhança ainda não alocados são atribuídos a um grupo; os membros do grupo são escalonados; cria-se um centróide do grupo ("pai"), que o representará no próximo nível de processamento (veja Figura 16, a seguir);

- Os vértices já alocados não são mais considerados;

- De forma iterativa são tratadas as vizinhanças progressivamente menos coesas;

- Vértices que "sobram" sozinhos em uma vizinhança que resulta com apenas dois elementos disponíveis são alocados no grupo de um vizinho deles (grupos de menos de três elementos não são permitidos pois a solução para seus "filhos" não pode ser ajustada à solução global);

- Vértices soltos, isto é, "donos" de vizinhanças em que todos os vizinhos foram alocados são deixados para o final e incluído em um grupo de "sobras".

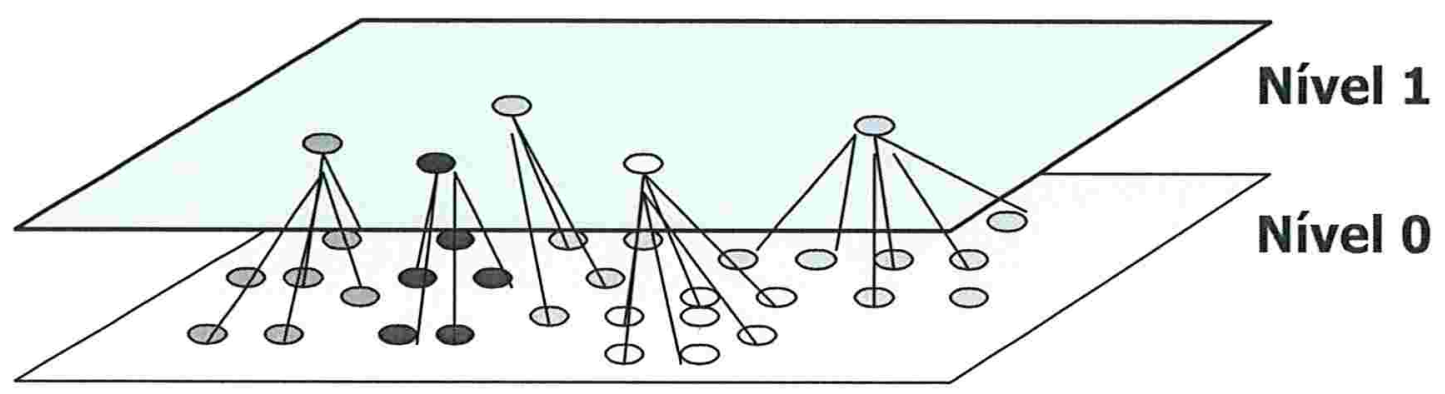

Figura 16 - Alocação de Vértices a Grupos e Criação de Representantes. 
Para controle do processo, os vértices originais são considerados como pertencentes a um "Nível 0"; já os centróides criados no processo de agrupamento de nós do Nível 0 são considerados pertinentes ao Nível 1. Na iteração 0, os novos vértices são "pais", em relação aos nós do Nível 0; na iteração 1, os centróides criados no Nível 1 passam a ser "filhos" e ganham "pais" no Nível 2, e assim por diante, conforme a Figura 17.

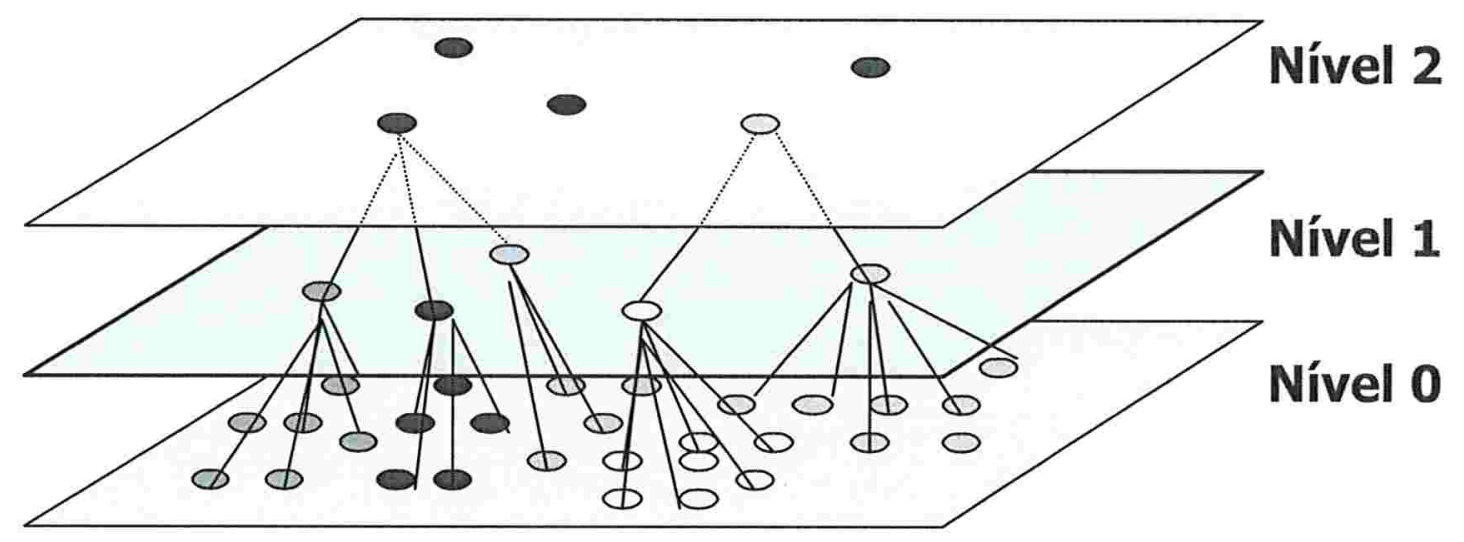

Figura 17 - Redução do Número de Vértices em Iterações Sucessivas.

O número de iterações "de subida" é controlada pelo código no corpo do programa (veja subseção 19.2), e foi ajustado manualmente em cada processamento. Caso haja interesse em automatizar uma regra de parada, seria simples, por exemplo, interromper as iterações quando o número de "representantes" obtido puder ser escalonado.

A Figura 18 mostra como os vértices da rede do Exemplo 2 foram alocados em 16 grupos. Os pontos vazados são os vértices originais e os pontos sólidos são os centróides criados para representar o grupo no Nível 1. A posição de todos os pontos é a que resultou ao final da aplicação do algoritmo proposto neste trabalho. 


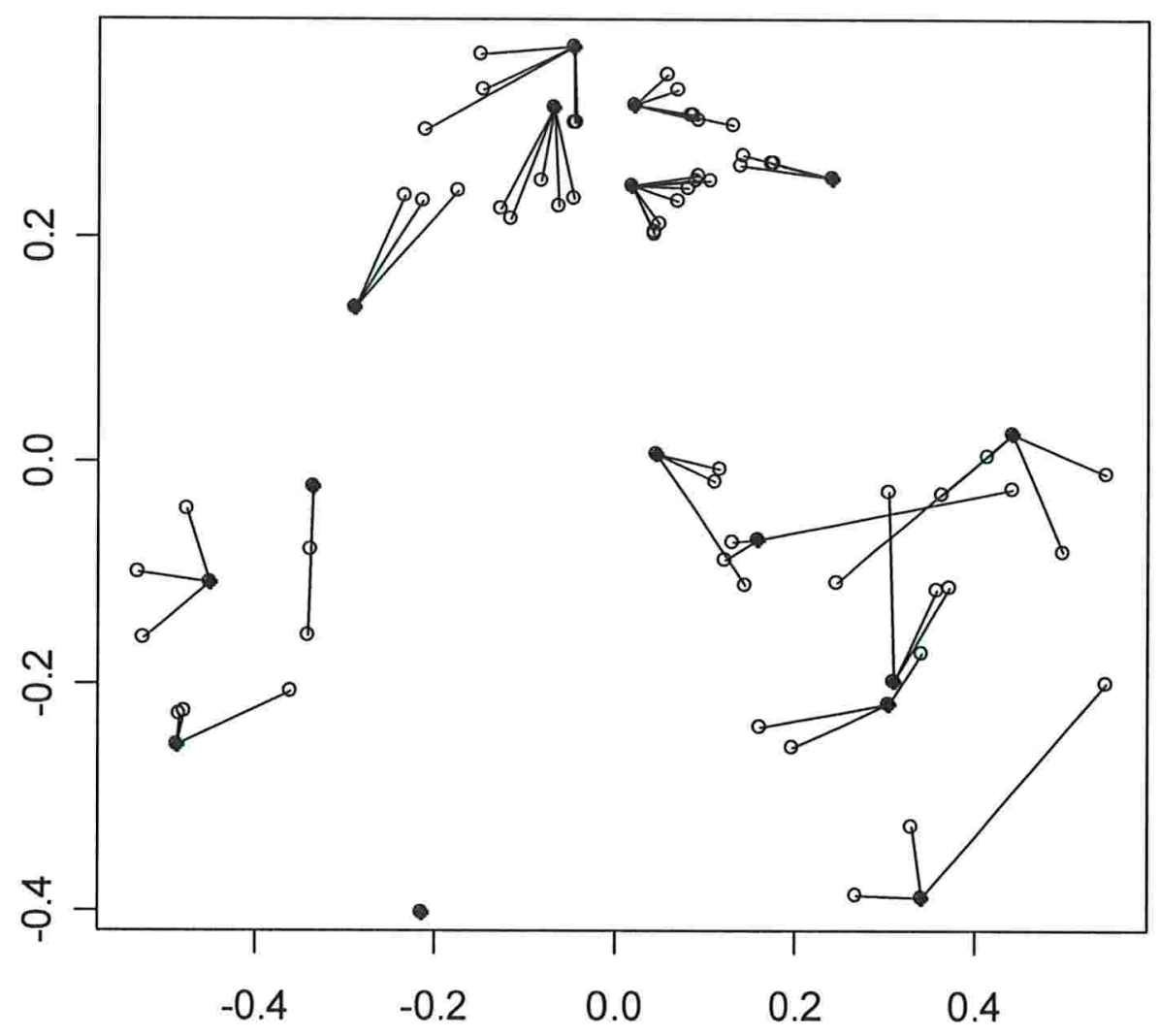

Figura 18 - Arquivo de Exemplo 2: Vértices da Rede (Nível 0, em Círculo Vazado) Ligados ao Centróide de Seu Grupo de Processamento (Nível 1, em Círculo Sólido).

\subsection{Coleta das Listas de Arestas}

As arestas entre os vértices necessárias à implementação do algoritmo são coletadas em diversos arquivos.

\subsection{1 dp0p0}

Com base na informação inicial de transações, disponível em TS, é calculada a Distância Temática entre os nós de usuários (os vértices de livros não são de 
interesse imediato neste trabalho, embora possam ser analisados e interpretados de maneira mercadologicamente útil).

Esta é a etapa computacionalmente "mais cara" de todo o algoritmo. Em uma solução completa, para $n$ vértices, $n^{2}$ distâncias deveriam ser calculadas. No entanto, duas estratégias de economia foram adotadas:

- com base no princípio da relevância local (subseção 12.4), foram calculadas distâncias temáticas apenas entre usuários vizinhos imediatos entre si (isto é, vizinhos em exatamente 2 passos na rede original);

- e, além disso, só foram armazenadas distâncias inferiores a 1.

As distâncias obtidas entre os vértices originais são equiparadas a arestas e armazenadas na matriz $d p 0 p 0$ ("distâncias de parentes 0 com parentes 0 ", isto é, distância entre vértices do Nível 0).

\subsection{2 dp1p0}

Uma vez formados os grupos do Nível 0 (no caso do Exemplo 2, em número de 16), e calculados seus centróides, a distância entre o centróide ("pai") e os vértices do grupo ("filhos") são calculadas com base em posições obtidas por escalonamento multidimensional clássico do grupo, e coletadas na matriz dplp0 ("distância de parentes de nível 1 e parentes de nível 0").

Estas arestas vinculam os filhos a seu pai, e são importantes na junção das soluções parciais por grupo.

\subsection{3 dp1p1}

A distância entre os "pais" $v_{i}$ e $v_{j}$, respectivamente centróides do grupo $i$ e do grupo $j$, é calculada como a menor distância entre um "filho" de $v_{i}$ e um filho de $v_{j}$. São duas as razões desta escolha:

- a primeira diz respeito ao conteúdo de informação de cada medida; no contexto da distribuição das distâncias temáticas que ocorrem na aplicação em foco, as distâncias menores são as mais informativas (veja subseção 12.3); 
- a segunda razão é de natureza computacional: é "barato" computacionalmente consolidar as distâncias temáticas originais para obter esta medida entre centróides.

As distâncias entre centróides criados no Nível 1 são armazenadas na matriz e no arquivo $d p 1 p 1$.

\subsubsection{Níveis Mais Agregados}

O processo de agrupamento de vértices, criação de representantes de nível mais elevado, cálculo e coleta de distâncias entre pais e filhos, e entre parentes de mesmo nível continua iterativamente até que os centróides resultantes sejam suficientemente pouco numerosos para serem escalonados por MDS clássico. Em cada iteração vão sendo formados sucessivamente as matrizes e os arquivos $d p 1 p 2 ; d p 2 p 2 ; d p 2 p 3 ; d p 3 p 3$; etc.

\subsection{Escalonando (de Cima para Baixo)}

Tendo atingido um nível de agregação suficiente para viabilizar o MDS clássico, inicia-se a solução do problema propriamente dita.

\subsubsection{Configuração do Último Nível (Nivel Mais Elevado)}

Quando o conjunto de centróides de um nível é suficientemente pouco numeroso, pode-se fixar coordenadas por meio do escalonamento multidimensional das distâncias entre eles.

Vejamos um exemplo. No caso do conjunto de dados Ex2.dat, isto já é possível após uma única iteração ${ }^{1}$.

Com a aplicação do algoritmo, os 71 vértices originais foram reunidos em 16 grupos, representados por seus centróides. As distâncias entre os centróides foram coletadas na matriz $d p 1 p 1$. Por sua vez, esta matriz, no formato de Lista

\footnotetext{
${ }^{1} \mathrm{Na}$ verdade, o conjunto original de 71 vértices poderia ter sido escalonado diretamente, sem a utilização do algoritmo proposto neste trabalho; esta possibilidade será utilizada no item 14 para a comparação dos dois métodos.
} 
de Arestas, foi transformada numa matriz quadrada de distâncias, assumindose que as distâncias faltantes têm valor 1. Em seguida, por MDS clássico fixou-se a configuração de centróides de Nível 1 e suas coordenadas foram armazenadas na matriz X1, cuja representação gráfica está na Figura 19.

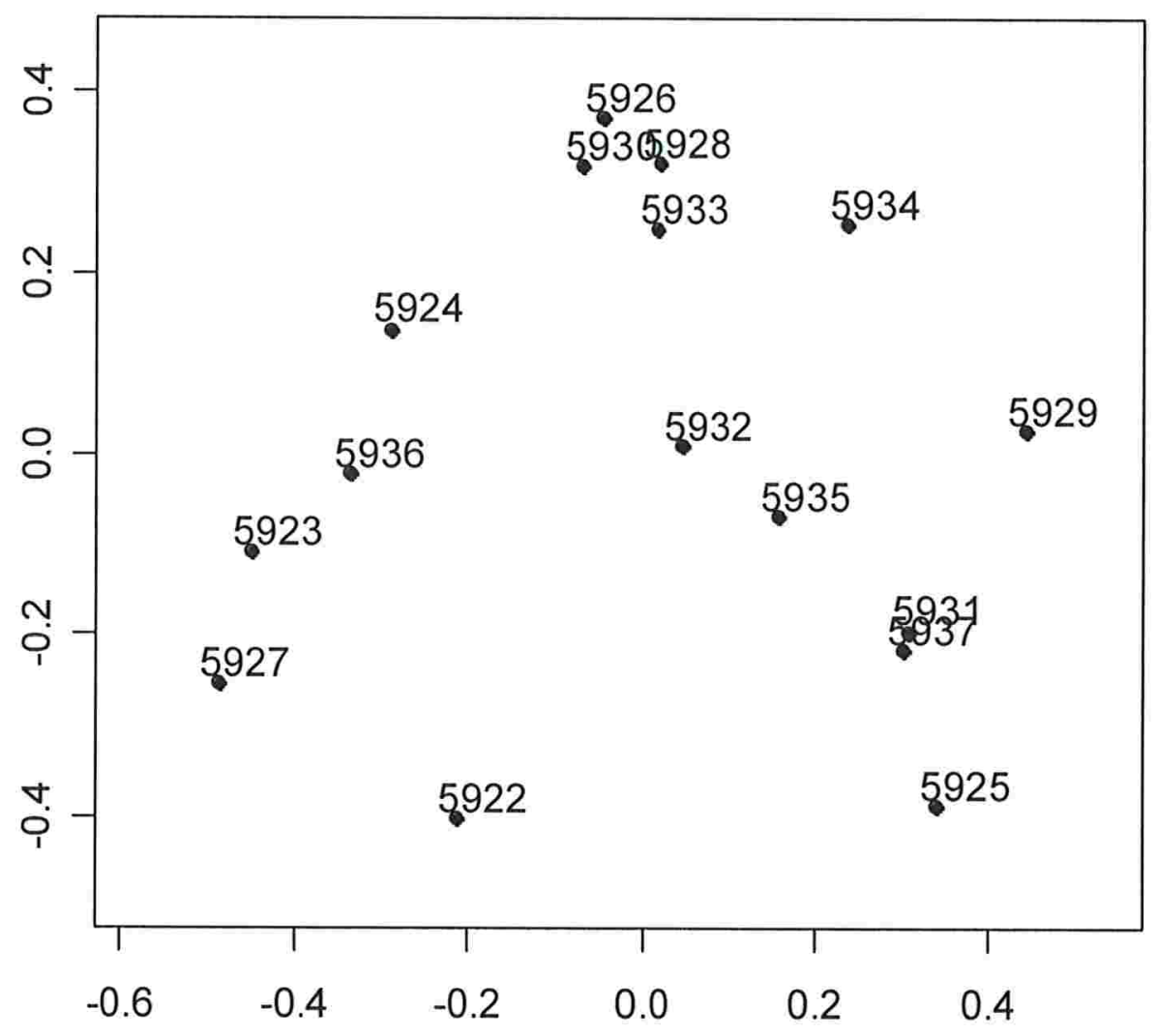

Figura 19 - Centróides de Nível 1 do Exemplo 2, com Rótulos de Vértices.

\subsubsection{Triangulando e Encontrando Soluções Parciais}

Para a busca de soluções parciais, adotou-se a estratégia de processar em grupos de três os vértices da configuração encontrada para um nível de iteração mais elevado já resolvido (no caso do Exemplo 2, estamos nos 
referindo à configuração representada na Figura 19, e obtida após apenas 1 iteração), juntamente com pontos do nível de baixo, ainda sem coordenadas.

Os motivos para isso são:

- Levando-se em consideração as distâncias entre 3 pais; entre estes pais e seus filhos; e entre todos os filhos destes 3 pais, é possível fixar, por escalonamento, a posição relativa de pais e filhos;

- O conjunto de distâncias obtidos desta maneira é suficientemente pequeno para ser tratado por MDS clássico (o algoritmo garante isso implicitamente porque as vizinhanças são pequenas; testes explícitos e rotinas de tratamento de eventuais exceções devem ser incorporadas ao programa em versões futuras);

- Como as posições absolutas dos pais já estava determinada, a posição absoluta dos filhos pode ser também determinada.

Cada grupo de 3 vértices é formado entre os vizinhos próximos, pois são estes que potencialmente têm influência mútua acentuada.

\subsubsection{Algoritmos de Triangulação}

O particionamento do interior de um conjunto de pontos em triângulos é um problema fundamental em geometria computacional, pois é o primeiro passo para a manipulação de objetos geométricos complicados. No plano, a triangulação é obtida pela inserção entre os vértices de arestas sem intersecção. A solução deve levar em consideração se o formato dos triângulos importa, a escala em que se vai trabalhar, restrições quanto ao traçado das arestas (por exemplo limitadas ao interior da figura), possibilidade de inclusão de pontos novos, etc. Os algoritmos mais simples "custam" $\mathrm{O}\left(n^{2}\right)$; algoritmos práticos andam em $\mathrm{O}(n \log n)$; e algoritmos de interesse apenas teórico consomem tempo linear (SKIENA, 1998).

O algoritmo "Triangle", de Jonathan Shewchuk da Universidade de CarnegieMellon, é um código em $\mathrm{C}$ que gera triangulações de Delaunay, triangulações de Delaunay restritas, e triangulações de Delaunay restritas aderentes a padrões de qualidade (por exemplo, de tamanho de ângulo). É rápido e robusto. O código está disponível em www.cs.cmu.edu/ quake/triagle.html. 
Foi nosso escolhido entre outras alternativas identificadas: GEOMPCK, de Barry Joe da Universidade de Alberta (ftp://ftp.cs.ualberta.ca/pub/geompack); Voronoi-2D de Steve Fortune (http://netlib.bell-labs.com/netlib/voronoi/ index.html).

A implementação do código Triangle no ambiente de $\mathrm{R}$, no entanto, apresentou muitos problemas que fogem ao escopo deste trabalho, e por este motivo, foi abandonada; ao final, optamos por implementar o nosso próprio algoritmo simplificado de triangulação, que, inclusive, leva em conta a inconveniência para este trabalho do compartilhamento de arestas entre os triângulos formados, típica das soluções de triangulação convencionais. Limites (veja subseção 17.1) e oportunidades de aperfeiçoamento (veja subseção 18.1.1) resultaram das nossas escolhas de implementação.

\subsubsection{Triangulação no Exemplo 2}

Nos dados do Exemplo 2, o resultado da triangulação do vértices do Nível 1 está representado na Figura 20. 


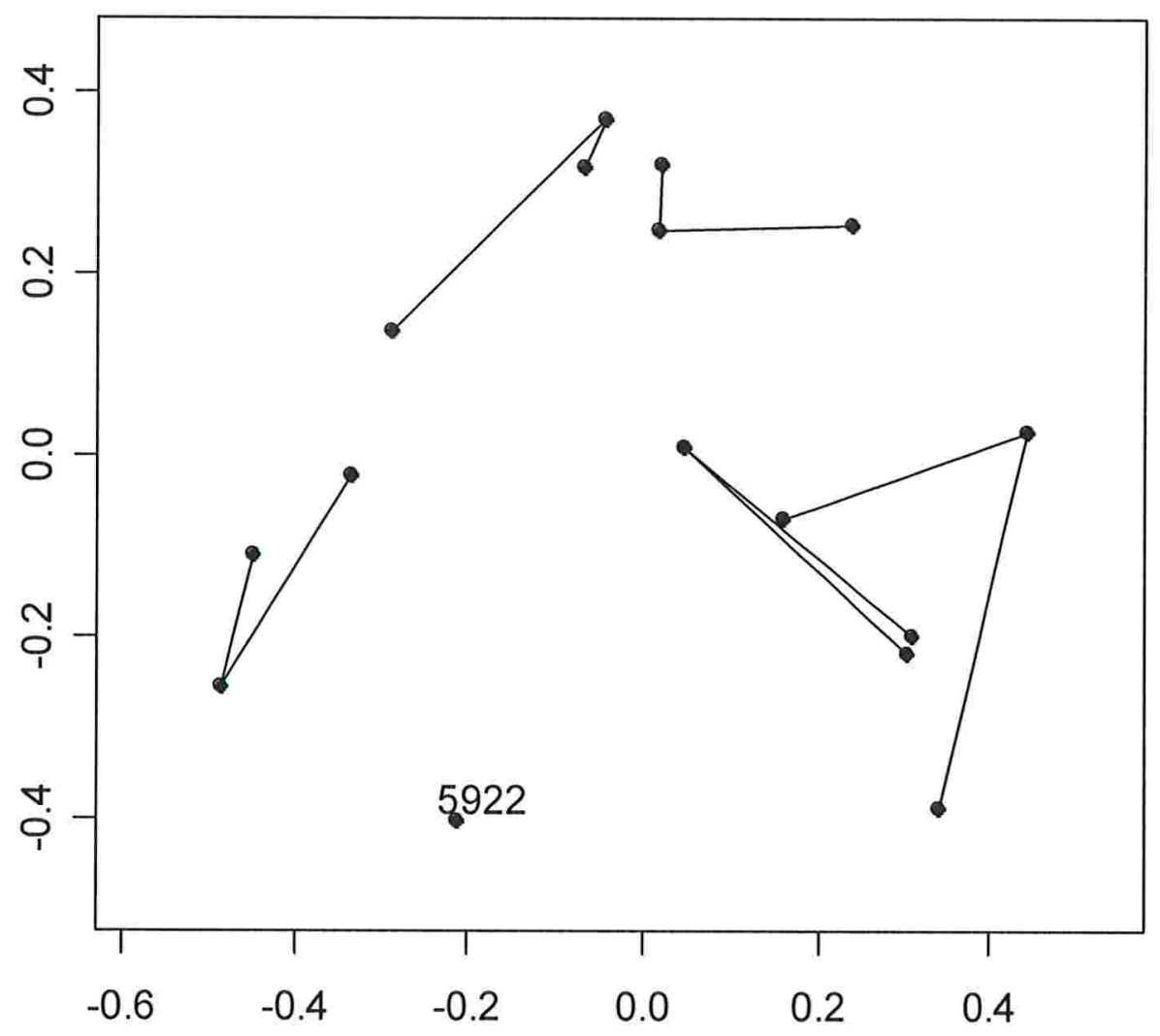

Figura 20 - Triangulação dos Vértices do Nível 1 do Exemplo 2.

Inúmeras exceções relativas ao número de vértices disponíveis para triangulação no final do procedimento tiveram que ser tratadas caso a caso no código. Por exemplo, no caso do arquivo EX2.dat, a última "triangulação" dos centróides do Nível 1 precisa reunir 4 pontos, para evitar que um deles fique isolado. A lógica geral do programa não permite o ajuste da solução parcial para grupos de distâncias com menos de 3 pais.

\subsubsection{Fixando as Coordenadas de Pais e Filhos em Um Triângulo}

Para cada conjunto de três centróides formado, as distâncias entre os próprios vértices do "triângulo", as distâncias entre os vértices do triângulo e seus 
respectivos filhos e as distâncias entre todos dos filhos destes pais são reunidas numa matriz quadrada de distâncias e escalonadas por MDS clássico.

No caso do Exemplo 2, Nível 1, e considerando-se o conjunto de vértices 5924, 5926 e 5930, as distâncias reunidas são as seguintes (Tabela 3):

Tabela 3 - Distâncias do Primeiro "Triângulo" Processado no Nível 1 do Exemplo 2.

\begin{tabular}{cccc}
\hline Origem & Vértice i & Vértice j & Distância \\
\hline dp1p1 & 5930 & 5924 & 0.28481 \\
& 5930 & 5926 & 0.05884 \\
& 5926 & 5924 & 0.33807 \\
\hline \multirow{2}{*}{ dp1p0 } & 5924 & 684 & 0.515201 \\
& 5924 & 2723 & 0.515201 \\
& 5924 & 4680 & 0.606040 \\
& 5926 & 494 & 0.533259 \\
& 5926 & 502 & 0.542315 \\
& 5926 & 686 & 0.542315 \\
& 5926 & 1078 & 0.354635 \\
& 5926 & 1347 & 0.354635 \\
& 5926 & 1724 & 0.533259 \\
& 5926 & 4540 & 0.354635 \\
& 5930 & 108 & 0.294828 \\
& 5930 & 950 & 0.432863 \\
& 5930 & 1168 & 0.601237 \\
& 5930 & 2810 & 0.432863 \\
& 5930 & 3815 & 0.549015 \\
\hline dp0p0 & 2810 & 502 & 0.76471 \\
& 2810 & 686 & 0.80000 \\
& 2810 & 950 & 0.76471 \\
& 2723 & 684 & 0.83333 \\
& 2723 & 1347 & 0.40000 \\
& 1724 & 494 & 0.54545 \\
& 1347 & 684 & 0.83333 \\
& 1168 & 502 & 0.77778 \\
& 1168 & 686 & 0.72727 \\
& 950 & 502 & 0.60000 \\
& 950 & 686 & 0.69231 \\
686 & 108 & 0.92308 \\
& 686 & 502 & 0.45455 \\
\hline
\end{tabular}


Escalonados os dados acima, obtemos a configuração representada na Tabela 4, e na Figura 21.

Tabela 4 - Configuração Processada no Triângulo 1 do Exemplo 2.

\begin{tabular}{crr}
\hline Vértice & $\mathbf{X 1}$ & $\mathbf{X 2}$ \\
\hline 108 & -0.15069 & 0.22345 \\
494 & 0.17629 & -0.37207 \\
502 & -0.36301 & -0.23422 \\
684 & 0.29347 & 0.27525 \\
686 & -0.35103 & -0.22427 \\
950 & -0.43230 & 0.06576 \\
1078 & 0.12198 & -0.23116 \\
1168 & -0.25447 & 0.03832 \\
1347 & 0.36211 & -0.00631 \\
1724 & 0.17629 & -0.37207 \\
2723 & 0.38844 & 0.27326 \\
2810 & -0.36803 & 0.11475 \\
3815 & -0.08595 & 0.19501 \\
4540 & 0.12198 & -0.23116 \\
4680 & 0.14252 & 0.19017 \\
5924 & 0.31552 & 0.36430 \\
5926 & 0.18764 & -0.40862 \\
5930 & -0.28075 & 0.33961 \\
\hline
\end{tabular}




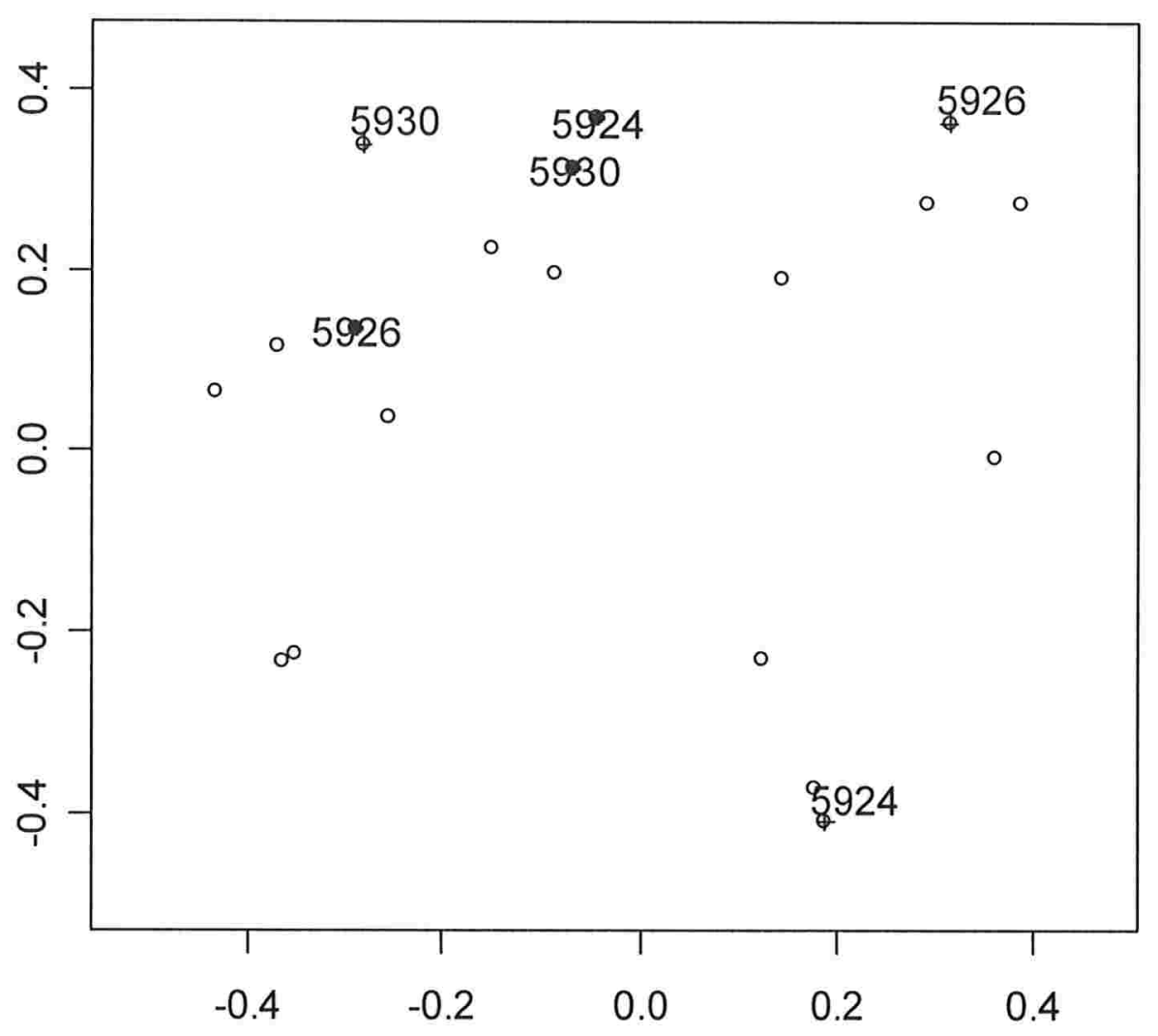

Figura 21 - Configuração no Triângulo 1 do Exemplo 2 (Pontos Vazados) e Coordenadas Originais dos Nós 5924, 5926 e 5930 (Pontos Sólidos).

\subsubsection{Juntando as Soluções Parciais}

Na Figura 21, além dos pontos vazados representando os pais (vazados com cruz) e filhos (vazados simples) processados na iteração, também foram incluídos pontos sólidos representando os vértices (pais) fixados no nível anterior. Observa-se que estas posições não coincidem.

Assume-se, então, que o espaço em que a solução parcial foi encontrada é uma deformação do espaço fixado no nível de cima. Uma análise de 
procrustes apenas dos pontos duplicados (isto é, dos pais) permite encontrar a transformação que dá um ajuste ótimo entre as duas configurações, no plano.

No Exemplo 2, a matriz de rotação A obtida é

$$
\begin{aligned}
& \text { [,1] [,2] } \\
& {[1,]-0.96527160 .2611063} \\
& \text { [2,] }-0.2611383-0.9653003 \text {, }
\end{aligned}
$$

o fator de dilação $\rho$ é

$$
\text { [1] 0.2233054, }
$$

e a translação rígida b é

$$
\begin{aligned}
& \text { [,1] [,2] } \\
& \text { [1,] }-0.13314140 .2731969 \text {. }
\end{aligned}
$$

A qualidade do ajuste neste triângulo deixa um pouco a desejar: o coeficiente de procrustes é

$$
\text { [1] } 0.5614142 \text {. }
$$


As configurações antes e depois do ajuste estão representadas na Figura 22 e na Figura 23, a seguir.

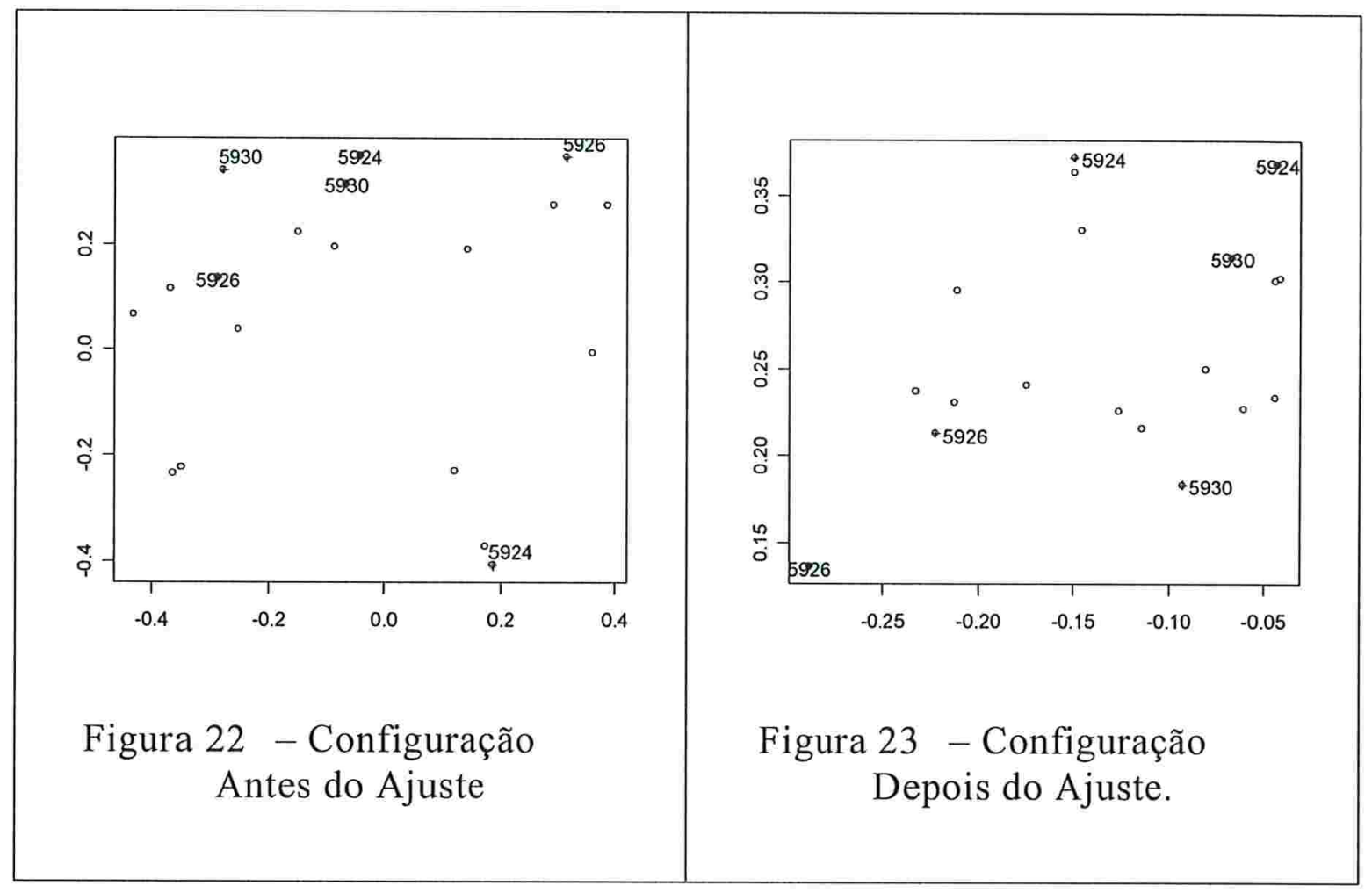

Após o ajuste, assume-se que as soluções parciais podem ser todas reunidas num único espaço daquele nível.

Aperfeiçoamentos para esta etapa de ajustes são sugeridos na subseção 18.1.2. 


\section{SUPERFÍCIE DE COESÃO}

Conforme já discutimos quando da apresentação do problema (veja subseção 9.6), o aumento da ordem e do tamanho da rede torna impraticável sua representação gráfica. Propusemos, então a troca de precisão na informação por representabilidade: em vez de desenhar as arestas, fazemos associar a cada vértice da rede escalonado sobre o espaço temático, uma altura que representa a coesão na vizinhança do vértice.

Por suavização e interpolação, calculam-se coordenadas para todos os pontos de um grid colocado sobre a base temática, obtendo-se a caracterização da superfície temática.

Pontos elevados na superfície temática indicam que naquela vizinhança, os pontos são intimamente ligados entre si: "morros" e "montanhas", portanto, indicam grupos usuários com interesse parecido. "Vales", por sua vez, indicam transição entre interesses temáticos.

Nós posicionados sobre picos caracterizam usuários com interesses especializados; nós posicionados sobre vales indicam usuários com interesses diversificados.

A Figura 24, a seguir, mostra que no relevo temático dos usuários do Exemplo 2 há três "morros" de interesse. 


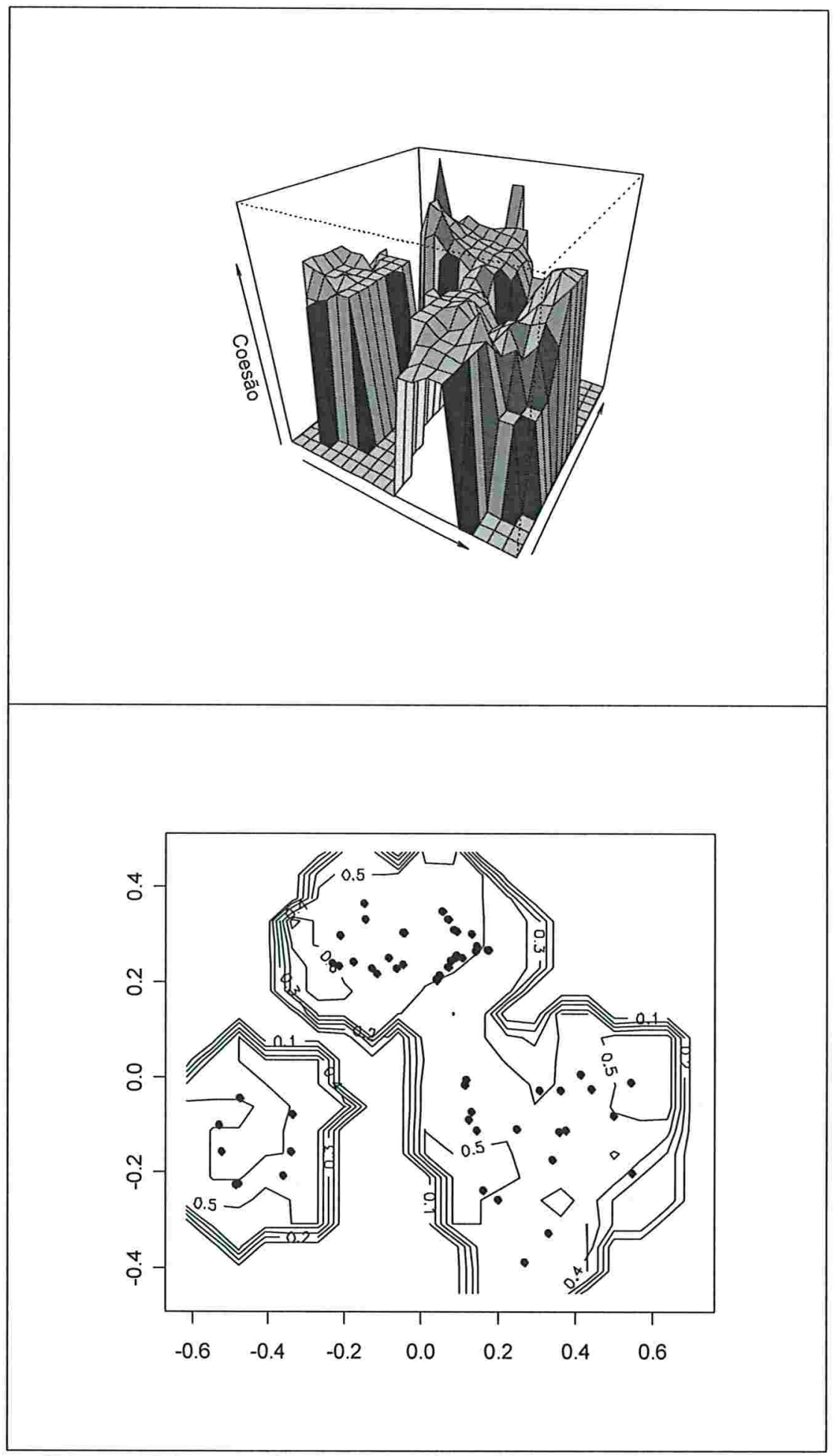

Figura 24 - Relevo Temático do Exemplo 2. 


\subsection{Interpretação do Relevo}

Com ajuda da Figura 25 e dos dados originais do problema, podemos interpretar o conteúdo temático das três elevações do relevo do Exemplo 2.

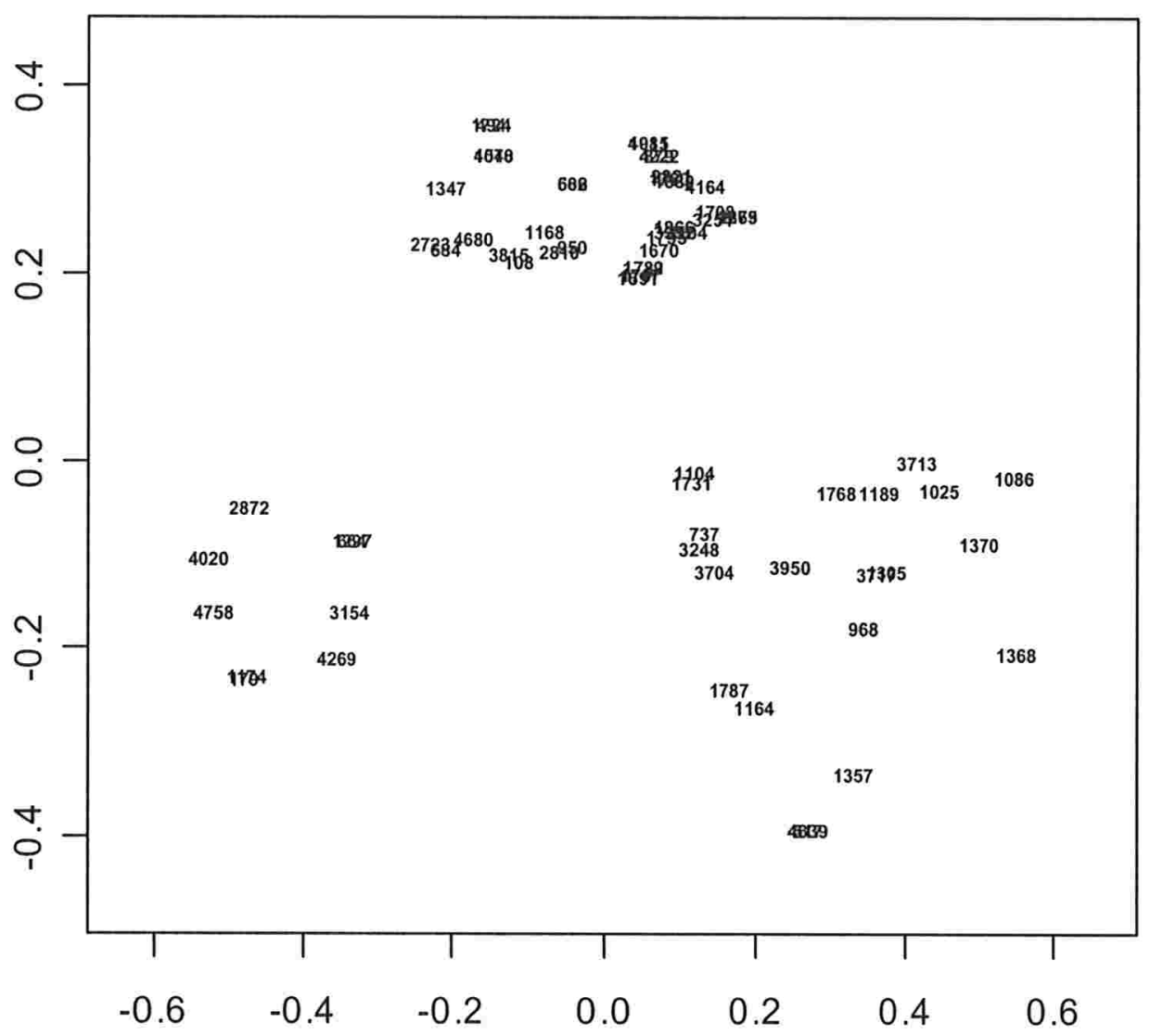

Figura 25 - Legenda dos Vértices da Rede do Exemplo 2.

O conjunto isolado, à esquerda (a Sudoeste), contém, os usuários 179, 664, $1174,1297,2872,3154,4020,4269$ e 4758 . Os livros mais retirados por estes 
usuários (isto é, com 3 ou mais ocorrências) estão listados na Tabela 5 e demonstram uma alta coesão em torno do assunto de Mercados Financeiros.

Tabela 5 - Livros Mais Retirados no "Morro Sudoeste"

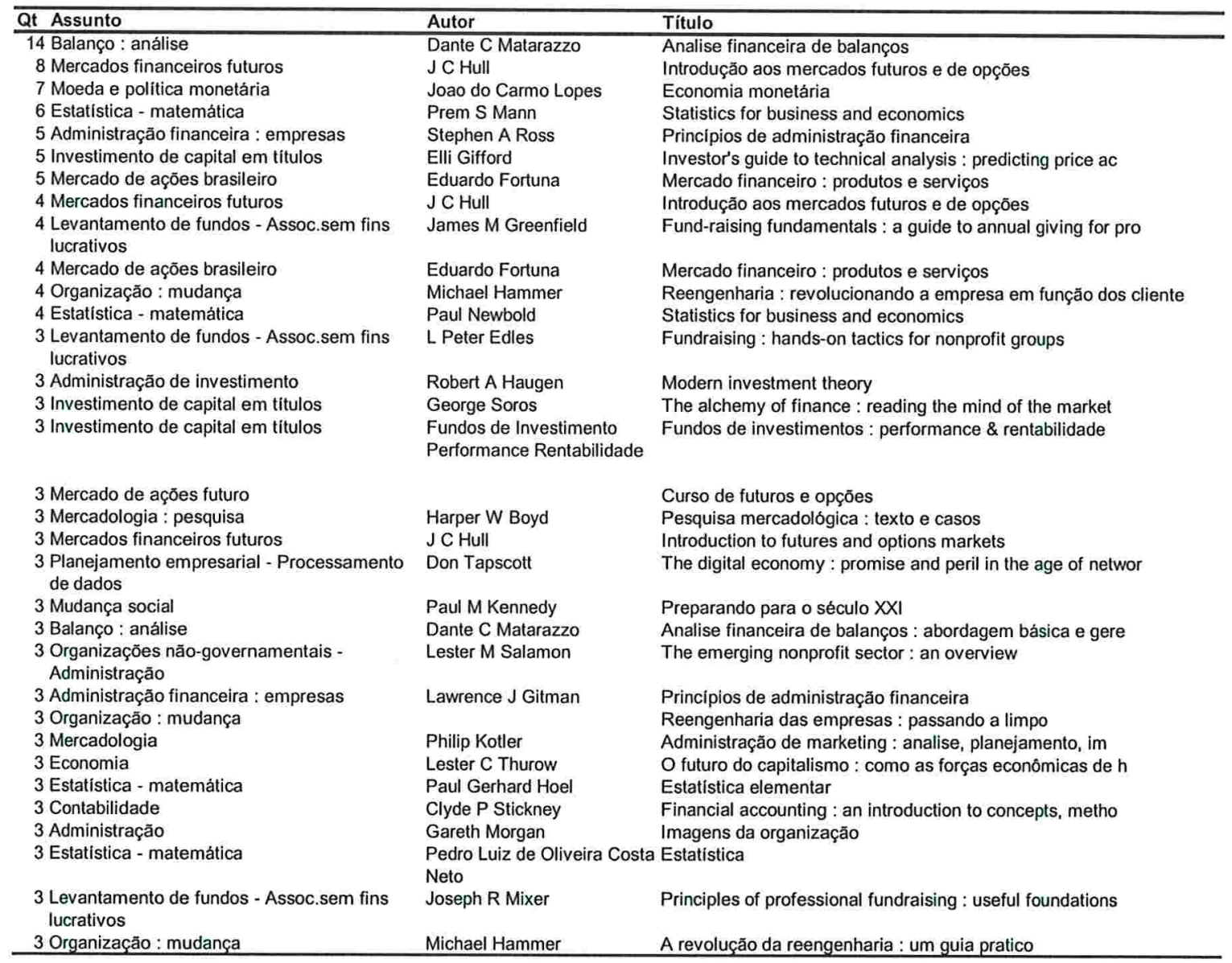

O morro abaixo e à direita (a Sudeste) é formado pelos usuários 517, 737, $968,1025,1086,1104,1164,1189,1305,1357,1368,1370,1731,1768$, $1787,3248,3704,3713,3717,3950,4639$. Os livros mais retirados por estes usuários estão listados na Tabela 6 e sugerem uma coesão em torno do tema de Administração Financeira e Planejamento. 
Tabela 6 - Livros Mais Retirados no "Morro Sudeste"

\begin{tabular}{|c|c|c|}
\hline Qt Assunto & Autor & Título \\
\hline 15 Administração financeira : empresas & Lawrence J Gitman & Princípios de administração financeira \\
\hline 14 Mercado de açōes brasileiro & Eduardo Fortuna & Mercado financeiro : produtos e serviços \\
\hline 11 Cadeias de Markov & William F Stewart & Introduction to the numerical solution of Markov chains \\
\hline 11 Desenvolvimento econômico & Nali de Jesus de Souza & Desenvolvimento econômico \\
\hline 10 Decisão - administração & Barry Render & Quantitative analysis for management \\
\hline 8 Direito do trabalho brasileiro & Octavio Bueno Magano & Manual de direito do trabalho \\
\hline 7 Decisão - administração & James R Evans & Introduction to simulation and risk analysis \\
\hline 7 Administração de investimento & $\begin{array}{l}\text { Paulo Roberto Vampre } \\
\text { Hummel }\end{array}$ & Analise e decisão sobre investimentos e financiamentos : \\
\hline 7 Decisão - administração & James R Evans & Introduction to simulation and risk analysis \\
\hline 7 Custos: contabilidade & Masayuki Nakagawa & $\mathrm{ABC}$ : custeio baseado em atividades \\
\hline 7 Contabilidade & M W E Glautier & Accounting theory and practice \\
\hline 6 Serviço ao cliente & & Mantendo clientes \\
\hline 6 Balanço : análise & Dante C Matarazzo & $\begin{array}{l}\text { Analise financeira de balanços : abordagem básica e } \\
\text { gere }\end{array}$ \\
\hline 6 Ciência & Thomas S Kuhn & A estrutura das revoluções cientificas \\
\hline 6 Tecnologia da informação & William H Inmon & Data architecture : the information paradigm \\
\hline 6 Metodologia Científica & $\begin{array}{l}\text { Gilberto de Andrade } \\
\text { Martins }\end{array}$ & Manual para elaboração de monografias e dissertações \\
\hline 5 Administração de investimento & & Capital budgeting under uncertainty \\
\hline 5 Mercado financeiro & Luiz Fernando Rudge & Mercado de capitais \\
\hline 5 Caracteristicas gerais da pesquisa & William Josiah Goode & Métodos em pesquisa social \\
\hline 5 Tecnologia da informaçäo & Shao Yong Chu & Banco de dados : organização, sistemas e administração \\
\hline 5 Sociologia da comunicação & Marshall McLuhan & Os meios de comunicação : como extensőes do homem \\
\hline $\begin{array}{l}5 \text { Planejamento empresarial - } \\
\text { Processamento de dados }\end{array}$ & Alex Berson & Data warehousing, data mining, and OLAP \\
\hline 5 Estatística - matemática & Paul Newbold & Statistics for business \& economics \\
\hline 5 Direito do trabalho brasileiro & Delio Maranhao & Direito do trabalho \\
\hline 4 Mercado de ações brasileiro & Eduardo Fortuna & Mercado financeiro : produtos e serviços \\
\hline 4 Administração de investimento & John D Finnerty & Project financing : asset-based financial engineering \\
\hline 4 Administração de investimento & Frank J Fabozzi & Investment management \\
\hline 4 Administração de investimento & Pierre Jacques Ehrlich & $\begin{array}{l}\text { Engenharia econômica : avaliação e seleção de projetos } \\
\text { d }\end{array}$ \\
\hline 4 Estatística - matemática & Mario F Triola & $\begin{array}{l}\text { Business statistics : understanding populations and } \\
\text { processe }\end{array}$ \\
\hline 4 Direito do trabalho brasileiro & & I Ciclo de Estudos de Direito do Trabalho \\
\hline 4 Mercado financeiro & Luiz Fernando Rudge & Mercado de capitais \\
\hline 4 Macroeconomia & G F Stanlake & Macroeconomia : uma introdução \\
\hline 4 Mercadologia & Philip Kotler & $\begin{array}{l}\text { Administração de marketing : (analise, planejamento e } \\
\text { cont }\end{array}$ \\
\hline 4 Valor : administração da produção & Joao Mario Csillag & Analise do valor : metodologia do valor \\
\hline 4 Valor : administração da produção & Joao Mario Csillag & Analise do valor : metodologia do valor \\
\hline 4 Direito do trabalho brasileiro & $\begin{array}{l}\text { Amauri Mascaro } \\
\text { Nascimento }\end{array}$ & Iniciação ao direito do trabalho \\
\hline 4 Direito do trabalho brasileiro & Delio Maranhao & Direito do trabalho \\
\hline 4 Administração financeira : empresas & Harold Bierman & $\begin{array}{l}\text { The capital budgeting decision : economic analysis of } \\
\text { invest }\end{array}$ \\
\hline 4 Investimento de capital em títulos & Kenneth H Shaleen & Technical analysis \& options strategies \\
\hline 4 Planejamento - administração de empresas & & Estratégia : a busca da vantagem competitiva \\
\hline 4 Jogos - matemática & Eric Rasmusen & Games and information : an introduction to game theory \\
\hline 4 Desenvolvimento econômico & Nali de Jesus de Souza & Desenvolvimento econômico \\
\hline 4 Macroeconomia & Rudiger Dornbusch & Macroeconomia \\
\hline 4 Administração financeira : empresas & Neil Seitz & Capital budgeting and long-term financing decisions \\
\hline
\end{tabular}

Finalmente, a elevação mais acima (ao Norte) na Figura 25, inclui 36 usuários: por exemplo, os de id 850,1168, 1347 e 4680. Os livros mais retirados por eles estão contabilizados na Tabela 7 e mostram uma orientação temática para tecnologia da informação. 
Tabela 7 - Livros Mais Retirados no "Morro Norte"

\begin{tabular}{|c|c|c|}
\hline Qt Assunto & Autor & Título \\
\hline 22 Tecnologia da informação & Richard E Walton & Tecnologia de informação : o uso de Tl pelas empresas q \\
\hline 17 Tecnologia da informação & Aguinaldo Aragon Fernandes & Gerência estratégica da tecnologia da informação \\
\hline \multicolumn{2}{|c|}{$\begin{array}{l}11 \text { Organizaçōes não-governamentais Julie Fisher } \\
\text { - Administração }\end{array}$} & Nongovernments: NGOs and the political development of th \\
\hline 9 Mercadologia & Jill H Ellsworth & Marketing on the Internet \\
\hline 9 Desenvolvimento econômico & John Friedmann & Empowerment : the politics of alternative development \\
\hline 8 Investimento de capital em títulos & Frank K Reilly & Investments \\
\hline $\begin{array}{l}8 \text { Administração financeira : } \\
\text { empresas }\end{array}$ & Lawrence J Gitman & Princípios de administração financeira \\
\hline 8 Tecnologia da informação & Norberto A Torres & Competitividade empresarial com a tecnologia de informação \\
\hline 7 Desenvolvimento econômico & Deborah Eade & The Oxfam handbook of development and relief \\
\hline 7 Investimento de capital em títulos & Lawrence J Gitman & Fundamentals of investing \\
\hline 6 Tecnologia da informação & Jose Davi Furlan & Megatendencias da tecnologia da informação \\
\hline 6 Administração de empresas & Max H Bazerman & Negociando racionalmente \\
\hline 5 Lógica & Irving M Copi & Introdução a lógica \\
\hline 5 Tecnologia da informação & & Formato IBICT : formato de intercâmbio bibliográfico e ca \\
\hline 5 Produção : administração & Roger G Schroeder & Operations management : decision making in the operations fu \\
\hline 5 Tecnologia da informação & Luiz Fernando Ballin Ortolani & Produtividade da tecnologia da informação: evidencias \\
\hline 4 Balanço : contabilidade & Umberto Mandarino & Analise de balanço no mercado de capitais \\
\hline 4 Organização: mudança & Richard L Nolan & Destruição criativa : um processo de seis etapas para transf \\
\hline 4 Investimento de capital em títulos & William F Sharpe & Investments \\
\hline 4 Mercadologia & Robert R Reeder & Industrial marketing : analysis, planning, and control \\
\hline 4 Marketing internacional & Vern Terpstra & International marketing \\
\hline 4 Administração & Gareth Morgan & Imagens da organização \\
\hline 4 Estatística - matemática & Paul Gerhard Hoel & Estatística elementar \\
\hline 4 Mercadologia & Alberto Luiz Albertin & Comercio eletrônico : modelo, aspectos e contribuiçōes \\
\hline 4 Contabilidade & Silverio das Neves & Contabilidade básica \\
\hline 3 Administração de empresas & William H Davidow & A corporação virtual : estruturação e revitalização \\
\hline 3 Matemática & Sebastiao Medeiros da Silva & Matemática para os cursos de economia, administração, ciência \\
\hline 3 Economia & Henri Denis & Historia do pensamento econômico \\
\hline 3 Mercadologia : pesquisa & David A Aaker & Marketing research \\
\hline 3 Administração de pessoal & Idalberto Chiavenato & Recursos humanos \\
\hline 3 Contabilidade & Jose Carlos Marion & Contabilidade empresarial \\
\hline
\end{tabular}

\subsection{Estratégia de Implementação da Representação Gráfica}

Para a elaboração da superfície temática, adotamos a estratégia descrita a seguir.

Inicialmente demarcamos a área ocupada pelo gráfico contendo os vértices da rede. Em seguida, colocamos sobre esta área um conjunto parametrizado de pontos de uma retícula. No exemplo, utilizamos uma retícula de $20 \times 20$ pontos (veja Figura 26). 


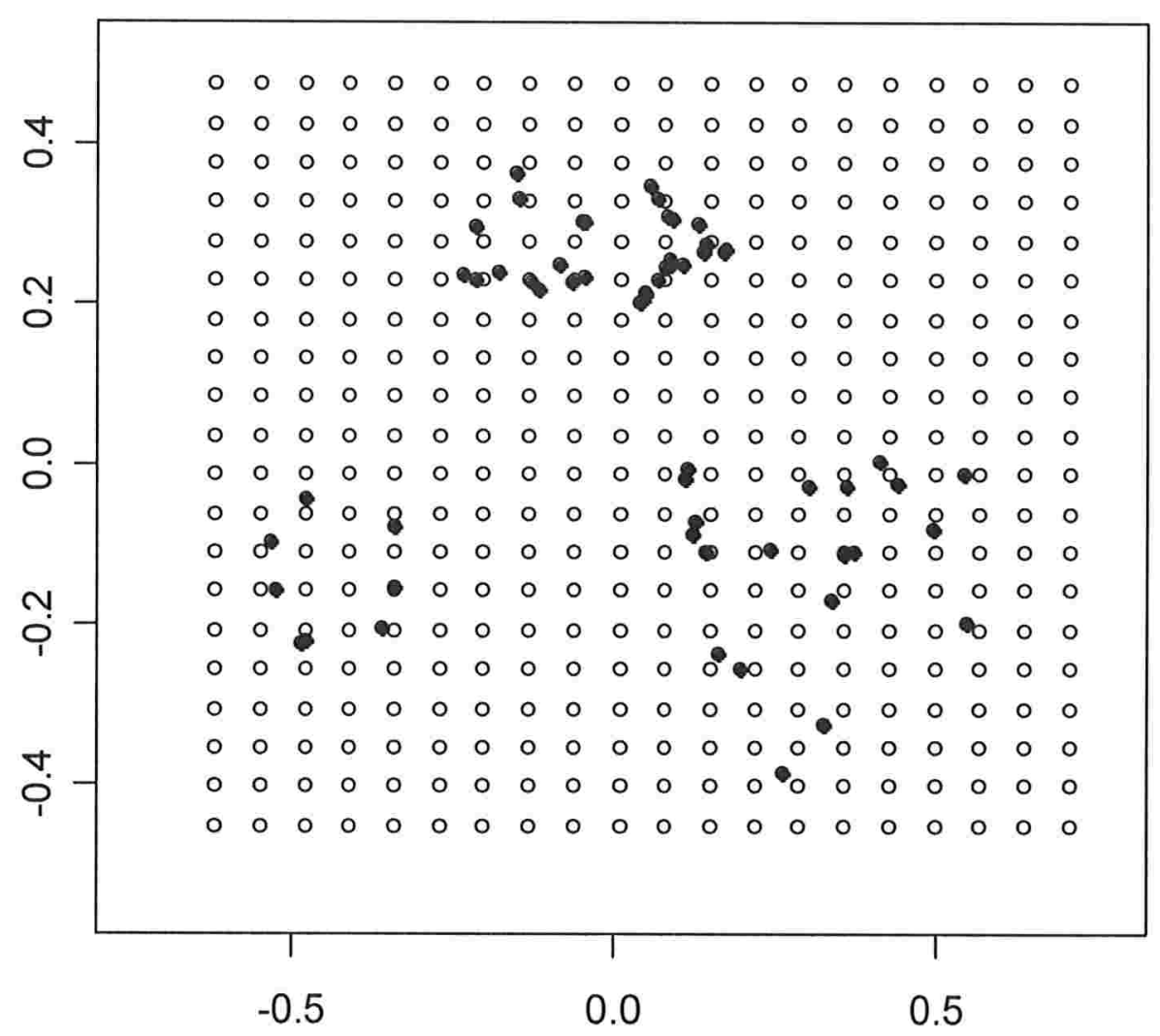

Figura 26 - Retícula sobre os Vértices do Exemplo 2.

Para cada ponto da retícula atribuiu-se a coesão média dos vértices que distavam menos de $d$ do ponto em questão (no exemplo $\mathrm{d}=2 * \mathrm{dx}$, onde $\mathrm{dx}$ é a distância horizontal entre dois pontos na retícula). Os valores de coesão calculados em cada ponto da retícula foram passados para as funções persp e contour do R, que produzem, respectivamente uma perspectiva 3-D dos dados, e um gráfico de curva de nível. 


\section{PARTICULARIDADES DO PROBLEMA DE COOPERAÇÃO INDIRETA}

Algumas características do tipo de rede formado na nossa aplicação foram repetidamente utilizadas como base de simplificações necessárias à viabilização do algoritmo proposto para sua representação gráfica por meio de escalonamento multidimensional das distâncias temáticas (Seção 6). Estas características convenientes são discutidas a seguir.

\subsection{Matriz de Adjacência Escassa}

Numa matriz de adjacência de rede não orientada, o número de arestas possíveis é $n(n-1) / 2$, onde $n$ é o número de nós distintos na rede. Assim, com o aumento de nós, o número de arestas possíveis cresce segundo $\mathrm{O}\left(n^{2}\right)$.

Admitindo-se que o grau médio $g$ dos nós é uma característica estável da rede, isto é, admitindo-se que $g$ é constante, o número de arestas observadas é dado por $n g / 2$. Assim, com o aumento de nós, as arestas crescem segundo $\mathrm{O}(n)$.

A densidade de arestas na rede, por sua vez, dada por $g /(n-1)$ diminui à medida que a ordem da rede aumenta. Isso significa que a matriz de adjacência conterá uma proporção de zeros cada vez maior.

Assim, se de um lado, o tamanho da matriz de distâncias explode conforme aumenta o número de vértices a analisar, tornando-se computacionalmente intratável, por outro lado esta explosão não acontece com o número de caselas contendo o valor " 1 ". Por isso, procuraremos trabalhar controlando apenas o endereço (índices) destas caselas - o que corresponde a trabalhar com a lista de arestas.

Na matriz do Exemplo 1, o grau médio dos nós é 2,6; as arestas observadas são 13; as arestas possíveis, 45. A densidade de arestas é 0,29. Cerca de $70 \%$ das caselas, portanto, contém zeros. Para economia, só é necessário acompanhar os $30 \%$ de caselas contendo uns. A economia aumenta drasticamente conforme aumenta o número de vértices na rede. 


\subsection{Matriz de Distâncias Temáticas Escassa}

Da mesma forma que na matriz de adjacência predominam os zeros (indicando falta de ligação), também na matriz de distância temática dominam as caselas que indicam ausência de relação temática; apenas, agora, estas caselas assumem o valor da distância máxima, isto é, o valor 1. Podemos economizar recursos acompanhando numa Lista de Distâncias, logicamente equiparável a uma Lista de Arestas, apenas os valores diferentes de 1.

\subsection{Distribuição das Distâncias Temáticas}

Mesmo entre as Distâncias Temáticas calculadas e acompanhadas, predominam amplamente as distâncias grandes. Elas são, portanto, pouco informativas. Assim, sempre que possível, valorizamos no algoritmo a conservação da informação relativa a arestas pequenas.

\subsubsection{Matriz D de Distâncias Temáticas}

A matriz $\mathbf{D}$ de distâncias temáticas (5.1) entre os nós da rede do Exemplo 1, em forma de lista e calculada com base na Lista de Vizinhanças (LV), é apresentada na Saída 7. O histograma das distâncias temáticas está apresentado na Figura 27.

Saída 7 - Matriz D de Distâncias (Temáticas) entre Usuários do Exemplo 1.

$\begin{array}{cccc}\mathbf{D} & & & \\ \mathbf{i} & \mathbf{X 1} & \mathbf{X 2} & \mathbf{X 3} \\ 1 & 100 & 101 & 0.4444444 \\ 2 & 100 & 102 & 0.5555556 \\ 3 & 100 & 105 & 0.7500000 \\ 4 & 100 & 107 & 0.2857143 \\ 5 & 100 & 108 & 0.2857143 \\ 6 & 101 & 102 & 0.5000000 \\ 7 & 101 & 105 & 0.8000000 \\ 8 & 101 & 107 & 0.4444444 \\ 9 & 101 & 108 & 0.4444444 \\ 10 & 102 & 105 & 0.7777778 \\ 11 & 102 & 107 & 0.5555556 \\ 12 & 102 & 108 & 0.5555556 \\ 13 & 105 & 107 & 0.7500000 \\ 14 & 105 & 108 & 0.7500000 \\ 15 & 107 & 108 & 0.2857143\end{array}$




\section{Distâncias Temáticas do Exemplo 1}

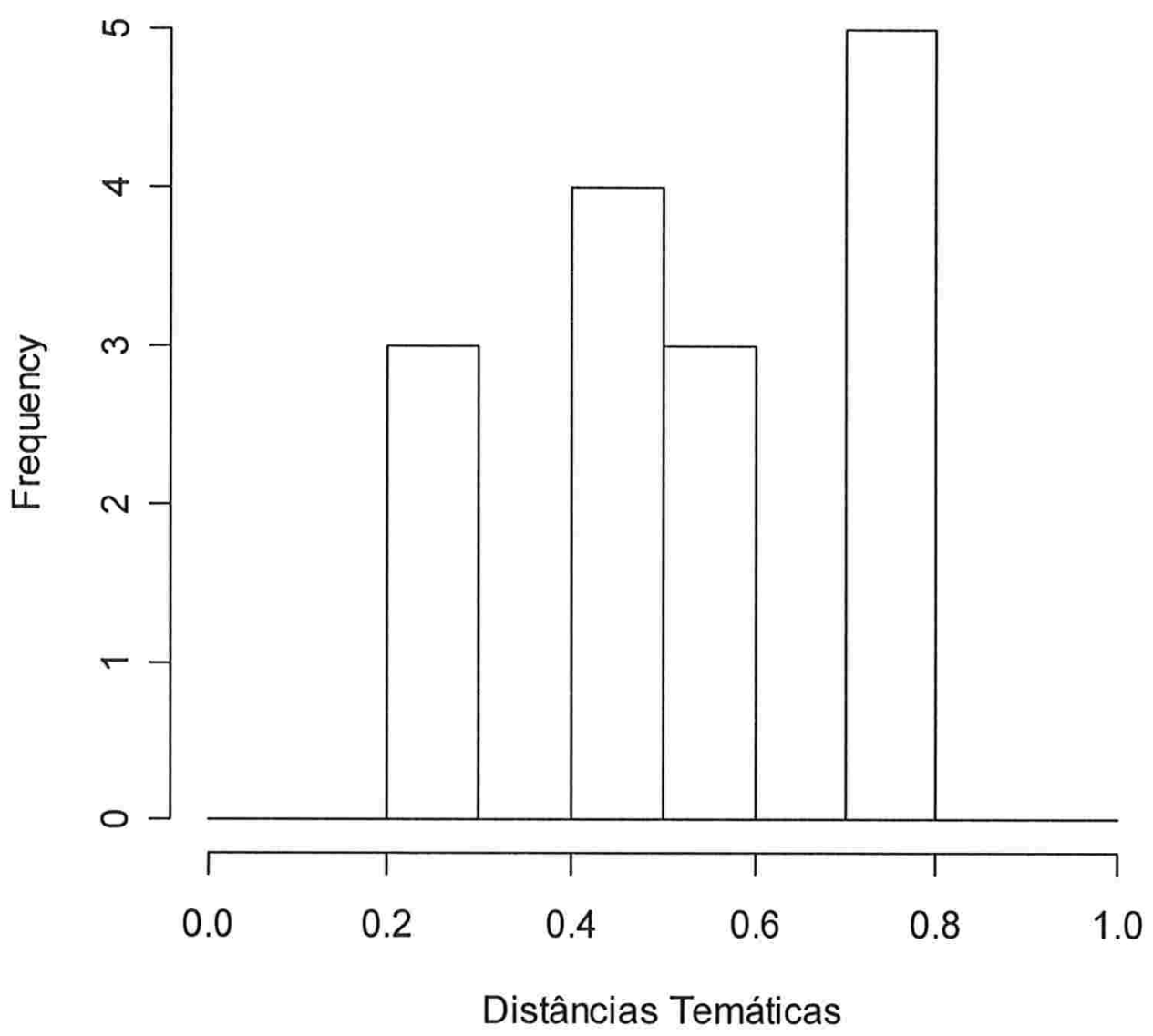

Figura 27 - Histograma das Distâncias Temáticas entre Usuários do Exemplo 1.

Como temos 6 usuários na rede, o número de distâncias entre eles é 6*5/2 $=15$. A lista de Distâncias Temáticas tem também 15 entradas, uma para cada aresta; está, portanto, completa.

$\mathrm{O}$ arquivo para o Exemplo 2 tem originalmente 1264 registros, que se reduzem a 175 após o pré-processamento. Implicitamente, na lista de transações há 71 usuários. Assim, há $71 * 70 / 2=2485$ distâncias entre os nós. No entanto, a matriz de distâncias (temáticas) retornada pelo programa tem apenas 147 linhas, conforme reprodução parcial da Saída 8, representada no histograma da Figura 28, a seguir. 
Saída 8 -Distâncias Temáticas entre Nós de Usuários do Exemplo 2.

$\begin{array}{rrrr}\mathbf{D} & & & \\ \mathbf{i} & \mathbf{X 1} & \mathbf{X 2} & \mathbf{X 3} \\ 1 & 108 & 1269 & 0.9230769 \\ 2 & 108 & 686 & 0.9230769 \\ 3 & 179 & 1866 & 0.9000000 \\ 4 & 179 & 1174 & 0.7000000 \\ 5 & 179 & 4020 & 0.7500000 \\ 6 & 179 & 4758 & 0.5000000 \\ 7 & 494 & 1724 & 0.5454545 \\ 8 & 494 & 1164 & 0.8461538 \\ 9 & 494 & 3254 & 0.8333333 \\ 10 & 494 & 3104 & 0.8333333 \\ \ldots & \ldots & \ldots & \ldots \\ 137 & 3248 & 4540 & 0.8000000 \\ 138 & 3352 & 4540 & 0.7777778 \\ 139 & 3950 & 4164 & 0.7000000 \\ 140 & 4011 & 4222 & 0.7777778 \\ 141 & 4020 & 4680 & 0.6666667 \\ 142 & 4020 & 4758 & 0.7000000 \\ 143 & 4269 & 4846 & 0.7500000 \\ 144 & 4639 & 4846 & 0.8181818 \\ 145 & 4682 & 4834 & 0.4000000 \\ 146 & 4682 & 5921 & 0.4000000 \\ 147 & 4834 & 5921 & 0.4000000\end{array}$




\section{Distâncias Temáticas do Exemplo 2}

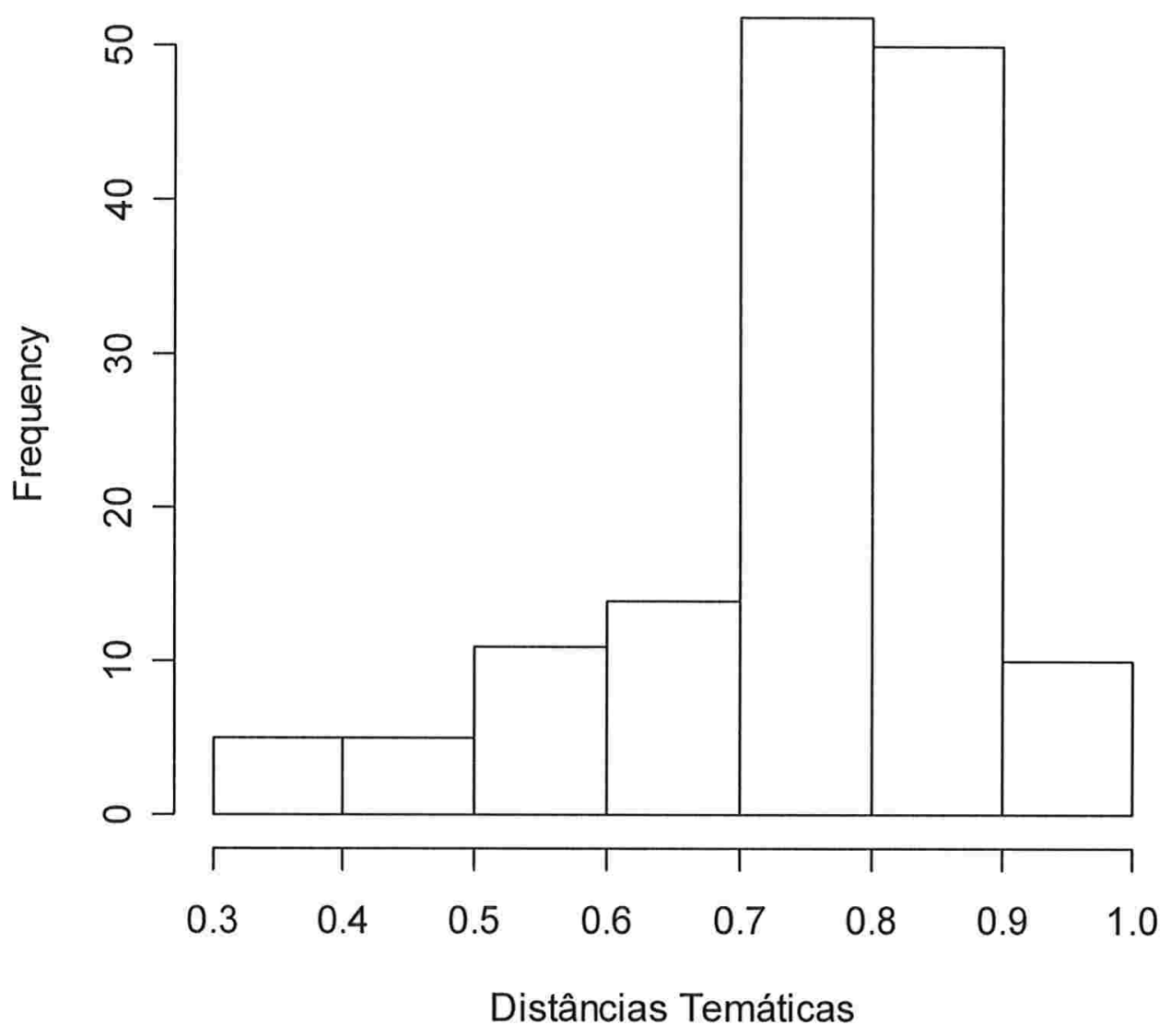

Figura 28 - Histograma das Distâncias Temáticas do Exemplo 2

$\mathrm{O}$ arquivo para o Exemplo 3 tem originalmente 4850 registros, que se reduzem a 2043 após o pré-processamento. Implicitamente na lista de transações há 596 usuários. Assim, há 596*595/2 = 177310 distâncias entre os nós. No entanto, a matriz de distâncias (temáticas) retornada pelo programa tem apenas 2445 linhas, conforme reprodução parcial da saída de computador, a seguir (Saída 9). O histograma correspondente está na Figura 29. 
Saída 9 - Distâncias Temáticas entre Nós de Usuários do Exemplo 3

$\begin{array}{rrrr}\mathbf{D} & & & \\ \mathbf{i} & \mathbf{X 1} & \mathbf{X 2} & \mathbf{X 3} \\ 1 & 55 & 1106 & 0.6315789 \\ 2 & 55 & 1211 & 0.6111111 \\ 3 & 55 & 2381 & 0.6666667 \\ 4 & 55 & 3092 & 0.6818182 \\ 5 & 55 & 3382 & 0.7586207 \\ 6 & 55 & 3401 & 0.7666667 \\ 7 & 55 & 4639 & 0.8444444 \\ 8 & 55 & 1868 & 0.9285714 \\ 9 & 55 & 3248 & 0.9230769 \\ 10 & 55 & 1439 & 0.8888889 \\ \ldots & \ldots & \ldots & \ldots \\ 2436 & 4773 & 5931 & 0.7307692 \\ 2437 & 4778 & 4790 & 0.8695652 \\ 2438 & 4778 & 4838 & 0.8636364 \\ 2439 & 4781 & 4827 & 0.9090909 \\ 2440 & 4790 & 4838 & 0.5384615 \\ 2441 & 4806 & 4814 & 0.8095238 \\ 2442 & 4814 & 4815 & 0.9310345 \\ 2443 & 4834 & 5938 & 0.8846154 \\ 2444 & 4834 & 5175 & 0.8518519 \\ 2445 & 4834 & 5921 & 0.6000000\end{array}$




\section{Distâncias Temáticas do Exemplo 3}

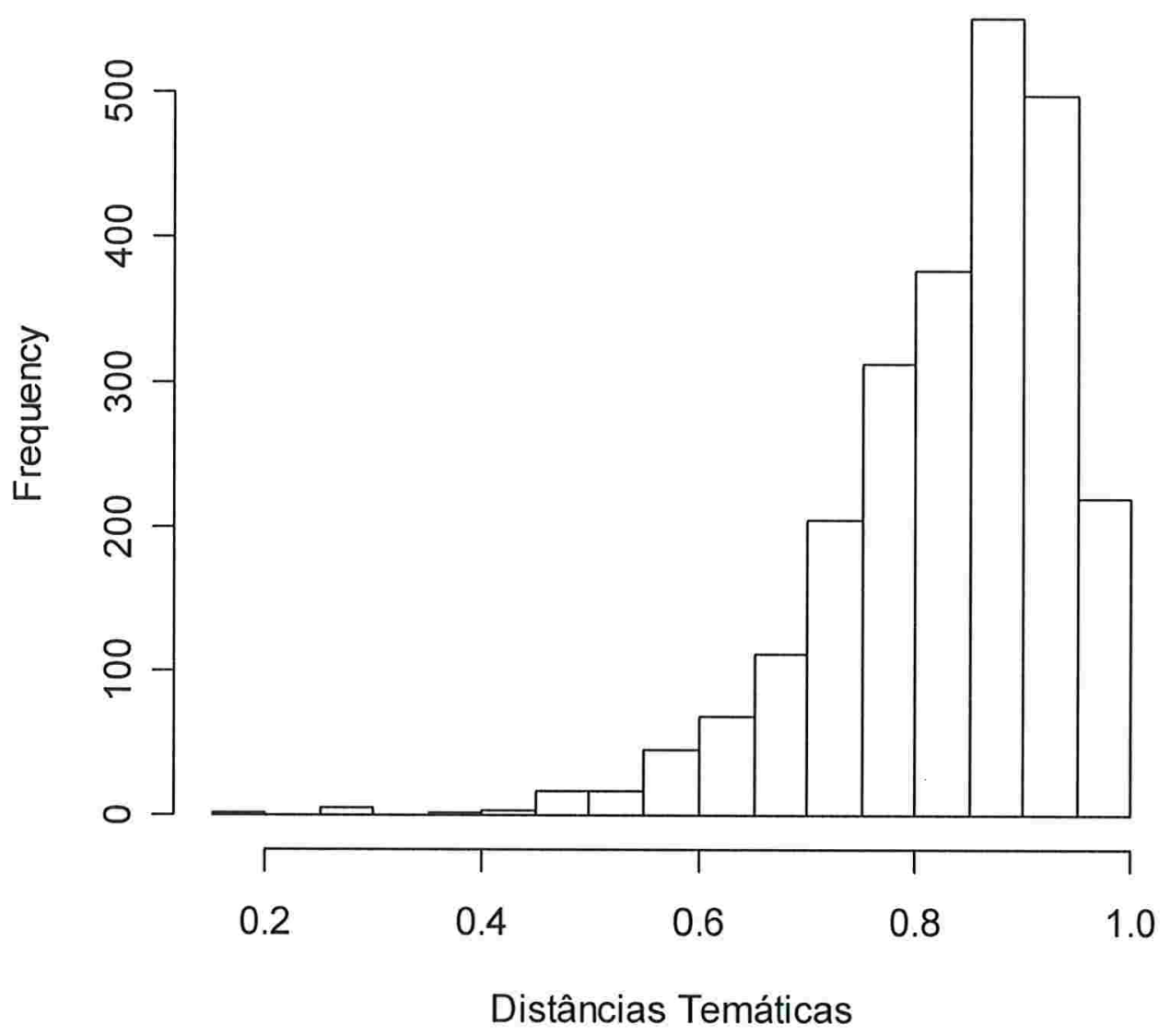

Figura 29 - Histograma das Distâncias Temáticas do Exemplo 3.

Pela comparação dos histogramas podemos constatar, a tendência para a ocorrência de distâncias temáticas grandes se acentua com o aumento do número de vértices. Isto é natural: quantos mais usuários são analisados, mais pares deles podem ser formados com pouco interesse comum.

\subsection{Relevância Local}

Uma idéia importada do Marketing Geográfico é que o impacto de uma ocorrência georeferenciada sobre a sua vizinhança decai com a distância. Transportada para o contexto de redes, pode-se assumir que vértices separados por muitos passos têm progressivamente menos informação um sobre o outro. 
Com base nesta idéia, sempre que possível, montaremos a matriz de adjacência apenas nas vizinhanças dos vértices sob consideração em cada iteração do algoritmo.

Também no cálculo da distância temática o conceito foi importante para redução do número de distâncias a calcular. Por outro lado, a utilização de vizinhanças em mais de um passo pode representar um aperfeiçoamento do algoritmo (veja a subseção 18.1.2). 


\section{CÓDIGO COMENTADO}

Nesta seção discutimos o algoritmo em si, em termos de sua programação.

\section{1. $R$}

O R é uma linguagem e um ambiente para computação estatística e gráfica. É similar à linguagem $\mathrm{S}$ desenvolvida nos Laboratórios Bell (anteriormente AT\&T e no momento Lucent Technologies) por John Chambers e colegas. O $\mathrm{R}$ pode ser considerado uma outra implementação do S. Há diferenças de conceito importantes, mas a maior parte do código escrito em $\mathrm{S}$ "roda" em $\mathrm{R}$.

É um freeware, e pode ser baixado a partir de www.r-project.org.

\subsubsection{Vantagens}

Além de fornecer uma grande variedade de funções estatísticas e gráficas, o R é altamente flexível para o desenvolvimento de extensões. Grande cuidado foi tomado para que os gráficos produzidos por este aplicativo tenham qualidade de impressão e sejam fáceis de manipular. Finalmente, tanto o $\mathrm{S}$ quanto o $\mathrm{R}$ são extremamente poderosos e econômicos na manipulação de vetores e matrizes. Por estes motivos, o $\mathrm{S}$ e $\mathrm{o} R$ freqüentemente são a linguagem de escolha na pesquisa estatística.

\subsubsection{Desvantagens}

A principal desvantagem que identificamos na utilização do $\mathrm{R}$ para a solução do nosso problema diz respeito ao gerenciamento de relacionamentos entre tabelas.

Por não ter funcionalidade relacional, do tipo utilizado em bancos de dados, grande cuidado deve ser tomado na manipulação de tabelas para manter a correspondência implícita na ordem dos resultados de manipulações com os dados originais armazenados em matrizes e vetores.

Em outras palavras, apenas a posição relativa das caselas em matrizes e vetores indica quais valores dizem respeito a quais objetos. Isso obriga 0 
programador a manter registros de índices que possibilitem associar o resultado dos cálculos aos objetos corretos.

Por exemplo, no nosso caso, qualquer descuido poderia ter levado a associar a coesão calculada para um vértice ao vértice errado. Esta questão tornou-se muito delicada quanto constatamos um bug de programação que leva, durante o processamento, ao "desaparecimento" de alguns vértices (veja 10.3.2 e 18.1.1). 


\subsection{Fluxograma}

\subsubsection{Pré-Processamento}

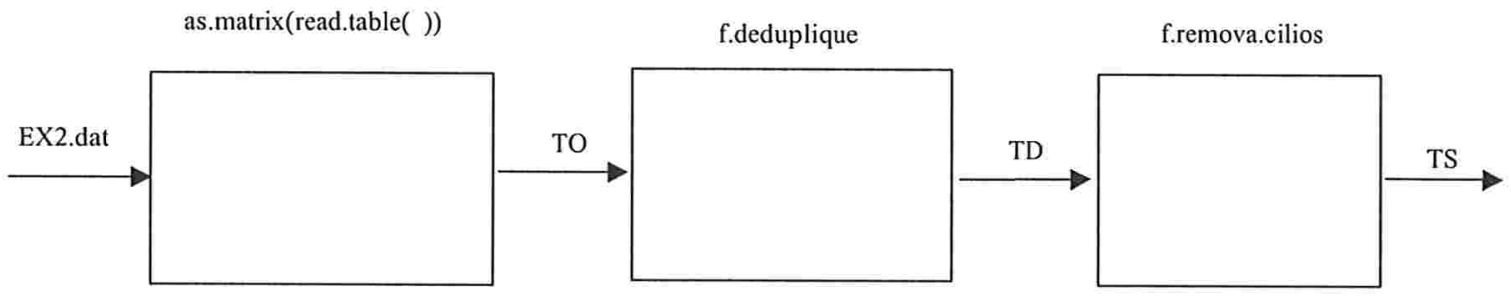

\subsubsection{Lista Vizinhos e Distância Temática}

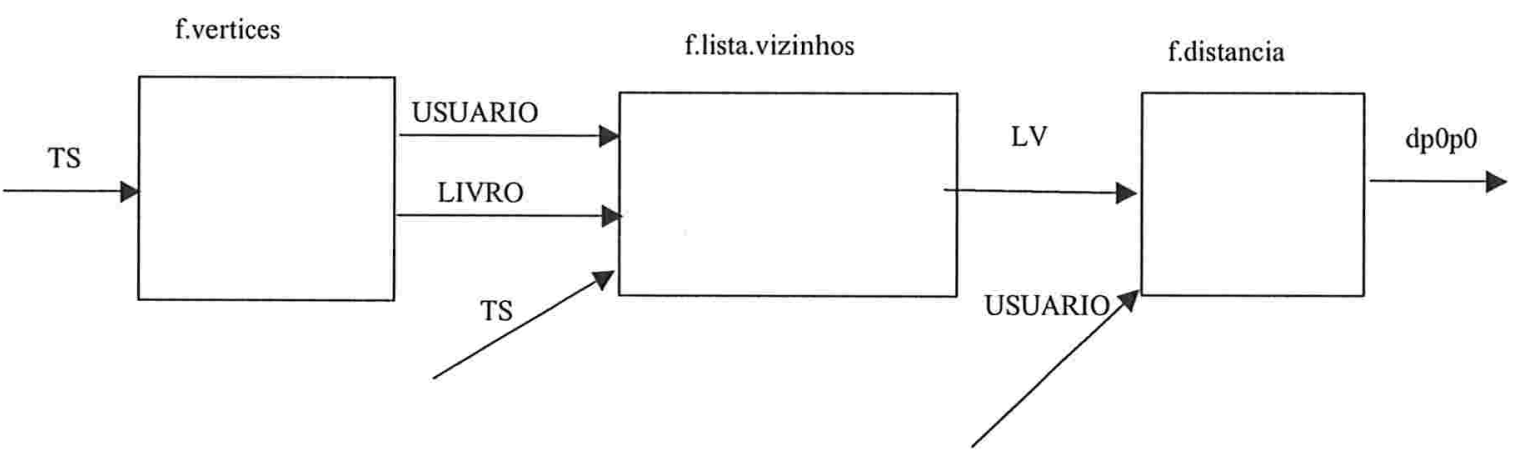




\subsection{3 "Sobe"}
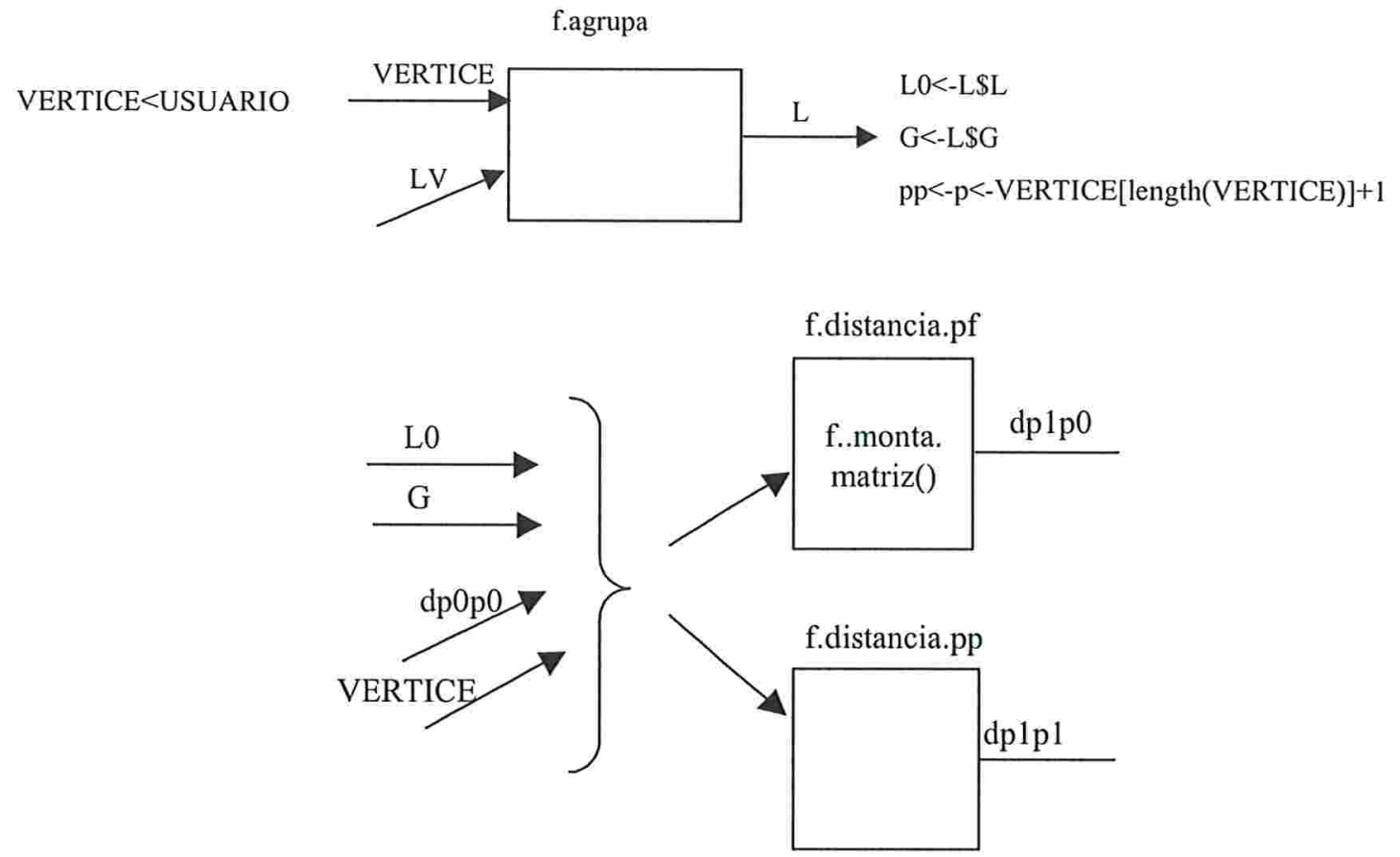

\subsection{4 "Desce"}

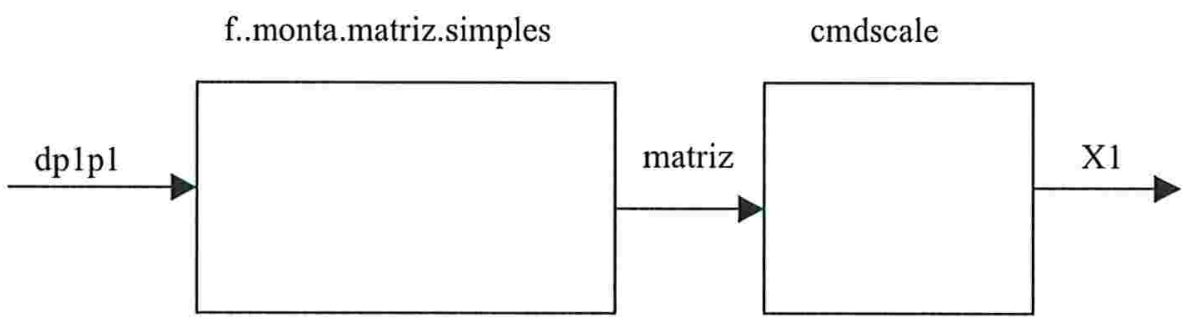




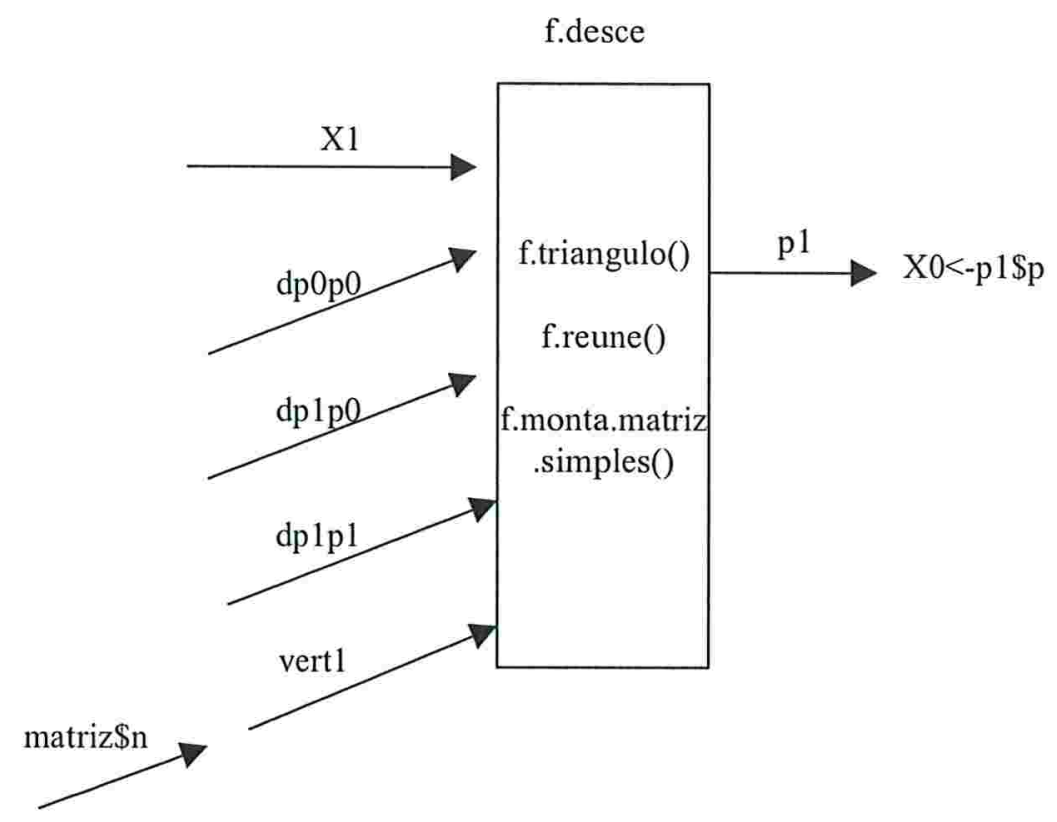

\subsection{Pseudo Código}

\subsubsection{Pré-Processamento}

- Da matriz de dados de entrada, na forma de Lista de Arestas, remova os registros duplicados;

- Remova os "cílios";

- Identifique os vértices dos dois modos.

\subsubsection{Lista Vizinhos e Distância Temática}

- Com base na lista de arestas, produza uma Lista de Vizinhanças;

- Com base nas vizinhanças, calcule as Distâncias Temáticas entre os nós.

\subsection{3 "Sobe"}

- Agrupe os nós (filhos) em grupos próximos;

- Crie um representante (pai) para o grupo no nível de cima;

- Calcule as distâncias entre pais e filhos;

- Calcule as distâncias entre pais e pais.

- Itere o "Sobe" até o número de pais criados ser escalonável; 
- Tendo atingido um nível em que os pontos são escalonáveis, escalone-os e fixe suas coordenadas.

\subsection{4 "Desce"}

- Tome três vértices do nível de cima; reúna a distância entre eles, a distância entre eles e seus filhos, e a distância entre estes filhos;

- Escalone este conjunto;

- Deforme o espaço da solução de maneira que as coordenadas dos pais se ajustem às coordenadas fixadas no nível de cima;

- Itere (dentro do "Desce") até todos os vértices do nível de cima, e por conseqüência todos os filhos neste nível, tenham sido escalonados;

- Itere (para baixo) até todos os níveis terem sido processados, isto é, até os pontos do Nível 0 terem sido fixados. 
13.4. Funções

Uma listagem detalhada das funções implementadas para a construção do algoritmo foi incluída ao final do trabalho como ANEXO: LISTAGEM DAS FUNÇÕES IMPLEMENTADAS EM R, no item 19. 


\section{COMPARAÇÃO DE DUAS SOLUÇÕES: MDS CLÁSSICO E ALGORITMO PROPOSTO}

A Figura 30 e a Figura 31 a seguir trazem, respectivamente, o escalonamento das distâncias temáticas por MDS Clássico para 2 dimensões $(\mathrm{k}=2)$; e o escalonamento obtido pela aplicação do algoritmo proposto neste trabalho, para os dados do Exemplo 2. Apesar da impressão de que uma rotação de cerca $135^{\circ}$ da primeira figura a tornaria bastante equivalente à segunda, na verdade a correspondência entre elas é fraca: o coeficiente de procrustes entre ambas é de 0,73 .

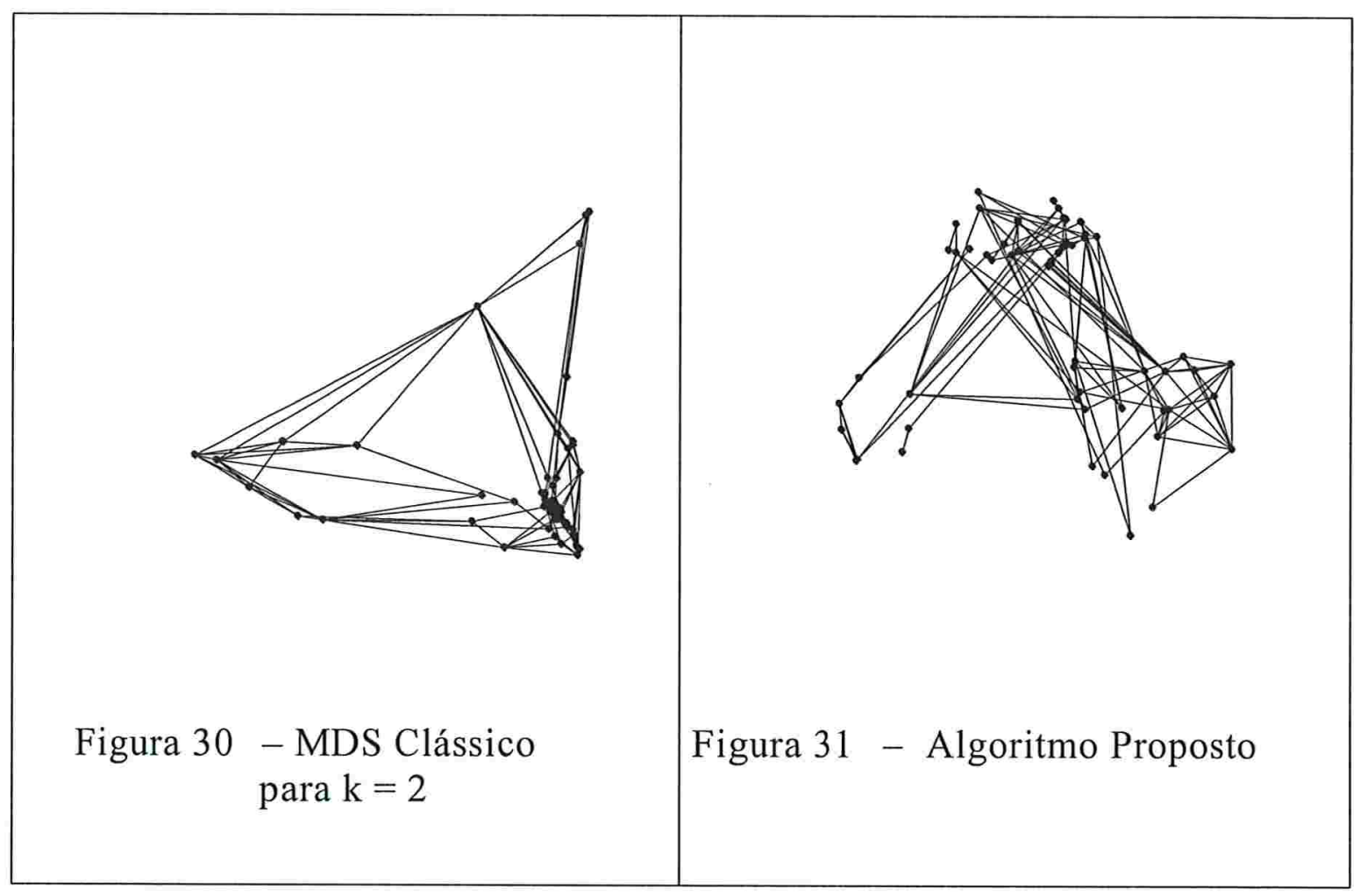

\subsection{Para a Aplicação, o MDS Clássico Não É Boa Referência}

Contrariamente ao que pode parecer à primeira vista, no entanto, a pouca aproximação entre as duas soluções apresentadas acima não é um problema. $\mathrm{Na}$ verdade, nas condições da aplicação para a qual o algoritmo foi desenvolvido, soluções próximas às obtidas pelo MDS Clássico não são desejáveis. Em primeiro lugar porque são muito arbitrárias; em segundo 
porque apresentam um stress (veja maiores detalhes na subseções 14.1.1 e 14.1.2) maior para as arestas de interesse.

\subsubsection{MDS Clássico Fornece Solução Praticamente Arbitrária}

Já constatamos em seções anteriores ser a matriz de distâncias entre os pontos que desejamos escalonar amplamente dominada por distâncias de valor 1; e que as distâncias diferentes de 1 são valores altos, isto é, próximos de 1 .

Se cada distância é considerada uma aresta e cada ponto um vértice, a configuração corresponderia a um poliedro quase regular e com dimensão $n-1$ (ou muito próxima desta valor), onde $n$ é o número de vértices.

Estamos, portanto, tratando de um objeto geométrico volumoso, e projetandoo num plano. Há uma enorme perda de informação.

No caso do Exemplo 2, estamos trabalhando com um objeto de 66 vértices, que, no máximo, precisaria de um espaço 65-dimensional para ser acomodado integralmente. Conforme argumentamos, espera-se que o volume efetivamente ocupado atinja as 65 dimensões.

A análise por Componentes Principais das coordenadas fixadas por escalonamento clássico em 65 dimensões confirma esta expectativa: revela que cada dimensão contribui quase igualmente, com 1,5\% da informação sobre a posição dos pontos. O scree-plot da Figura 32 reflete esta situação. Note que a escala do eixo vertical está truncada em 0,996. 
Scree Plot dos 65 Componentes

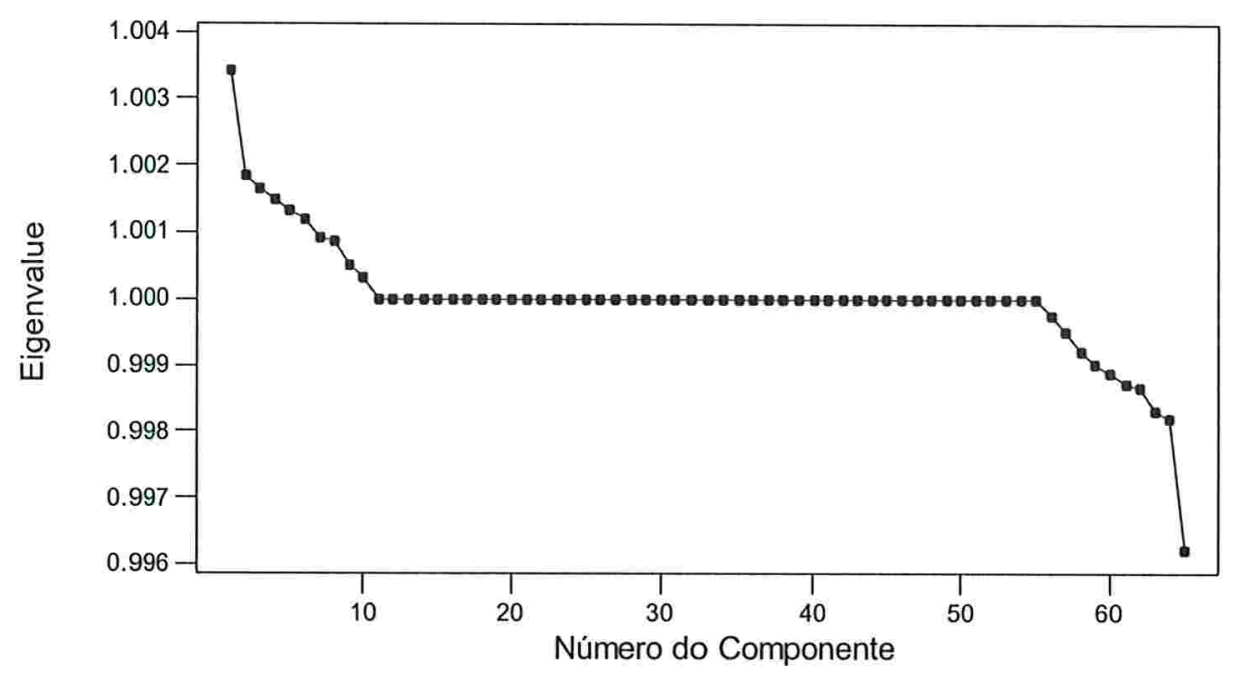

Figura 32 - Scree-plot dos Componentes do Exemplo 2

Disso conclui-se que, apenas acompanhando as direções dos eixos, há $65 * 64 / 2=2080$ projeções ortogonais bidimensionais alternativas e equivalentes em termos de variância, para a configuração estudada.

\subsubsection{Algoritmo Proposto Produz Stress Menor Onde Interessa}

Definimos stress para efeitos de discussão nesta subseção como uma medida de desajuste entre a Distâncias Temática $(\partial)$ e a distância calculada com base na configuração fixada por escalonamento $(d)$.

$$
\text { stress }=\sum(\partial-d)^{2}
$$

Como já discutimos (veja subseção 12.3), as distâncias que carregam informação para o problema são aquelas diferentes de 1 e que constam de dp0p0. Assim, calculando-se o stress para as duas soluções apresentadas na Figura 30 e na Figura 31, obtemos respectivamente 61,52 e 47,04, com nítida vantagem para o algoritmo proposto. 
De fato, mesmo considerando-se o escalonamento clássico nas 65 dimensões, e estudando-se o stress nas possíveis projeções de 2 dimensões ao longo dos eixos daquele espaço, obtemos a distribuição refletida no histograma da Figura 33. Nota-se que o stress obtido com o algoritmo proposto $(47,04)$ é menor do que aquele obtido em qualquer das 2080 projeções no espaço escalonado por MDS Clássico. Dentre estas últimas, o menor valor é de 55,64.

\section{Histograma do Stress em 2080 Projeções}

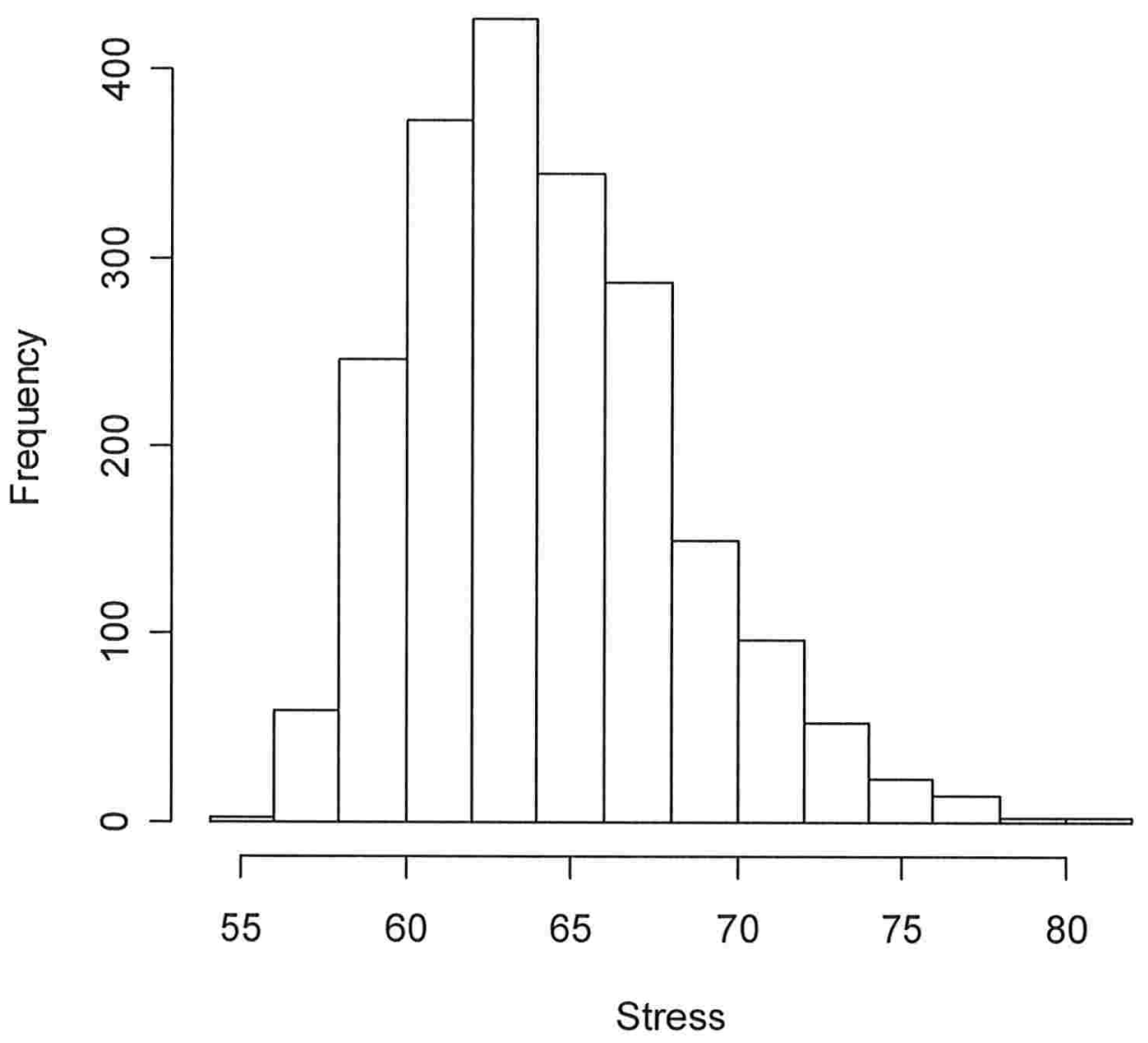

Figura 33 - Distribuição do Stress

nas Projeções ao Longo dos Eixos do Espaço de 65 Dimensões Tomados 2 a 2. 
Na verdade, os motivos para isso parecem claros: como o MDS Clássico necessita que a matriz de distância seja montada integralmente, o peso relativo das distâncias diferentes de 1 é ali menor do que nas soluções parciais, depois consolidadas, calculadas pelo algoritmo proposto neste trabalho.

Desta característica do algoritmo proposto resulta que os vértices tematicamente mais próximos ficam mais próximos na configuração obtida; as distâncias mais distorcidas são as que não interessam.

Finalmente, depreende-se que este fenômeno se acentua quando o número de vértices aumenta, o que torna o algoritmo proposto ainda mais desejável (sem mencionar que o MDS Clássico torna-se computacionalmente inaplicável). 


\section{Quarta Parte: Fechamento}

\section{CONCLUSÃO}

\subsection{Data Mining: Problemas e Soluções na Representação de Redes}

Data Mining é um campo de estudo mal definido, uma combinação de Estatística, Tecnologia da Informação (principalmente programação e gestão de bancos de dados), Inteligência Artificial, técnicas de visualização e conhecimento sobre o campo semântico da aplicação.

No caso da aplicação de Filtro Colaborativo que motivou este trabalho, a técnica empregada foi a de Análise de Redes. A característica de mineração de dados decorreu do grande volume de transações a processar. Para fazê-lo, há duas abordagens complementares: a representação gráfica e avaliação matemática da rede.

Desenhar "bem" uma rede permite entender-lhe a estrutura (SKIENA, 1998). A representação gráfica permite entender o grande quadro.

A representação matemática permite calcular medidas de interesse e é suporte para a representação gráfica. Ambas permitem identificar padrões.

Para ambas as estratégias há soluções bem consolidadas para redes pequenas. Também para ambas, os procedimentos consolidados tornam-se disfuncionais à medida que aumenta a ordem $\mathrm{e} o$ tamanho da rede.

Neste trabalho, conceitos de matemática, estatística, computação, marketing e geomarketing foram utilizados para a produção de uma solução ao problema colocado, de representar uma rede de usuários da biblioteca como uma superfície de coesão sobre uma base tematicamente escalonada. 


\section{CONTRIBUIÇÕES DO TRABALHO}

Foram as seguintes as principais contribuições do trabalho:

- proposição dos conceitos de base escalonada (seção 10) e de superfície (contínua) de coesão (seção 11) para a representação de redes;

- implementação de um algoritmo para o cálculo de Distâncias Temáticas (subseções 5.1 e 19.1.7);

- combinação das técnicas de escalonamento clássico e procrustes (seções 6 e 7, particularmente subseção 7.2.1; e subseção 19.1.18);

- definição da estratégia e implementação de um algoritmo para o escalonamento multidimensional de vértices de uma rede de ordem elevada (seção 13);

- utilização de uma abordagem multidisciplinar para o encaminhamento da solução, com ampla utilização de características próprias da aplicação (seção 12);

- verificação da interpretabilidade da solução proposta e comparação com alternativas de Escalonamento Clássico (seção 14). 


\section{LIMITAÇÕES}

O trabalho apresentado também apresenta várias limitações.

\subsection{Triangulação}

Por um erro de lógica da função triângulo, pode acontecer, e freqüentemente acontece, que vértices sejam desprezados na triangulação; neste caso, eles resultam sem coordenadas ao final da iteração no nível em processamento e não podem ser incluídos na iteração de descida para os níveis seguintes. Este bug está profundamente enraizado na programação do algoritmo e sua correção implica alterações generalizadas no código, o que era inviável para o cronograma deste trabalho.

Como solução provisória, e tendo em vista que a origem da necessidade de desenvolvimento do algoritmo é o excesso de dados, optamos simplesmente por remover os vértices perdidos durante o processamento, e todos os seus filhos.

No Exemplo 2 o problema ocorre. O vértice perdido no Nível 1 é o 5922 (veja Figura 20). Por propagação, 5 pontos (dentre os 71) da configuração final também são perdidos.

A solução final, embora incompleta, não fica qualitativamente prejudicada. A falha será corrigida nas próximas versões do programa.

\subsection{Informática, Interface}

O trabalho apresentado tem por objetivo desenvolver conceitos. Embora acabe profundamente envolvido com a programação da solução para prova dos conceitos, não é um trabalho em Ciência da Computação: a programação realizada não tem pretensão de ser eficiente ou elegante, mas objetiva apenas colocar os conceitos em prática.

Tampouco foi desenvolvida uma interface amigável, como é necessário em aplicações de Data Mining. 


\subsection{Técnica Descritiva}

A técnica apresentada é descritiva.

\subsection{Isolamento da Base de Dados}

A solução apresentada não oferece alternativas para integrá-la de maneira mais orgânica à base de dados originais. Em conseqüência, a interpretação dos resultados é trabalhosa e artesanal.

\subsection{Desconexão de Interface Gráfica}

Tampouco foi desenvolvida uma maior integração do algoritmo com uma interface gráfica. Também a conexão dos resultados matemáticos com a representação gráfica foi feita de forma manual e artesanal. 


\section{PRÓXIMOS PASSOS}

Todas as limitações acima podem ser entendidas como oportunidades para novos trabalhos e aperfeiçoamentos. Destacamos alguns a serem implementados na seqüência.

\subsection{Aperfeiçoamentos Planejados}

\subsubsection{Triangulação - Remoção de Bug Conhecido e Aproveitamento de Redundância}

A função de triangulação precisa ser revista para remoção do bug identificado; no momento ele está sendo apenas gerenciado. Nesta oportunidade talvez seja conveniente, em vez de corrigir o algoritmo, incorporar outro algoritmo de triangulação existente, mais rápido e robusto.

Está também em aberto o desenvolvimento de uma estratégia para o aproveitamento da redundância dos algoritmos de triangulação convencionais para obtenção iterativa de um escalonamento melhor ajustado.

\subsubsection{Iteração no Cálculo da Distância Temática}

Foi identificada a conveniência da inclusão dos vizinhos de segunda ordem e de ordem superior no cálculo da Distância Temática. Isto resultará em uma matriz dp $0 p 0$ mais populada, e, portanto, com mais informação.

\subsubsection{Aperfeiçoamento do Ajuste por Procrustes}

O desenvolvimento de uma análise de procrustes não linear pode ser útil no aperfeiçoamento da junção das soluções parciais.

\subsubsection{Ajuste Fino: Uma Janela Voadora}

Uma etapa de "iteração geográfica" no algoritmo de descida pode servir para uma melhoria no resultado do ajuste entre as soluções parciais. 
18.1.5 Stress Deve ser Indiferente a Distorções de $\delta_{\mathrm{ij}}=1$ para $\mathrm{d}_{\mathrm{ij}}>1$

A implementação de um escalonamento por mínimos quadrados, com uma função de stress modificada para distâncias (calculadas com base na configuração) maiores do que 1 , na fase de descida, pode levar a um melhor ajuste entre as soluções parciais.

\subsection{Idéia Novas para Interpretação dos Resultados}

Para a caracterização da solução proposta como uma solução de Data Mining, é necessário agregar mais "inteligência" ligada ao campo semântico da aplicação original (geração de recomendações para usuários da biblioteca). A seguir apresentamos algumas sugestões.

\subsubsection{Delimitação Automática do Relevo}

Automatização da criação de grupos de usuários com interesse temático afim; geração das listas de recomendação; caracterização dos grupos na representação gráfica.

\subsubsection{Medidas de Interesse}

Geração automatizada de relatórios sobre as características do grupo: tamanho, atividade, coesão, liderança, etc.

\subsubsection{Identificação de "Conectores"}

No caso dos livros, identificar os itens do acervo com características de conectores, na definição de GLADWELL (2000). 


\section{ANEXO: LISTAGEM DAS FUNÇÕES IMPLEMENTADAS EM R}

\subsubsection{Deduplique}

Entrada: Matriz original de dados, com duas colunas contendo códigos de usuários e livros (TO).

Saída: $\quad$ Matriz da entrada, sem linhas duplicadas (TD).

f.deduplique $<$ - function(m)

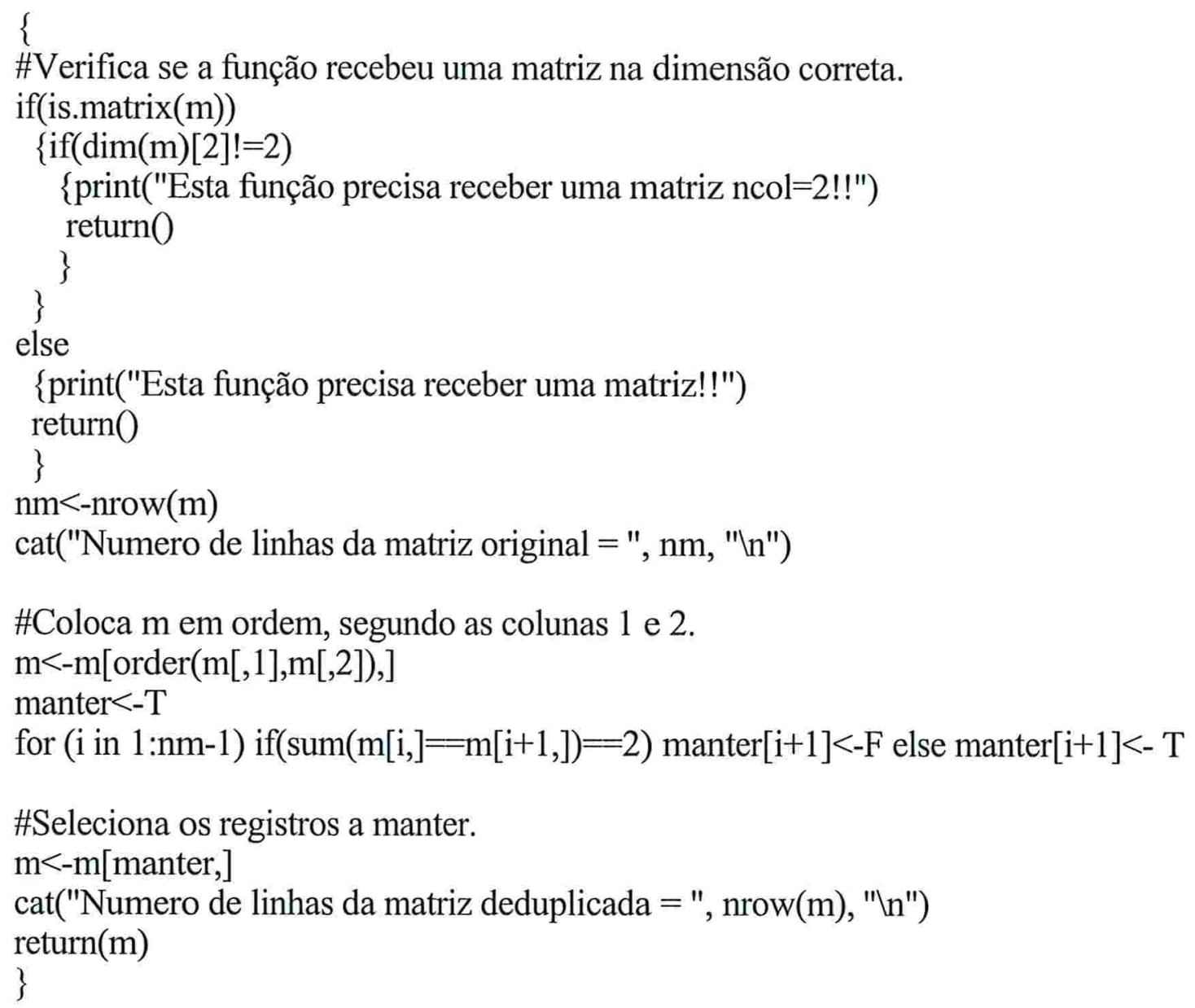




\subsubsection{Remova Cílios}

Entrada: $\quad$ TD.

Saída: $\quad$ Matriz sem nós de grau 1 (TS).

f.remova.cilios $<-$ function(m)

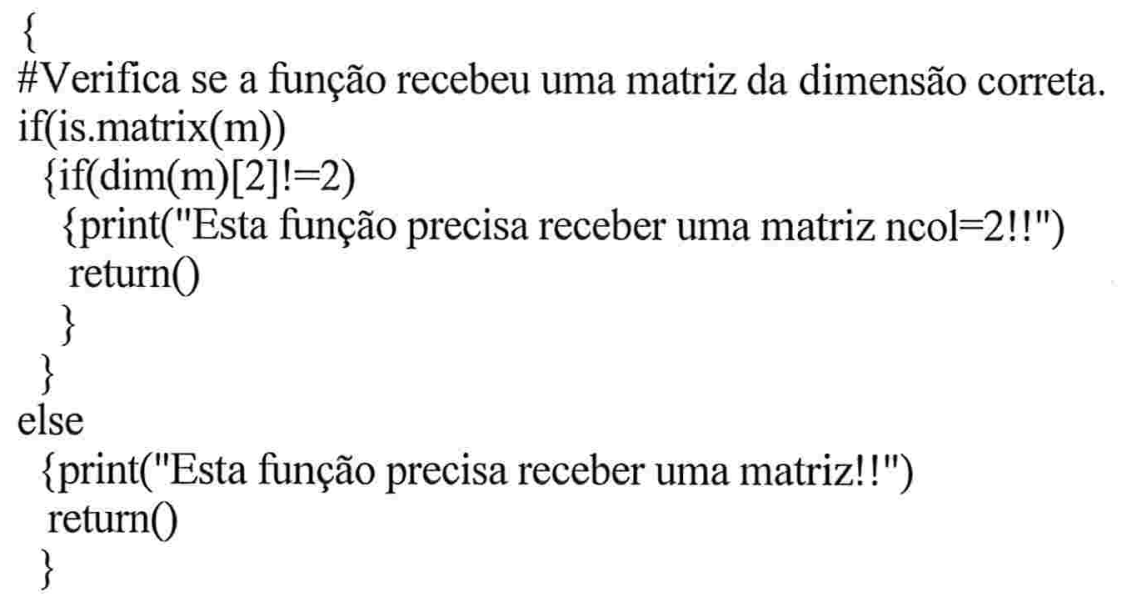




\subsubsection{Vértices}

Entrada: Coluna (usuário ou livro) da matriz TS.

Saída: $\quad$ Vetor com os distintos nós existentes na coluna.

f.vertices $<$-function(no)

\{

\#Verifica se a função recebeu um vetor.

if(! is.vector(no))

\{print("Esta função precisa receber um vetor!!") return()

\}

no<-unique(sort(no))

return(no)

\} 


\subsubsection{Lista Vizinhos}

Entrada: Códigos de usuários da TS; códigos de livros da TS; tamanho dos vetores de usuários e livros; vetor de usuários distintos; chave (ligada, desligada) para remoção de vizinhanças de um único nó.

Saída: $\quad$ Lista de Vizinhos 1 e 2; Grau 2; e Coesão de cada vértice.

f.lista.vizinhos<-function(m1,m2,n1,n2,no,ligado)

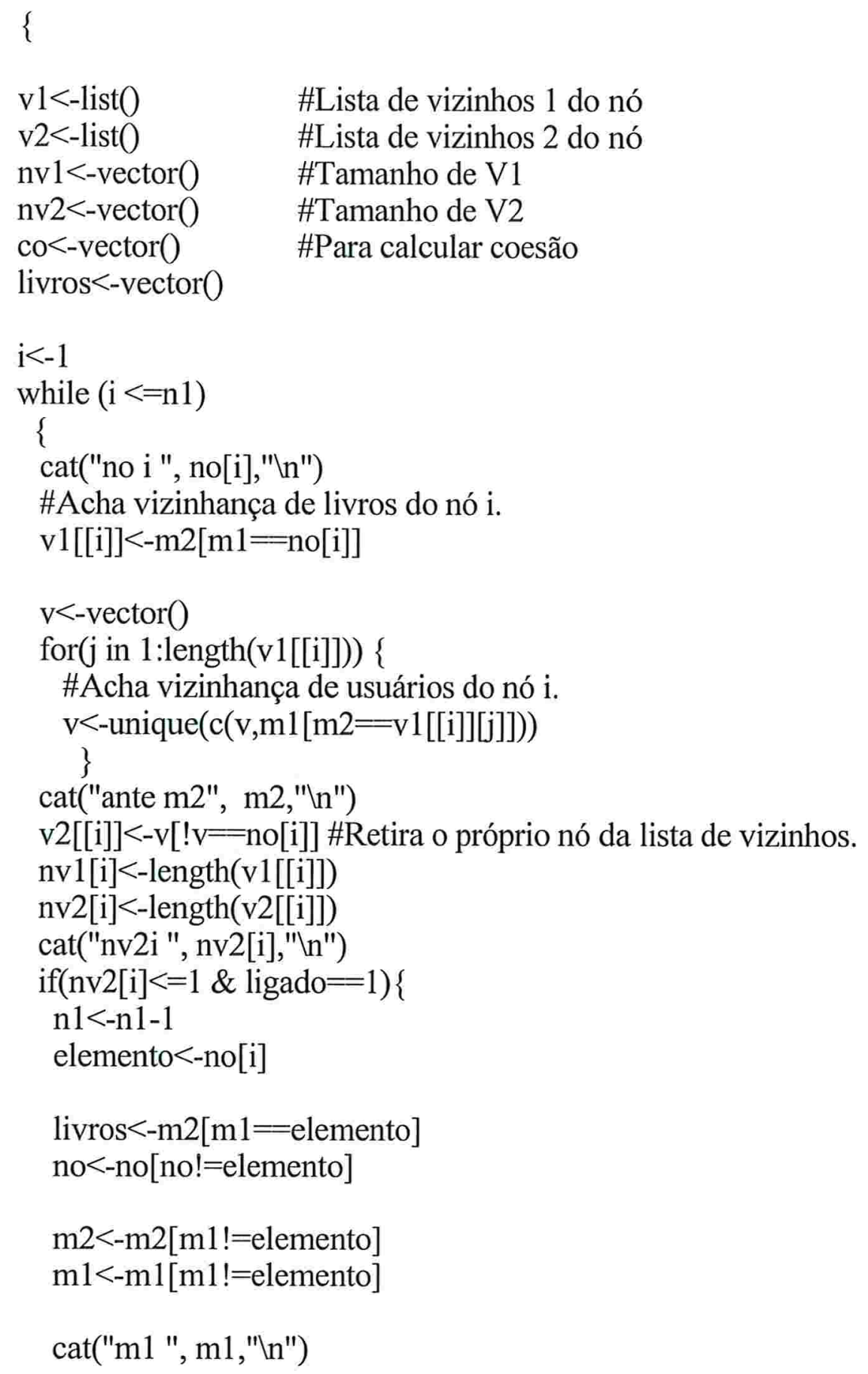




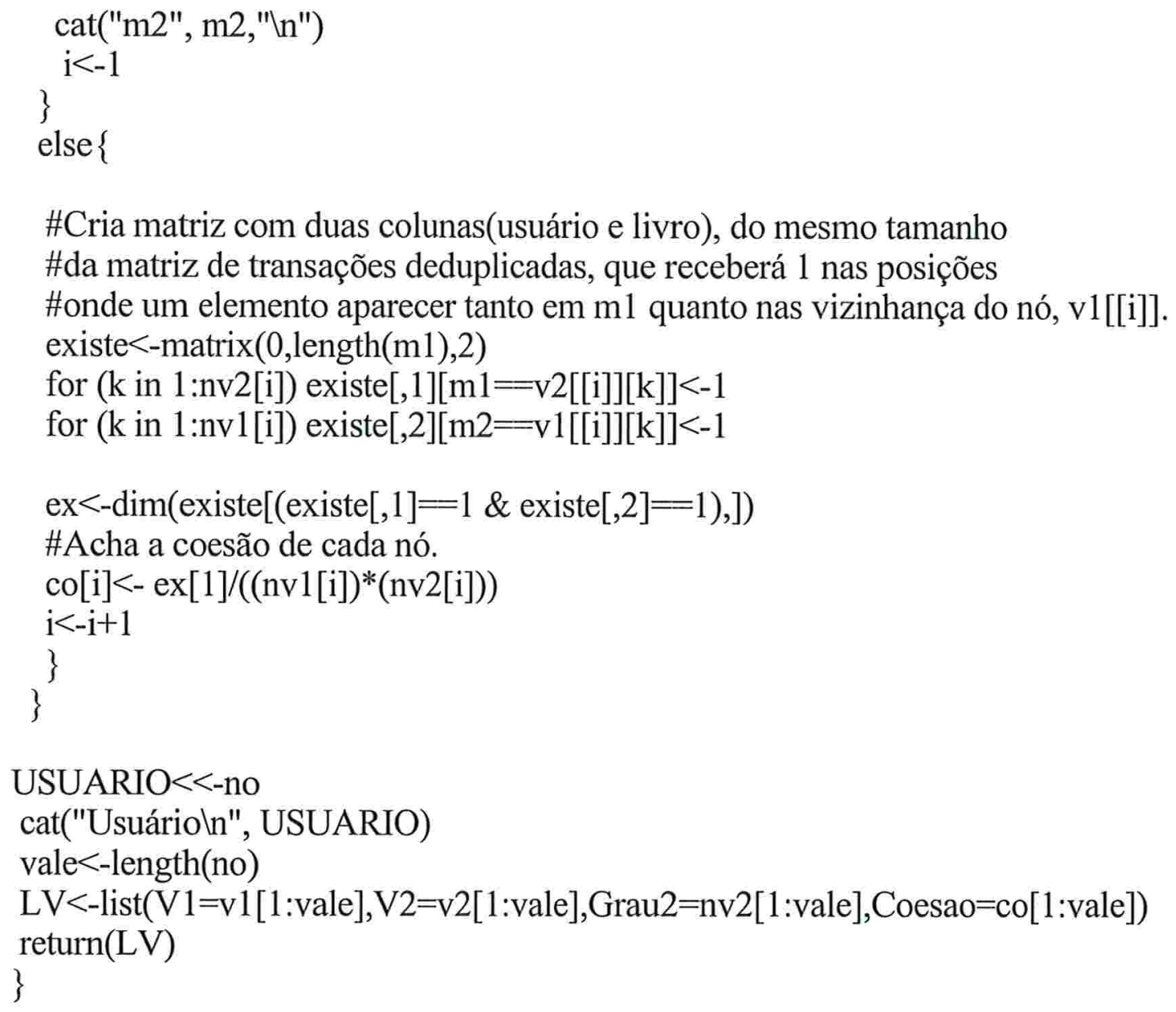




\subsubsection{Cria Transação}

Entrada: Vizinhança em 2 passos de um conjunto de vértices; grau em 2 passos; ids dos nós.

Saída: $\quad$ Lista de arestas entre os vértices.

f.cria.transacao $<$-function(v2, grau2, no)

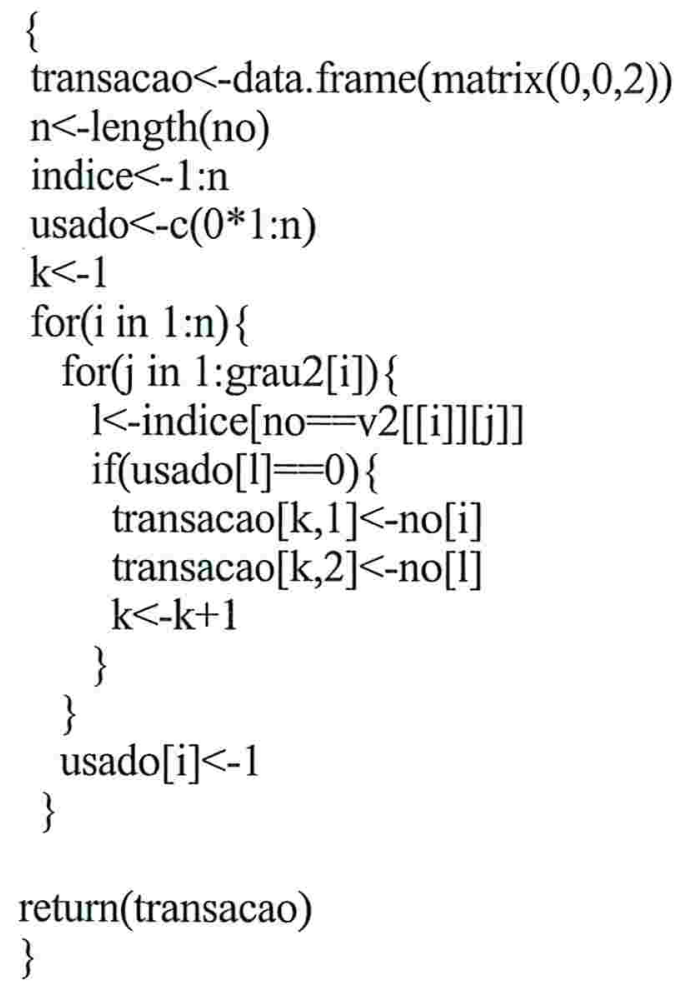




\subsubsection{Lista Vizinhos Simples}

Entrada: $\quad$ Lista de distâncias entre vértices; vetor com ids distintos de vértices.

Saída: $\quad$ Vizinhos em 1 passo; grau do nó; coesão do nó.

f.lista.vizinhos.simples $<$-function(distpp,vertice)

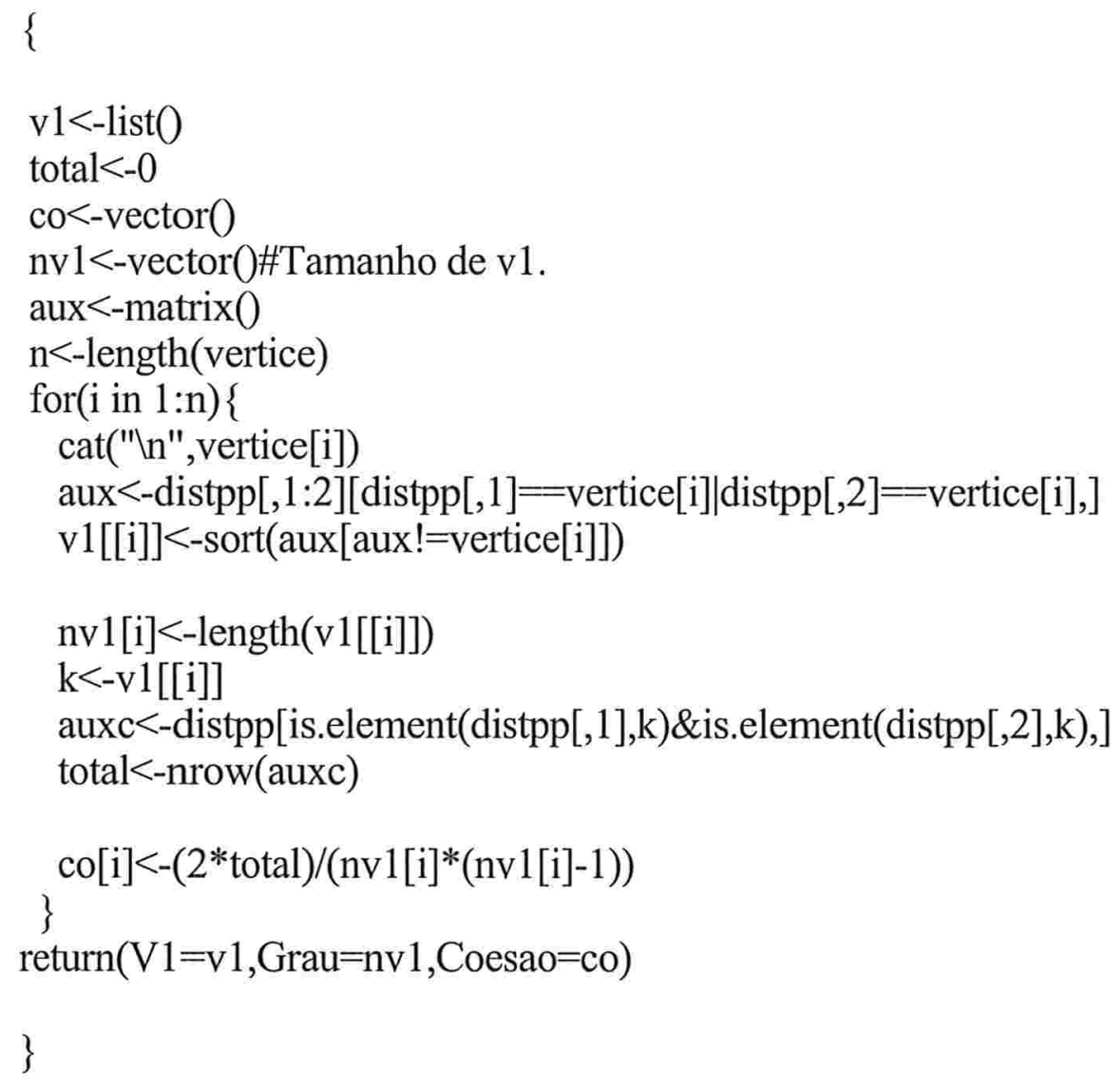




\subsubsection{Distância Temática}

Entrada: LVu\$V1 (isto é, vizinhança de usuário em 1 passo - portanto livros); LVu\$V2 (isto é, vizinhança de usuário em 2 passos, - portanto usuários).

Saída: $\quad$ Matriz com distâncias temáticas entre usuários.

f.distancia<-function(V1,V2,grau2,no)

\{

\#Matriz contendo usuários nas colunas 1 e 2 e distância na coluna 3.

dist<-data.frame $(\operatorname{matrix}(0,1,3))$

$\mathrm{k}<-1$ \#Indica linha da matriz dist.

n<-length(no)

indice $<-1: n$

usado $<-\mathrm{c}(0 * 1: \mathrm{n})$

\#Calculando distância entre usuário e usuário

for (i in $1: n)$

\{

for ( $\mathrm{j}$ in 1 :grau2[i])

\{

cat("no",no,"ln")

cat("i e j",i,j,"ไn")

$1<$-indice[no $==\mathrm{V} 2[[\mathrm{i}]][\mathrm{j}]]$

if(usado[1] ==0)\{\#Evita calcular a mesma distância mais de uma vez cat("indice l",l,"'n")

ui<-union(V1[[i]],V2[[i]])

ul<-union(V1[[1]],V2[[1]])

if (length(intersect(ui,ul))!=0) \#Não registra distancias iguais a 1 $\{$ dist $[\mathrm{k}, 1]<-\mathrm{no}[\mathrm{i}]$ $\operatorname{dist}[\mathrm{k}, 2]<-\mathrm{no}[\mathrm{l}]$

dist[k,3]<-1-(length(intersect(ui,ul))/length(union(ui,ul))) $\mathrm{k}<-\mathrm{k}+1$

\}

\}

usado[i] $<-1$

\}

return(dist)

\} 


\subsubsection{Agrupa}

Entrada: Vértice, Vizinhos 2, Grau2, Coesão.

Saída: $\quad$ Vetor com o nome dos grupos em cada nível e número de centróides.

f.agrupa $<$-function(no, v2, g2, co)

\{

$\mathrm{k}<-0$

cont $<-0$

$\mathrm{n}<-$ length(no)

indice $<-1: n$

\#Zero como número.

$\mathrm{v} 2[\mathrm{~g} 2==0]<-0$

$\operatorname{co}[\mathrm{g} 2==0]<-0$

\#Ordena por Coesao e Grau2, controlando um índice.

$\mathrm{o}<-\operatorname{order}(\mathrm{co}, \mathrm{g} 2)$

$1 \mathrm{v}<$-cbind(indice,co,g2) $[0$,

print(lv)

$\mathrm{L}<-\mathrm{c}(0 * 1: \mathrm{n}) \quad$ \#Cria vetor de tamanho $\mathrm{n}$ para colocar nome do grupo.

usado<-L \#Indica se vértice já foi usado.

i<-n \#Como está na ordem crescente de coesão e grau2, o começo é pelo fim.

g<-1 \#Número do grupo (centróide).

while $($ any $($ usado $=0)$ )

\{

if (usado[i] $=0$ )

\{

usado[i] $<-1$

$\mathrm{L}[\mathrm{i}]<-\mathrm{g}$

cont $<-1$

\#Para cada vizinho de lv[i,1] verifica se o vizinho já foi usado ou não.

for $(\mathrm{j}$ in $1: \operatorname{lv}[\mathrm{i}, 3])\{$ 
\#Coloca o vértice no último grupo coeso.

if(usado[no $=\mathrm{v} 2[[\operatorname{lv}[\mathrm{i}, 1]]][\mathrm{j}]]==1) \mathrm{k}<-\mathrm{L}[\mathrm{no}=\mathrm{v} 2[[\mathrm{lv}[\mathrm{i}, 1]]][\mathrm{j}]]$

if(usado[no $=\mathrm{v} 2[[\operatorname{lv}[\mathrm{i}, 1]]][\mathrm{j}]]=0)$ \#Indice baseado no índice que o nó tinha inicialmente na matriz.

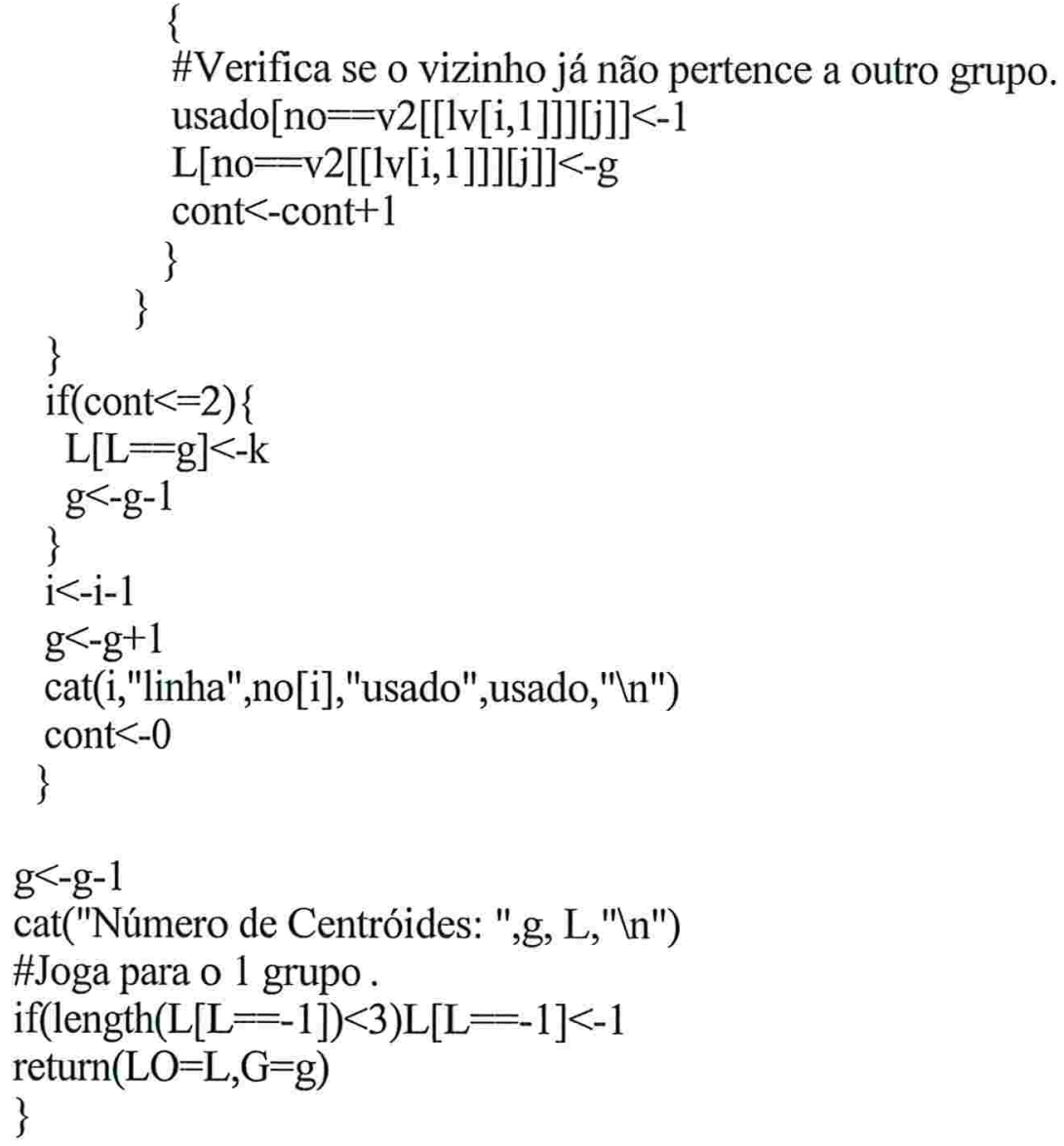




\subsubsection{Distância Pai - Filho}

Entrada: Vetor $\mathbf{I}$ com os grupos dos vértices, quantidade de grupos, matriz dist com as distâncias temáticas entre todos os vértices, vetor dos usuários (vértices).

Saída: Matriz com todas as distâncias dos vértices de um grupo até o centróide.

f.distancia.pf<-function(l,g,dista,no)

\section{\{}

\#dista<-recebe a distância do corpo do trabalho

\#dist.vetor->contém as distâncias em forma vetorial na matriz de 3 colunas.

\#dist.matriz->contém distâncias em forma matricial conforme determina o cmdscale. \#dist.pf->uma linha contendo as distâncias entre pais e filhos durante processamento.

distfpf<-matrix $(0,0,0)$

dist.pf<-data.frame(matrix $(0,1,3))$

$\mathrm{i}<-1$

$\mathrm{kk}<-\mathrm{p}$

while $(\mathrm{i}<=\mathrm{g})$

\{

\#Seleciona apenas as distancias do grupo i e monta matriz de distancia para MDS.

dist.matriz $<$-f.monta.matriz $($ dista,no $[1=\mathrm{i}])$

\#Matriz com as distancias entre elementos de um mesmo grupo.

print(dist.matriz)

\#Escalona o grupo i.

\#A ordem de $\mathrm{X}$ está como no $[\mathrm{l}=\mathrm{i}]$ para ligar cada ponto a um vertice em no[l=i]. $\mathrm{X}<$-cmdscale(dist.matriz)

$\mathrm{n}<$-length(no[l=i])

\#Acha as distâncias euclidianas até o centróide.

cat("n",n,"ไn\n")

for(j in 1:n)

\{

dist.pf[j,1]<-kk

dist.pf[j,2]<-no[l=-i] [j]

dist.pf[j,3]<-sqrt((X[j,1])^2+(X[j,2])^2)

\}

dist.pf<-dist.pf[1:n,]
\#Matriz completa com resultados.

\#Linha da vez. 
\#Cria id do novo centróide.

$\mathrm{kk}<-\mathrm{kk}+1$

$\mathrm{i}<-\mathrm{i}+1$

distfpf<-rbind(distfpf,dist.pf)

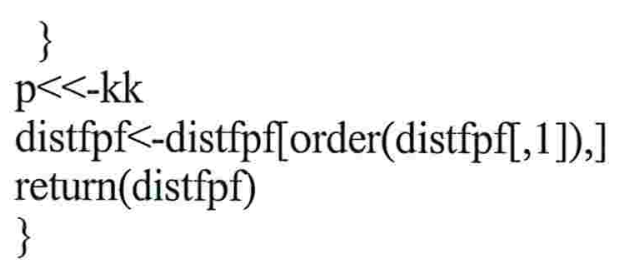




\subsubsection{Monta Matriz}

Entrada: Vetor com as distâncias entre as os pontos de um mesmo grupo; vetor contendo os ids dos membros do grupo.

Saída: $\quad$ Matriz subdiagonal de distâncias entre os membros do grupo.

f.monta.matriz<-function(dist.vetor,no)

\section{\{}

\#dist.vetor->Contém as distâncias em matriz de 3 colunas.

dist.vetor $<-$

as.matrix(dist.vetor[is.element(dist.vetor[,1],no)\&is.element(dist.vetor[,2],no),])

$\mathrm{m}<$-nrow(dist.vetor)

\#Subdiagonaliza os índices.

for (i in $1: \mathrm{m})$

\{

if (dist.vetor[i,1]<dist.vetor[i,2])

\{

temp<-dist.vetor[i,1]

dist.vetor $[\mathrm{i}, 1]<-$ dist.vetor $[\mathrm{i}, 2]$

dist.vetor $[\mathrm{i}, 2]<-$ temp

\}

\}

if $($ ncol(dist.vetor $)=1)$ dist.vetor $<-$ t(dist.vetor $)$

n<-length(no)

\#Monta matriz subdiagonal.

dist.matriz<-matrix $(1, \mathrm{n}, \mathrm{n})$

$\operatorname{diag}($ dist.matriz $)<-0$

indice $<-c(1: n)$

for (i in $1: \mathrm{m}$ )

\{

dist.matriz $[$ indice $[$ no $=$ dist.vetor $[\mathrm{i}, 1]]$,indice $[$ no $=$ dist.vetor $[\mathrm{i}, 2]]]<$-dist.vetor $[\mathrm{i}, 3]$ \}

dist.matriz<-as.dist(dist.matriz)

return(dist.matriz)

\} 


\subsubsection{Distância entre Centróides}

Entrada: Vetor I com grupos dos vértices, quantidade de grupos, matriz dist com as distâncias temáticas entre todos os vértices, vetor dos usuários(vértices).

Saída: $\quad$ Matriz com todas as distâncias entre os centróides de um grupo.

f.distancia.pp<-function(l,g,dista,no)

$$
\{
$$

library(mva)

\#dista<-recebe a distância do corpo do trabalho (dist é reservando na library $m v a$ ).

\#dist.pp->contém as distancias entre os pais.

dist.pp<-matrix(0,nrow(dista),3)

\#Monta matriz com as distâncias entre os vértices de um mesmo grupo.

for (i in 1:length(no))

\{

dist.pp[,1][dista[,1] $==\mathrm{no}[\mathrm{i}]]<-1[\mathrm{no}==\mathrm{no}[\mathrm{i}]]$

dist.pp[,2][dista[,2] $=\mathrm{no}[\mathrm{i}]]<-1[\mathrm{no}=\mathrm{no}[\mathrm{i}]]$

dist.pp[,3]<-dista[,3]

\}

print(dist.pp)

\#Subdiagonaliza índices.

for (i in 1:nrow(dist.pp)) \{

if (dist.pp[i,1] < dist.pp[i,2])

\{

aux $<$-dist.pp $[i, 1]$

dist.pp $[\mathrm{i}, 1]<$-dist.pp $[\mathrm{i}, 2]$

dist.pp $[\mathrm{i}, 2]<$-aux

\}

\#Retira as distâncias ii.

dist.pp<-dist.pp[dist.pp[,1]!=dist.pp[,2],]

dist.pp[,1]<-(dist.pp[,1] + pp-1)

dist.pp[,2]<-(dist.pp[,2] + pp-1)

print(dist.pp)

\#Ordena dist.pp.

dist.pp<-dist.pp[order(dist.pp[,1],dist.pp[,2],dist.pp[,3]),]

\#Deduplica pela menor distância.

manter<- $\mathrm{T}$

for (i in 1:(nrow(dist.pp)-1)) 


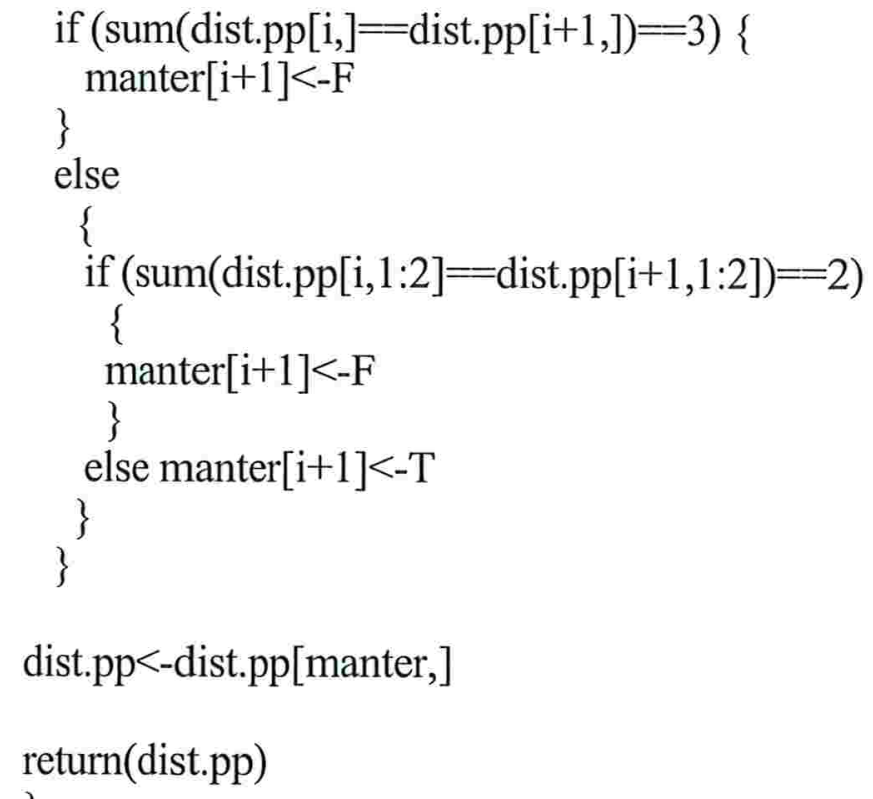




\subsubsection{Desce}

Entrada: Matriz com coordenadas escalonadas dos centróides do nível; distância entre centróides; distância entre centróides e filhos; distâncias entre os filhos.

Saída: $\quad$ Configuração dos filhos; vértices distintos na configuração.

f.desce<-function(X,dpp,dpf,dff)

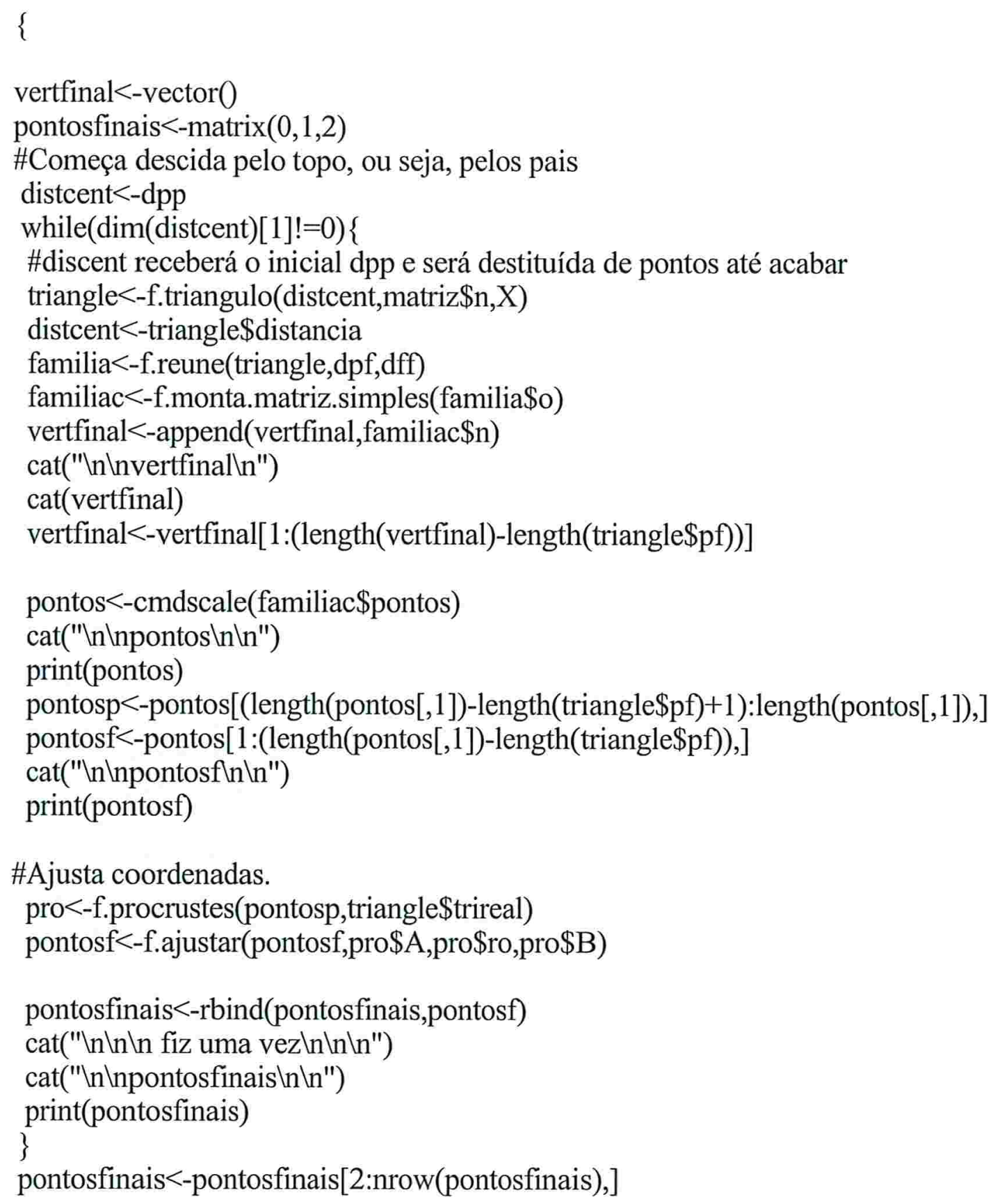


cat("'nlnvertfinalın")

ord<-order(vertfinal)

cat(vertfinal,ord)

cat("pontosfinais $\backslash n ")$

print(pontosfinais)

pontosfinais<-pontosfinais[ord,]

cat("pontosfinais $\backslash n ")$

print(pontosfinais)

return $(\mathrm{p}=$ pontosfinais, $\mathrm{v}=$ sort $($ vertfinal $))$

\} 


\subsubsection{Triângulo}

Entrada: Matriz com as distâncias entre centróides (DIST), nós (vértices) do nível a ser escalonado, matriz de configuração (real) dos pontos escalonados.

Saída: $\quad$ Lista contendo as distâncias remanescentes em DIST, as distâncias entre os três pontos escolhidos, os três pontos escolhidos, e suas respectivas coordenadas escalonadas.

f.triangulo<-function(DIST, vertices, real)

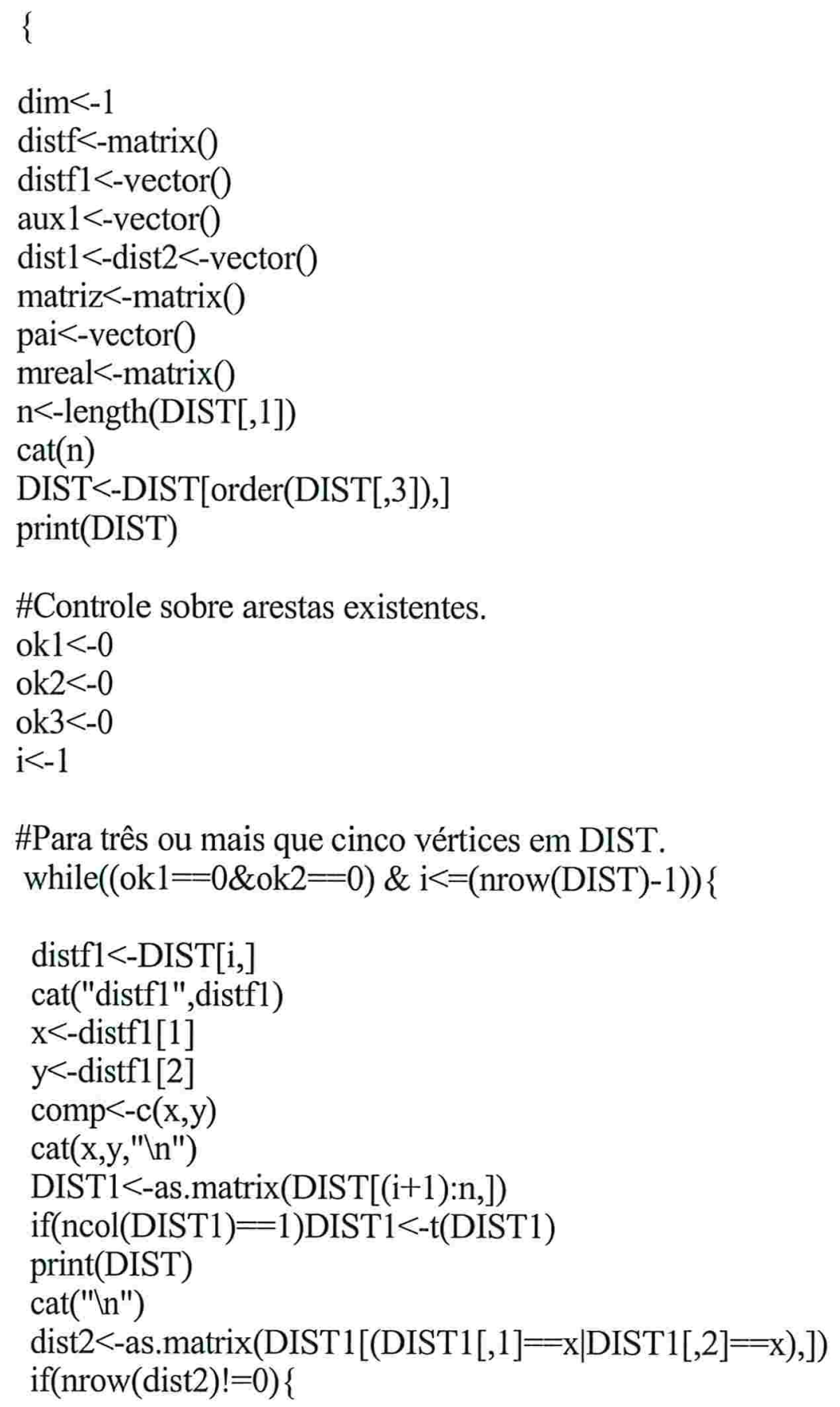




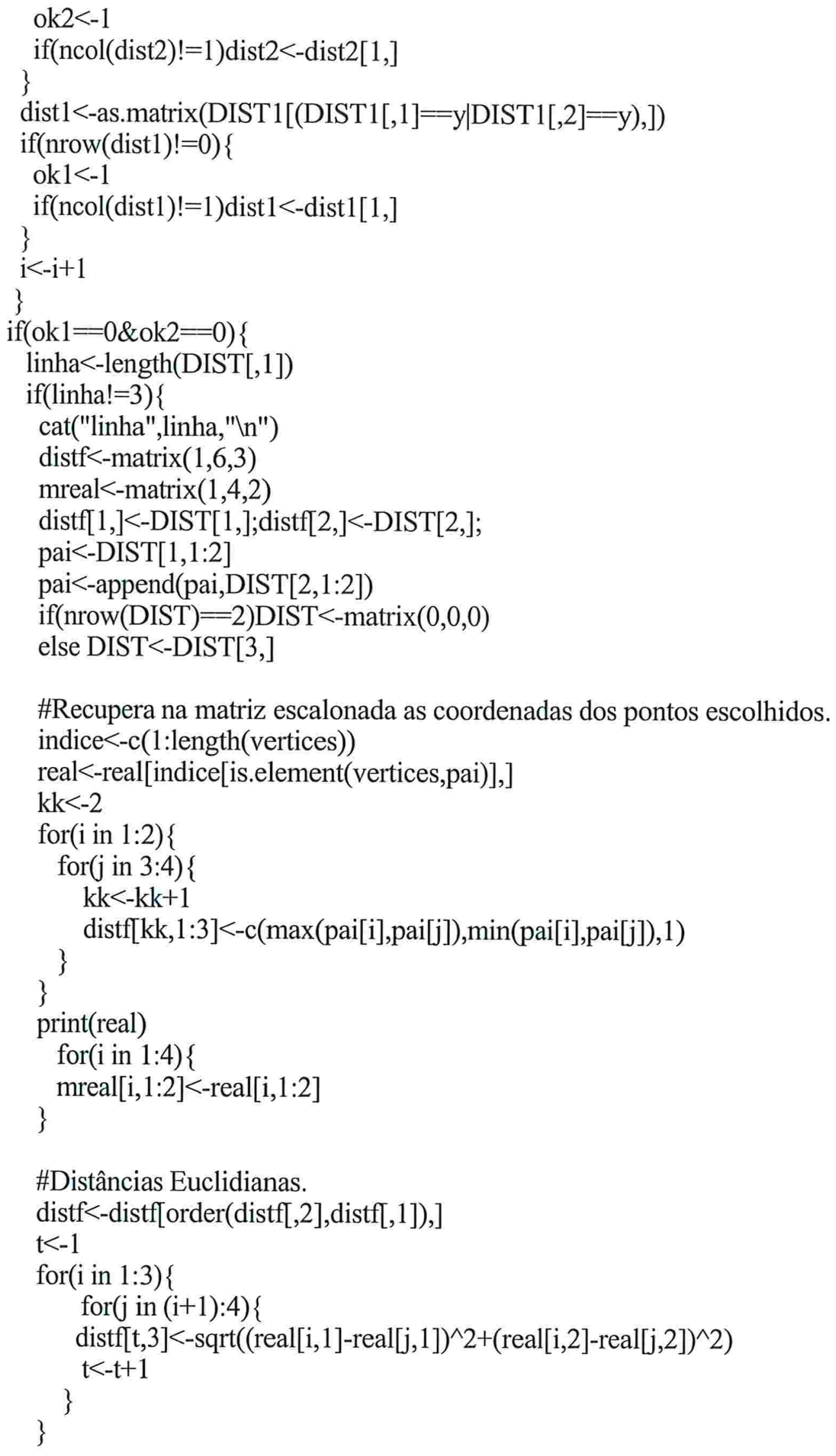

\#Recupera na matriz escalonada as coordenadas dos pontos escolhidos. indice $<$-c(1:length(vertices)) 


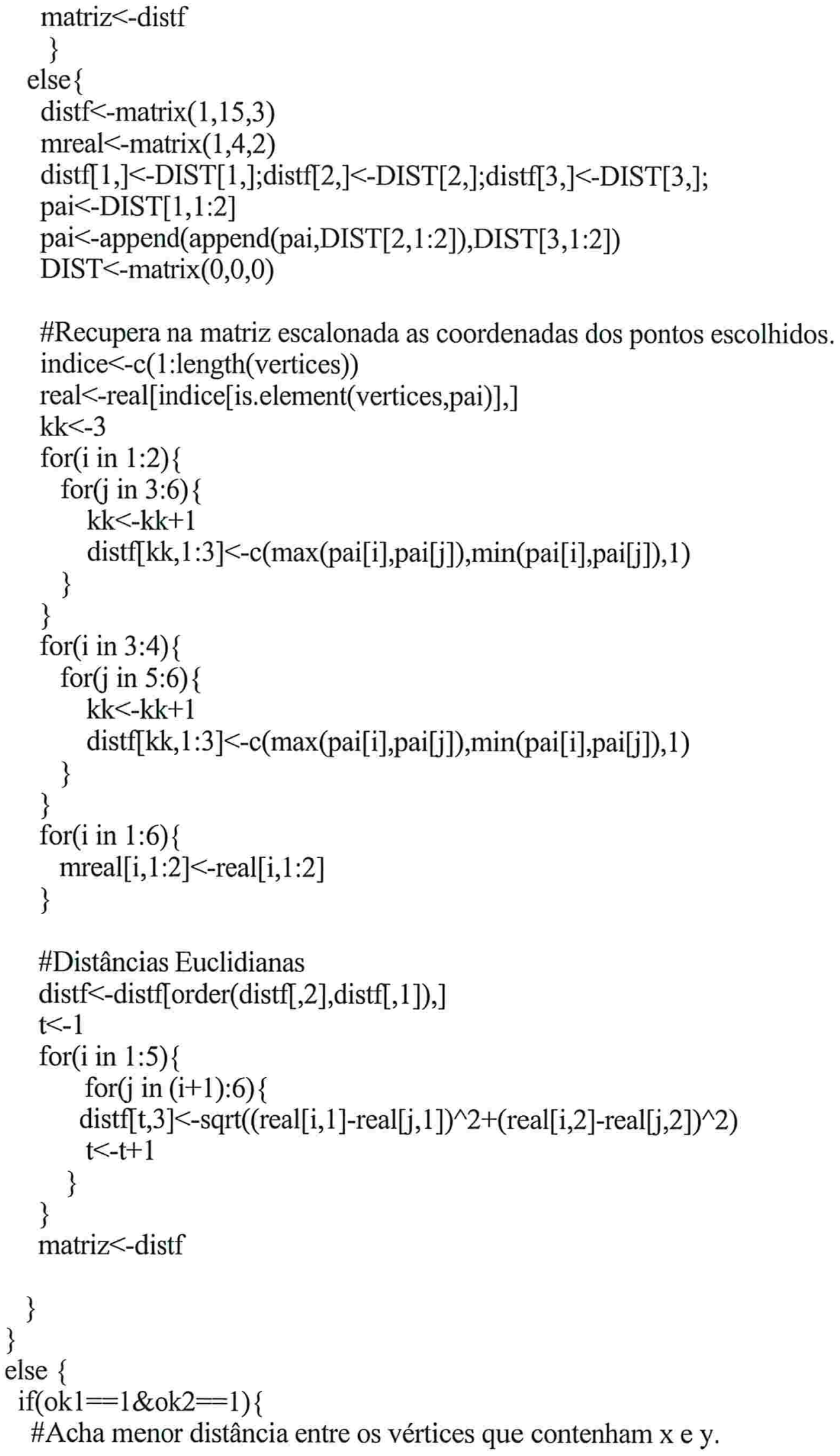




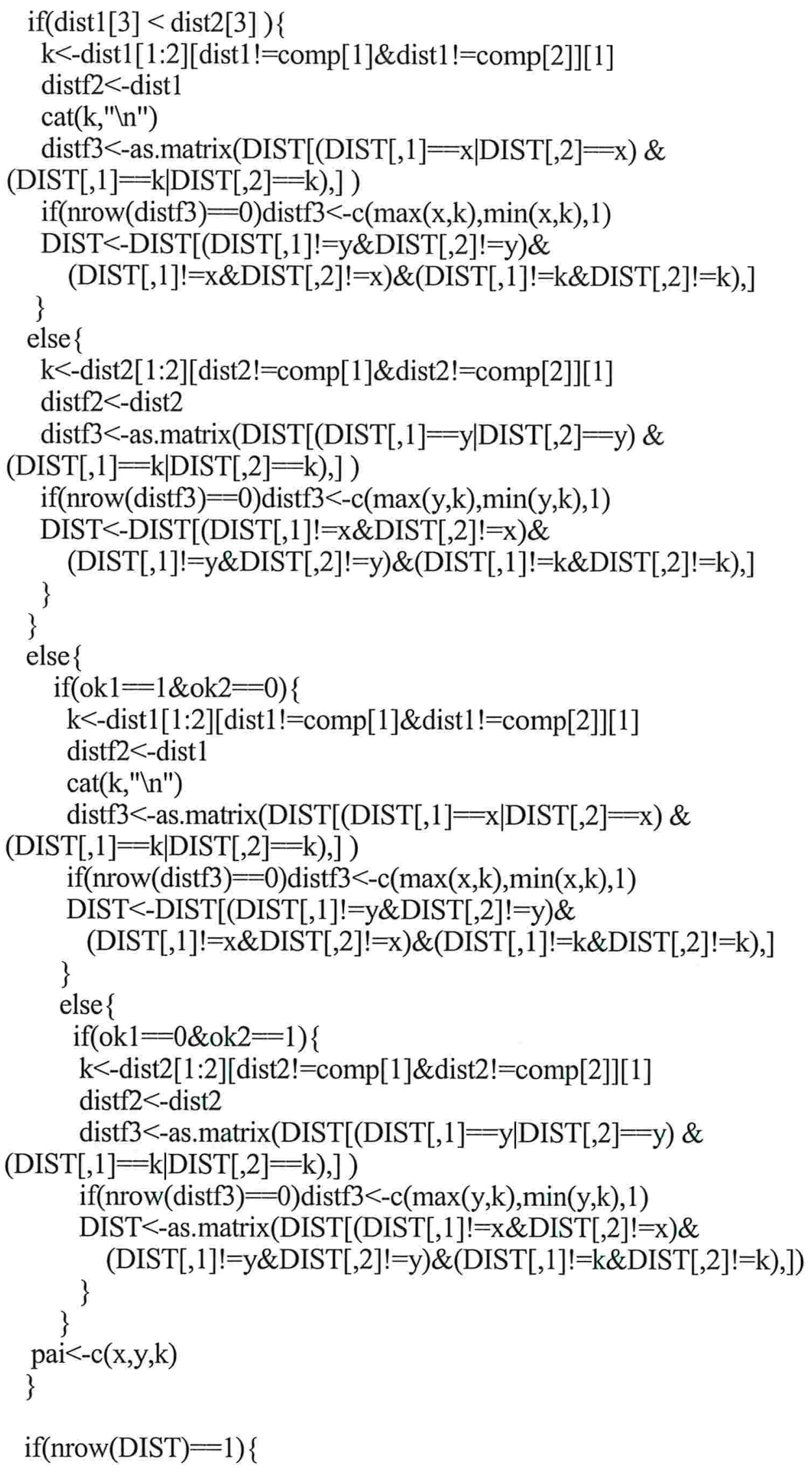




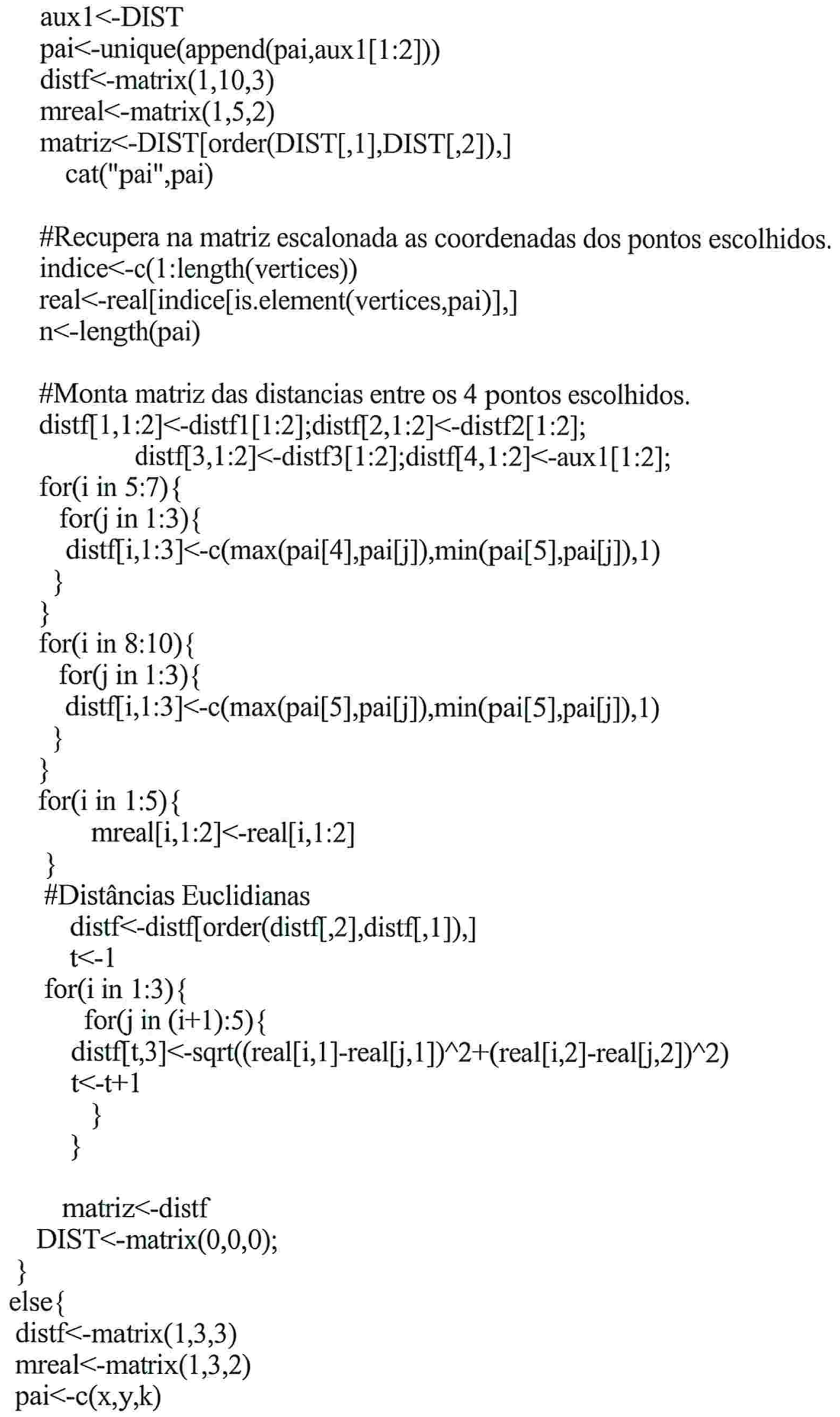

\#Recupera na matriz escalonada as coordenadas dos pontos escolhidos. indice $<-c(1:$ length(vertices)) 
\#Recupera na matriz escalonada as coordenadas dos pontos escolhidos.

indice $<-c(1:$ length(vertices))

real<-real[indice[is.element(vertices,pai)], ]

\#Monta matriz das distâncias entre os 3 pontos escolhidos.

distf[1,1:2]<-distf1[1:2]; distf[2,1:2]<-distf2[1:2]; distf[3,1:2]<-distf3[1:2];

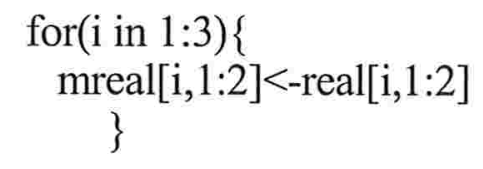

\#Distâncias Euclidianas.

distf<-distf[order(distf[,2],distf[,1]), ]

$\mathrm{t}<-1$

for(i in 1:2)\{

for $(\mathrm{j}$ in $(\mathrm{i}+1): 3)\{$

$\operatorname{distf}[t, 3]<-\operatorname{sqrt}\left((\operatorname{real}[i, 1]-\operatorname{real}[j, 1])^{\wedge} 2+(\operatorname{real}[i, 2]-\operatorname{real}[j, 2])^{\wedge} 2\right)$ $\mathrm{t}<-\mathrm{t}+1$

\}

$$
\text { \} }
$$

matriz<-distf

\}

\}

cat("DISTfinal $\backslash n ")$

return(distancia $=$ DIST, tri $=$ matriz, $\mathrm{pf}=$ pai, trireal=mreal) \} 


\subsubsection{Reúne}

Entrada: Distâncias remanescentes em DIST; distâncias entre 3 pais escolhidos; ids dos pais escolhidos; coordenadas dos pais escolhidos; distâncias entre pais e filhos; distâncias entre filhos.

Saída: $\quad$ Matriz contendo as distâncias relevantes reunidas.

f.reune $<$-function(distc,distpf,distff)

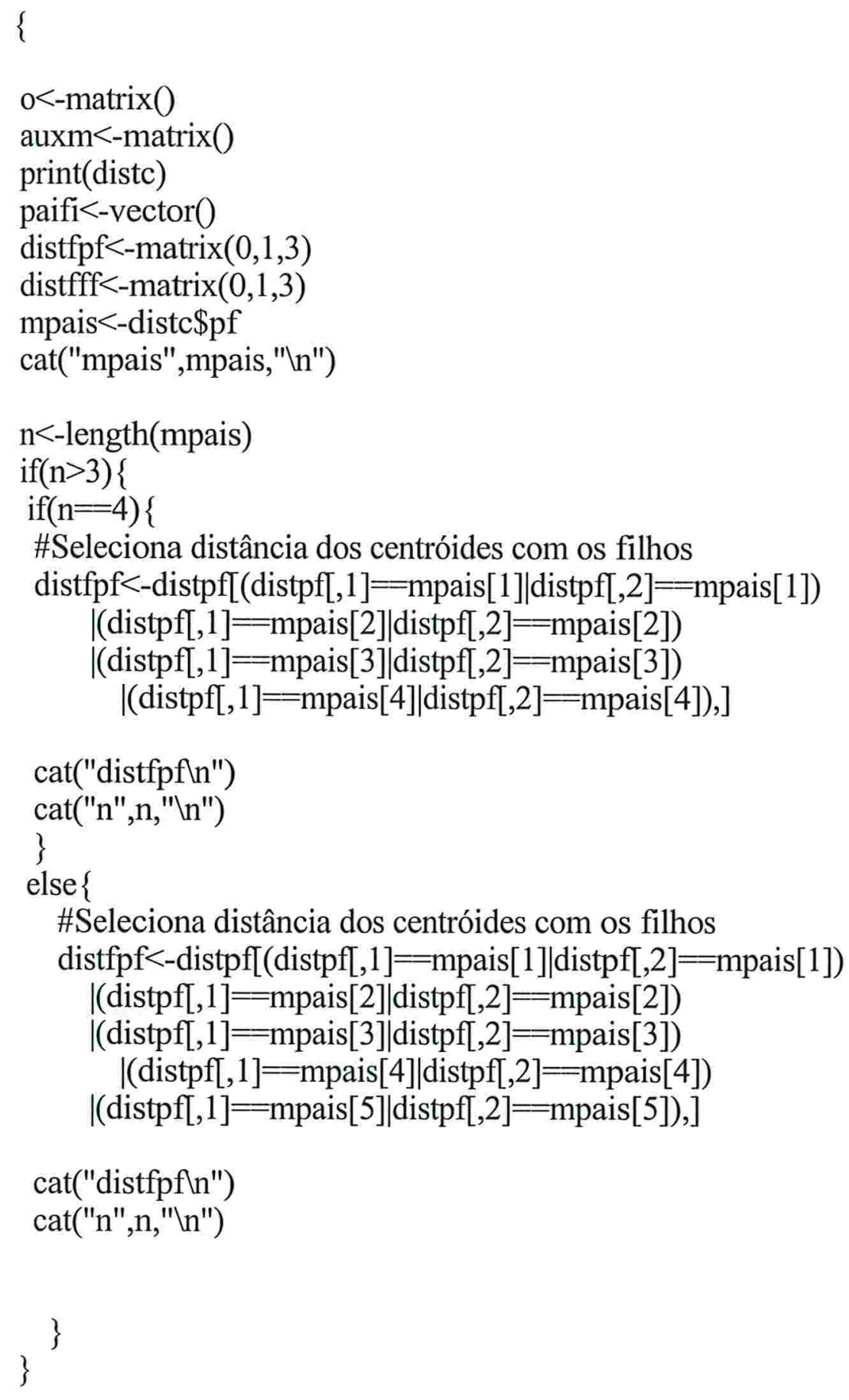




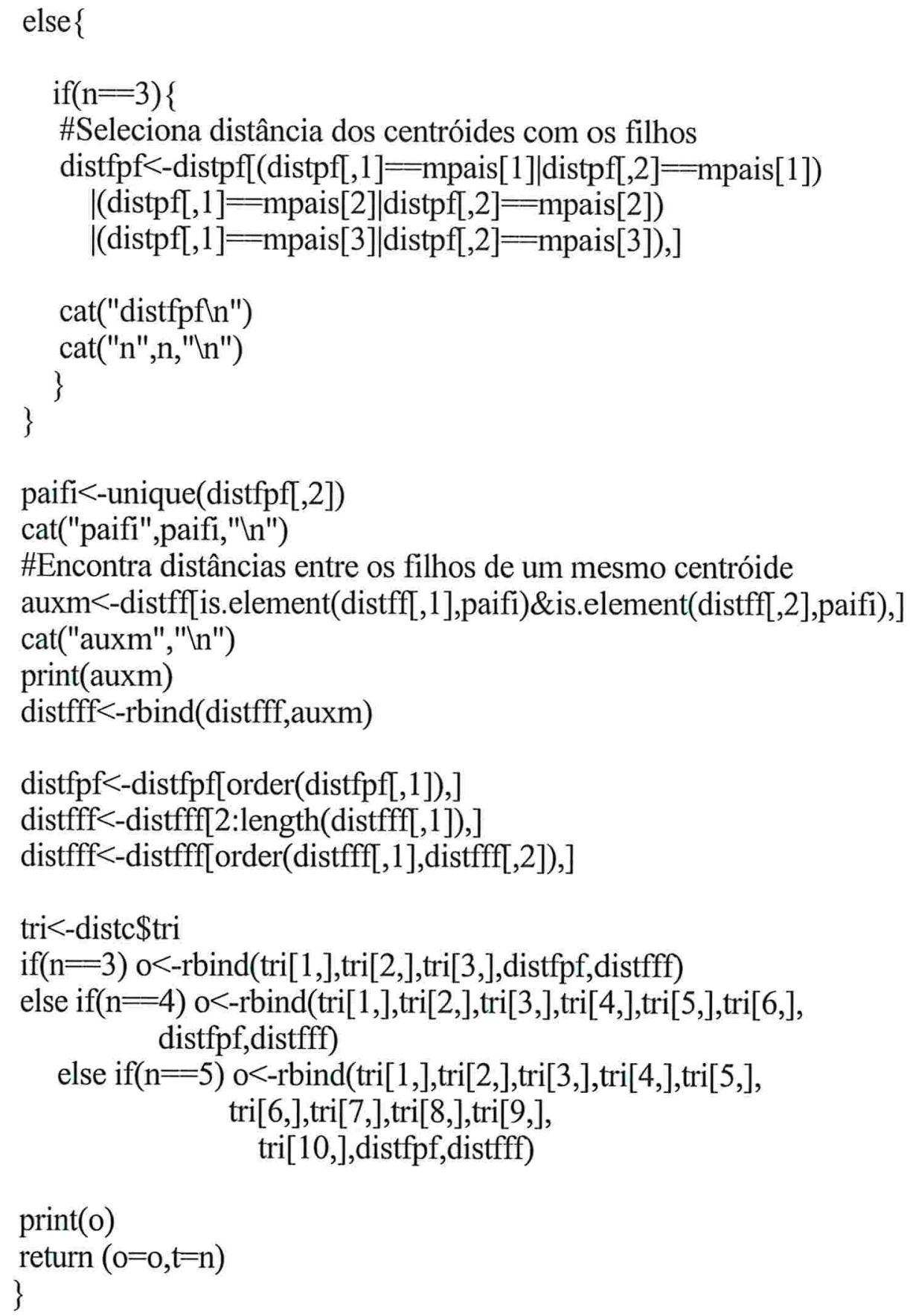




\subsubsection{Monta Matriz Simples}

Entrada: $\quad$ Matriz $\mathrm{n} \times 3$ com distâncias.

Saída: $\quad$ Matriz $\mathrm{n} \times \mathrm{n}$ subdiagonal, com distâncias.

f.monta.matriz.simples $<$-function(dist.vetor)

\{

no<-sort(unique(c(dist.vetor[,1],dist.vetor[,2])))

$\mathrm{n}<$-length(no)

cat(no)

dist.matriz<-matrix $(1, n, n)$

$\operatorname{diag}($ dist.matriz $)<-0$

indice $<-1: n$

for(i in $1: n)\{$

dist.vetor[dist.vetor[,1] $=$ no[i],1]<-indice[i]

dist.vetor[dist.vetor[,2] =-no[i],2]<-indice[i]

\}

dist.vetor<-arrumaposicao(dist.vetor)

print(dist.vetor)

for(i in 1:nrow(dist.vetor))

dist.matriz[(dist.vetor[i,1]),(dist.vetor[i,2])]<-dist.vetor[i,3]

dist.matriz<-as.dist(dist.matriz)

return $($ pontos $=$ dist.matriz, $\mathrm{n}=\mathrm{no})$

\} 


\subsubsection{Arruma Posição}

Entrada: Matriz nx 3 de distâncias.

Saída: $\quad$ Mesma matriz, com índices subdiagonalizados.

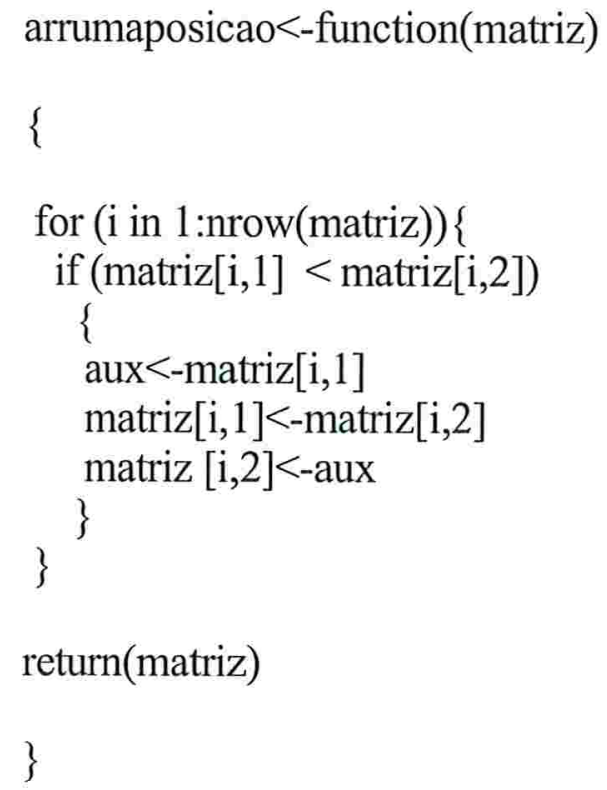




\subsubsection{Traço}

Entrada: Matriz quadrada.

Saída: $\quad$ Traço da matriz.

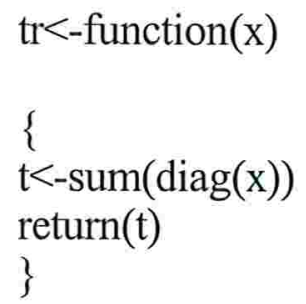




\subsubsection{Procrustes}

Entrada: Configuração a ser deformada; configuração fixa.

Saída: Matriz de rotação; fator de dilação; translação rígida; coeficiente de procrustes.

f.procrustes $<-$ function $(\mathrm{xv}, \mathrm{yv})$

\{

$\mathrm{x}<-\mathrm{xV}$

$\mathrm{y}<-\mathrm{yv}$

if $(\operatorname{dim}(\mathrm{x})[1] !=\operatorname{dim}(\mathrm{y})[1]|\operatorname{dim}(\mathrm{x})[2] !=\operatorname{dim}(\mathrm{y})[2]| \operatorname{dim}(\mathrm{x})[2] !=2)$

\{

print("Erro: as matrizes devem ter o mesmo número de linhas e duas colunas.") return()

\}

\#Centrar $\mathrm{x}$ e y no $(0,0)$.

xo $<-\mathrm{t}(\operatorname{as} . m a t r i x(\mathrm{c}(\operatorname{mean}(\mathrm{x}[, 1])$, mean $(\mathrm{x}[, 2]))))$

$\mathrm{x}[, 1]<-\mathrm{x}[, 1]-\mathrm{xo}[1,1]$

$\mathrm{x}[, 2]<-\mathrm{x}[, 2]-\mathrm{xo}[1,2]$

yo<-t(as.matrix $(\mathrm{c}(\operatorname{mean}(\mathrm{y}[, 1]), \operatorname{mean}(\mathrm{y}[, 2]))))$

y[,1]<-y[,1]-yo[1,1]

$\mathrm{y}[, 2]<-y[, 2]-y o[1,2]$

\#Rotação ótima

$\mathrm{c}<-\mathrm{t}(\mathrm{x}) \% * 0 \mathrm{y} \% * \% \mathrm{t}(\mathrm{y}) \% * 0 \mathrm{x}$

ei<-eigen(c)

sqrtc<-ei $\$$ vectors $\% * \% \operatorname{diag}($ sqrt(ei $\$$ values $)) \% * 0$ t(ei\$vectors)

$\mathrm{A}<-$ sqrtc $\% * \%$ solve $(\mathrm{t}(\mathrm{y}) \% * 0 \mathrm{x})$

\#Dilação

ro $<-\operatorname{tr}(\operatorname{sqrtc}) / \operatorname{tr}(\mathrm{t}(\mathrm{x}) \% * 0 \mathrm{x})$

\#Translação rígida

$\mathrm{B}<-\mathrm{yv}-\mathrm{ro} * \mathrm{x} \% * \% \mathrm{~A}$

\#Qualidade do ajuste

$\mathrm{R} 2<-1-\left(\left(\operatorname{tr}(\mathrm{sqrtc})^{\wedge} 2\right) /(\operatorname{tr}(\mathrm{t}(\mathrm{x}) \% * \% \mathrm{x}) * \operatorname{tr}(\mathrm{t}(\mathrm{y}) \% * \% \mathrm{y}))\right)$

$\operatorname{return}(A=A, r o=r o, B=B, R 2=R 2)$

\} 


\subsubsection{Ajustar}

Entrada: Coordenadas a ajustar, matriz de rotação, fator de dilação, translação rígida.

Saída: Coordenadas ajustadas.

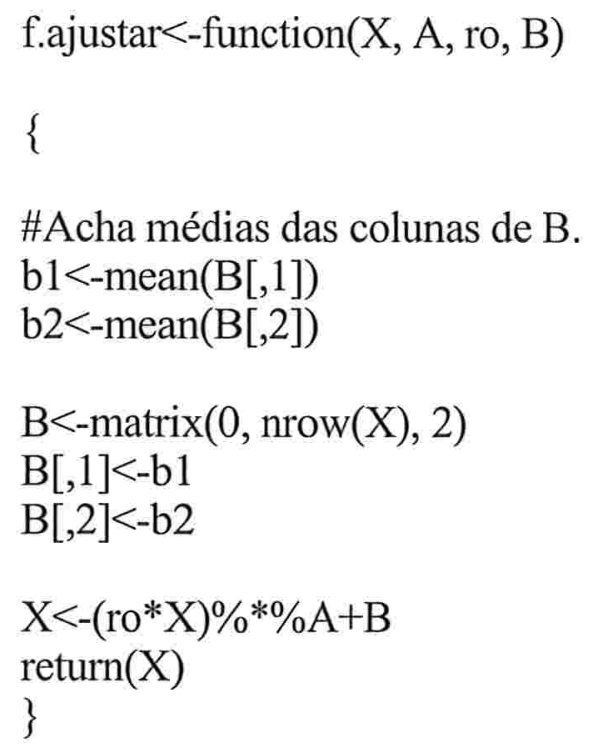




\subsubsection{Suaviza Dados}

Entrada: Matriz com coordenadas x e y da configuração; coesão de cada ponto; extremos do gráfico criado anteriormente, raio para suavização, número de partes em que dividir os eixos.

Saída: $\quad$ Coordenadas em $\mathrm{x}$ e coordenadas em y dos pontos de medida; e valor $\mathrm{z}$ das medidas em forma de matriz.

f.suaviza.grafico $<$-function(matriz,coesao,parametros,raio,lado)

\{

\#Cria matriz grade.

matriz<-cbind(matriz,coesao)

grade $<$-matrix $\left(0\right.$, lado` $\left.^{\wedge}, 3\right)$

\#Fixa distância entre pontos.

$\mathrm{dx}<$-(parametros[2]-parametros[1])/lado

dy<-(parametros[4]-parametros[3])/lado

xcoord<-seq(parametros[1]+dx,parametros[2],dx)

ycoord<-seq(parametros[3]+dy,parametros[4],dy)

for (i in 0:(lado-1))

for $(\mathrm{j}$ in 1 :lado)

\{

grade[(i*lado)+j,1]<-xcoord $[\mathrm{i}+1]$

grade[(i*lado $)+\mathrm{j}, 2]<-$ ycoord $[\mathrm{j}]$

\}

nm<-nrow(matriz)

\#Verifica para cada ponto de medida todos os vértices no seu raio de alcance.

for(i in 1:lado^2)

\{

$\operatorname{print}(\mathrm{i})$

$\mathrm{co}<-\mathrm{c} 0$

for(j in 1:nm)

\{

\#Teste se está dentro do círculo.

dist<-sqrt $\left((\operatorname{grade}[\mathrm{i}, 1]-\text { matriz}[\mathrm{j}, 1])^{\wedge} 2+(\operatorname{grade}[\mathrm{i}, 2]-\right.$ matriz[j,2])^2)

if $($ dist $<=($ raio*dx $))$ co $<$-append $($ co,matriz[j,3]) \} 
\#Grade[i] recebe coesão média dos elementos de seu raio de alcance.

if(is.nan(mean(co))) grade $[\mathrm{i}, 3]<-0$

\}

else grade $[\mathrm{i}, 3]<-$ mean $(\mathrm{co})$

dados $<$-matrix(grade[,3],lado,lado,byrow=TRUE)

return $(\mathrm{x}=\mathrm{xcoord}, \mathrm{y}=\mathrm{ycoord}, \mathrm{z}=$ dados $)$

\} 


\subsection{Corpo do Trabalho - Para o Exemplo 2}

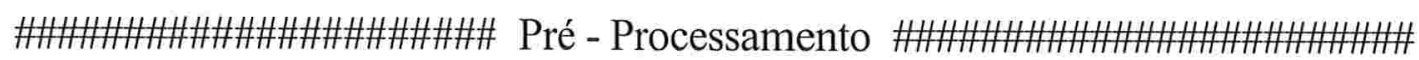

library(mva)

TO<-as.matrix(read.table("IMEtrans2.dat"))

save(TO, file="TO.r")

$\mathrm{TD}<$-f.deduplique(TO)

save(TD, file="TD.r")

$\mathrm{rm}(\mathrm{TO})$

TS<-f.remova.cilios(TD)

save(TS, file="TS.r")

colnames(TS)<-c("usuário","livro")

$\mathrm{rm}(\mathrm{TD})$

USUARIO<-f.vertices(TS[,1])

LIVRO $<$-f.vertices(TS[,2])

LV<-f.lista.vizinhos(TS[,1],TS[,2],length(USUARIO),length(LIVRO),USUARIO,1) save $(L V$, file="LV1.r")

f.lista.vizinhos(ts[,1],ts[,2],length(USUARIO1),length(LIVRO1),USUARIO1,1)

dp0p0<-f.distancia(LV\$V1,LV\$V2,LV\$Grau2,USUARIO)

save $\left(\mathrm{dp} 0 \mathrm{p} 0\right.$, file $\left.=" \mathrm{dp} 0 \mathrm{p} 0 . \mathrm{r}^{\prime \prime}\right)$

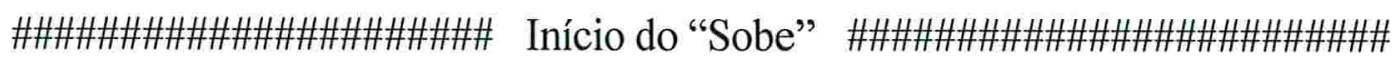

\#\#\#\#\#\#\#\#\#\#\#\#\#\#\#\#\#\#\#\#\# Nível 0 \#\#\#\#\#\#\#\#\#\#\#\#\#\#\#\#\#\#\#\#\#\#

VERTICE0<-USUARIO

L<-f.agrupa(VERTICE0,LV\$V2,LV\$Grau2,LV\$Coesao,0)

L0<-L\$L \#Listagem na ordem de VERTICE, indicando o grupo que cada usuário pertence.

G<-L\$G \#Número de grupos formados no nível 1 (número de centróides) $\mathrm{rm}(\mathrm{L})$

pp $<$-p $<$-VERTICE0[length(VERTICE0)]+1

dp1p0<-f.distancia.pf(L0,G,dp0p0,VERTICE0)

save (dp1p0, file="dp1p0.r") 


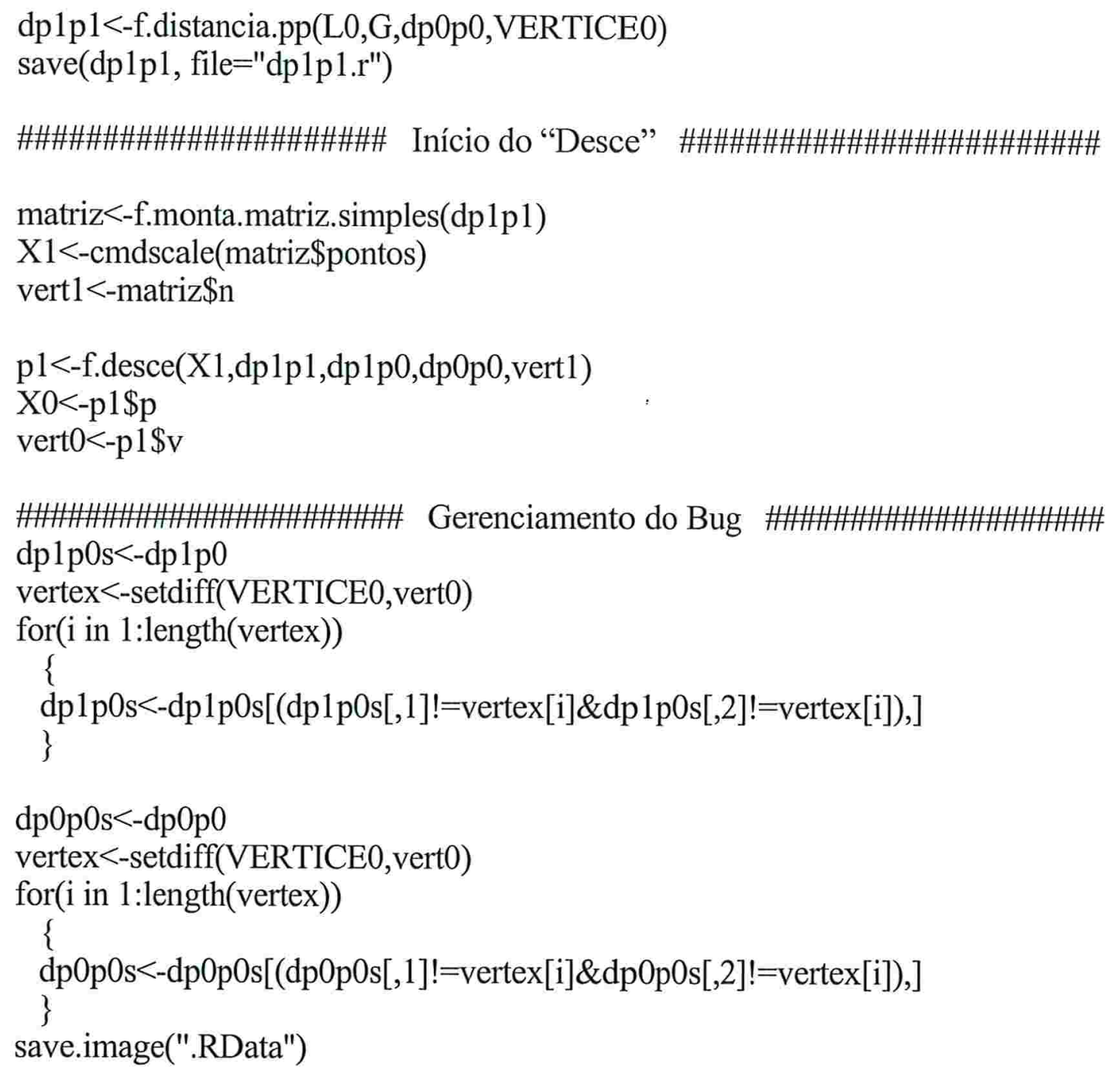




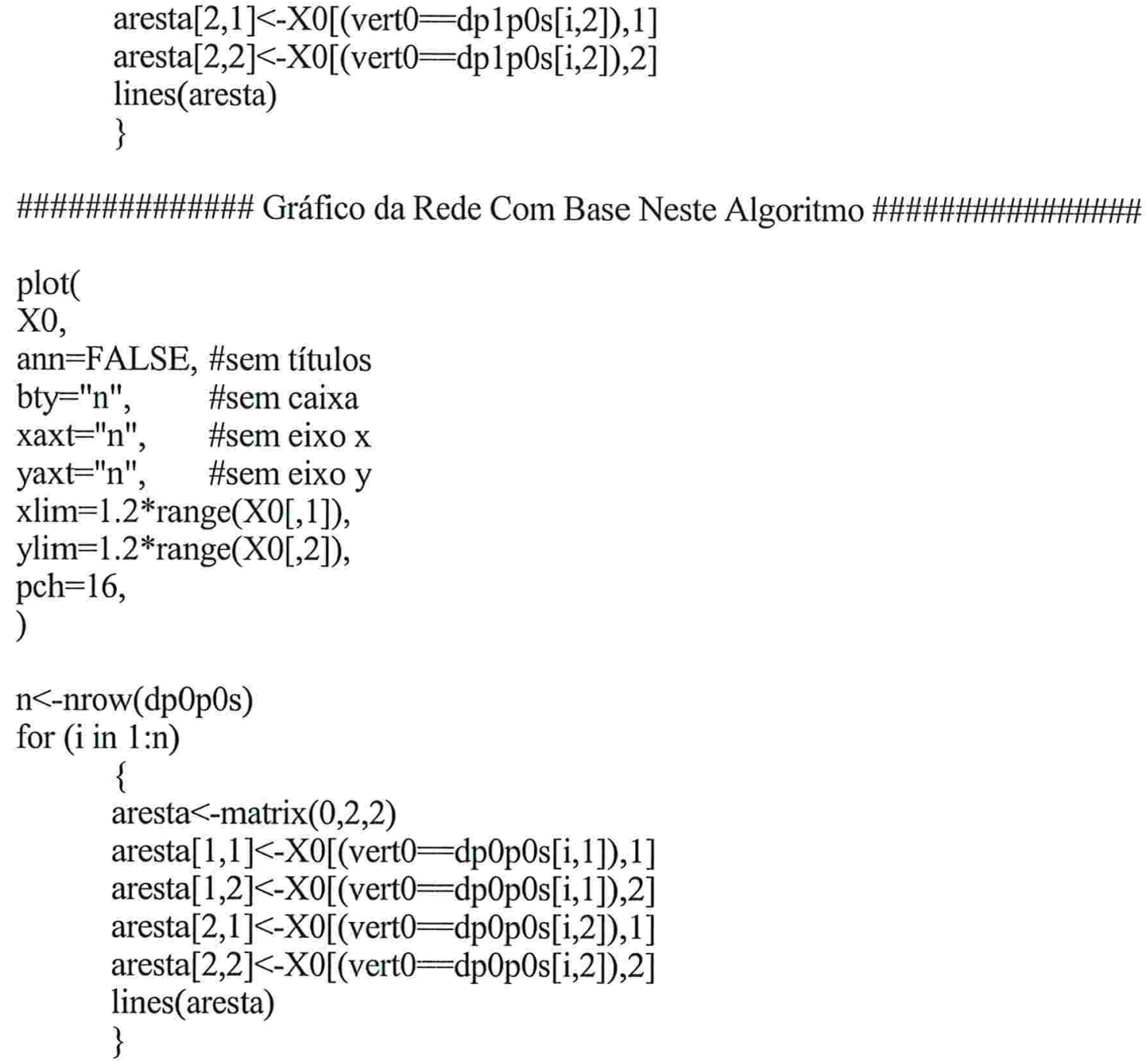

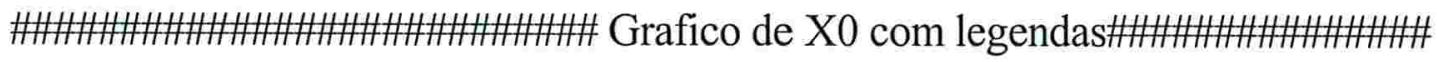

plot(

$\mathrm{X} 0$,

type="n",

ann=FALSE,

$x \lim =1.2 *$ range $(\mathrm{X} 0[, 1])$,

ylim $=1.2 *$ range $(\mathrm{X} 0[, 2])$

)

$\operatorname{text}(\mathrm{X} 0[, 1], \mathrm{X} 0[, 2]$, vert0, font $=2, \operatorname{cex}=.5)$

\#\#\#\#\#\#\#\#\#\#\#\#\#\#\# Gráfico em Perspectiva \#\#\#\#\#\#\#\#\#\#\#\#\#\#\#\#\#

$\operatorname{plot}(\mathrm{X} 0$, ann=FALSE,xlim=1.2*range $(\mathrm{X} 0[, 1]), \mathrm{ylim}=1.2 *$ range $(\mathrm{X} 0[, 2])$, type="n") 


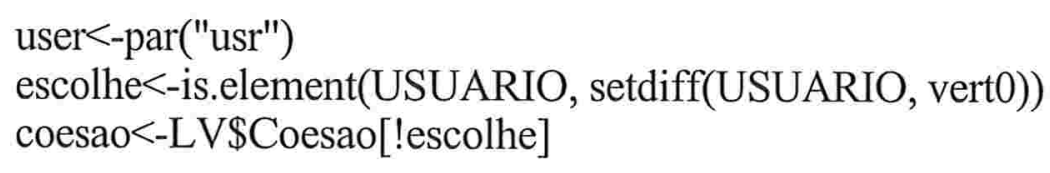




\section{BIBLIOGRAFIA}

AHO, Alfred V; HOPCROFT, John E; e ULLMAN, Jeffrey D. The design and Analysis of Computer Algorithms. Reading: Addison-Wesley Publishing Company, 1974

ARANHA, Francisco. "E-Service em Bibliotecas: Geração de Valor para Pesquisadores por Meio de Cooperação Indireta". RAE - Revista de Administração de Empresas, São Paulo: FGV/EAESP, v. 40, n. 4, Out/Dez 2000, pp. 84-93.

ARANHA, Francisco. Perfil de Usuários da Biblioteca Karl A. Boedecker: Geração de Valor para Pesquisadores por Meio de Cooperação Indireta. São Paulo: FGV/EAESP/NPP, Relatório de Pesquisa no. 14, 2001a, 64 pp.

ARANHA, Francisco. Análise de Redes em Procedimentos de Cooperação Indireta: Utilização no Sistema de Recomendações da Biblioteca Karl A. Boedecker. São Paulo: FGV/EAESP/NPP, Relatório de Pesquisa no. 27, 2001b, 77 pp.

BALAKRISHNAN, V. K. Theory and Problems in Graph Theory. New York: McGraw-Hill, 1997, 293 pp.

BARABASI, Albert-Laszlo. Linked: The New Science of Networks. Cambridge (MA): Perseus Publishing, 2002, 280pp.

BATTISTA, Giuseppe di; EADES, Peter; TAMASSIA, Roberto; e TOLLIS, Ioannis G. Graph Drawing: Algorithms for the Visualization of Graphs. Upper Saddle River: Prentice Hall, 1999, 397pp.

BEATTY, Sharon E. e SMITH, Scott M. "External Search Effort: An Investigation Across Several Product Categories". Journal of Consumer Research, Gainesville, v. 14, p. 83-95, June 1987. 
BERRY, Michael e LINOFF, Gordon. Data Mining Techniques For Marketing, Sales and Customer Support. New York: John Wiley and Sons, 1997, $454 \mathrm{pp}$.

BERRY, Michael e LINOFF, Gordon. Mastering Data Mining: The Art and Science of Customer Relationship Management. New York: John Wiley and Sons, 2000, 494 pp.

BOLLOBÁS, Béla. Random Graphs. London; Orlando: Academic Press, 1985, $447 \mathrm{pp}$.

BOLLOBÁS, Béla. Modern Graph Theory. New York: Springer, 1998, 394 pp.

BUSSAB, Wilton O; MIAZAKI, Édina S. e ANDRADE, Dalton F. Introdução à Análise de Agrupamentos. São Paulo: IME/USP, 1990, $105 \mathrm{pp}$.

CABENA, Peter; HADJINIAN, Pablo; STADLER, Rolf; VERHEES, Jaap; e ZANASI, Alessandro. Discovering Data Mining, Upper Saddle River: Prentice Hall, 1997, 195 pp.

CARSON, Kerry D; CARSON, Paula P; e PHILIPS, Joyce S. The ABCs of Collaborative Change: The Manager's Guide to Library Renewal. Chicago: ALA Editions, 1997, 272 pp.

CLUNG, Fan e GRAHAM, Ron. Erdos on Graphs: His Legacy and Unsolved Problems. Wellesley, Mass: A. K. Peters, 1998.

COX, Trevor F. e COX, Michael A. Multidimensional Scaling, $2^{\text {nd }}$ ed. Boca Raton: Chapman \& Hall/CRC, 2001, 308 pp.

GLADWELL, Malcom. The Tipping Point. London: Abacus, 2000, 279 pp. 
GOOD, N; SCHAFER, J; KONSTAN, J; BORCHERS, A; SARWAR, B; HERLOCKER, J; and RIEDL, J. Combining Collaborative Filtering with Personal Agents for Better Recommendations. Minneapolis: GroupLens Research Project, Department of Computer Science and Engineering, University of Minnesota. http://www.cs.umn.edu/research/grouplens/aaai-99.pdf (link válido em 23/07/01), 7 pp.

GRAHAM, R. L. e NESETRIL, J. The Mathematics of Paul Erdos. Berlin: Springer, 1997.

GRANOVETTER, Mark S. The Stregth of Weak Ties. American Journal of Sociology, Volume 78, Issue 6, May 1973, pp. 1360-1380.

HAIR, Joseph; ANDERSON, Rolph; TATHAM, Ronald; e BLACK, William. Multivariate Data Analysis, $4^{\text {th }}$ ed., Englewood Cliffs: Prentice Hall, 1995, 745pp.

HANN, Leslie. "High-Tech Sleuths". Best's Review, Nov. 1998, pp. 83-85.

JENSEN, David. "Prospective Assessment of AI Technologies for Fraud Detection". Working Papers of the AAAI-99 Workshop on Artificial Intelligence Approaches to Fraud Detection and Risk Management.

JOHNSON, Richard A. e WICHERN, Dean W. Applied Multivariate Statistical Analysis, $5^{\text {th }}$ ed. Englewood Cliffs: Prentice Hall, 2002.

KAUTZ, Henry; SELMAN, Bart; e SHAH, Mehul. "Combining Social Networks and Collaborative Filtering", Communications of the ACM, March 1997a, vol. 40, n. 3, pp. 63-65.

KAUTZ, Henry; SELMAN, Bart; e SHAH, Mehul. "The Hidden Web", AI Magazine, Summer 1997b, pp. 27-36. Disponível em http://www.research. att.com/ kautz/referralweb/doc/aimag.pdf, link válido em 27/12/99 às 11h10). 
KNOKE, David e KUKLINKSI, James H. Network Analysis, Newbury Park: Sage Publications, Sage University Paper 28, 1982, 96 pp.

LARGE, Peter. The Micro Revolution Revisited. New Jersey: Rowman \& Allanheld, 1984.

MIDGLEY, David F. "Patterns of Interpersonal Information Seeking for the Purchase of a Symbolic Product". Journal of Marketing Research, Chicago, v. 20, p. 74-83, Feb. 1983.

MILLER, Kathy. "Librarians Getting a Handle on Knowledge". Information World Review, June 1998, pp. 25-26.

NEWMAN, Joseph W. e STAELIN, Richard. "Information Sources of Durable Goods". Journal of Advertising Research, New York, v. 13, p. 19-29, Apr. 1972

PAYTON, David. "Discovering Collaborators by Analyzing Trails Trough an Information Space", Artificial Intelligence and Link Analysis Papers from the 1998 Fall Symposium, October 23-25, Orlando Florida.

PEPPERS, Don e ROGERS, Martha. "Is Your Company Ready for One-toOne Marketing?". HBR, January-February 1999, pp. 151-163.

RAMO, Joshua C. "The Fast-Moving Internet Economy Has A Jungle of Competitors... And Here Is the King: Jeffery Preston Bezos, 1999 Person of the Year', TIME Magazine, 27/12/1999, pp. 42-59.

ROGERS, Everett M. Diffusion od Innovations, $4^{\text {th }}$ ed. New York: The Free Press, 1995, $518 \mathrm{pp}$.

SANTOS, Érico R. Implantação de Tecnologia de Data Warehouse em Bibliotecas com Uso de Tecnologia Adequada. São Paulo: FGV/EAESP, 2000, 53 pp. 
SCHWARTZ, Michael e WOOD, David. "Discovering Shared Interests Using Graph Analysis". Communications of the ACM, August 1993, vol. 36, n. 8, pp. 78-89.

SKIENA, Steven S. The Algorithm Design Manual. New York: SpringerVerlag, 1998, 486 pp.

SMYTH, Barry e COTTER, Paul. "A Personalized Television Listings Service". Communications of the ACM. New York: Association for Computing Machinery, v. 43, n. 8, Aug 2000, pp. 107-111.

SWANSON, Don e SMALHEISER, David. "Link Analysis of Medline Titles as an Aid to Scientific Discovery". http://kiwi.uchicago.edu/ libtrends.html, link válido em 04.01.2000.

TRUDEAU, Richard J. Introduction to Graph Theory. New York: Dover, 1993, 203 pp.

WASSERMAN, Stanley e FAUST, Katherine. Social Network Analysis: Methods and Applications. Cambridge: Cambridge University Press, 1994, 825 pp.

WASSERMAN, Stanley e GALASKIEWCZ, Joseph (eds.). Advances in Social Network Analysis, Thousand Oaks: Sage Publications, 1994, 299 pp.

WATTS, Duncan J. Small Worlds: The Dynamics of Networks between Order and Randomness. Princeton: Princeton University Press, 1999, $262 \mathrm{pp}$.

WILSON, Robin J. Introduction to Graph Theory. Harlow: Prentice Hall, 1996, 171.

WURMAN, Richard Saul. Ansiedade de Informação. São Paulo: Cultura, 1991, 380 pp. 


\section{Índice Remissivo}

\section{A}

acessibilidade de documentos na Internet, 15 AHO, HOPCROFT e ULLMAN, 12 algoritmo escalável, 12

Amazon.com, 18

análise de agrupamentos, 8

análise de cestas, 8

análise de redes, $8,10,14,15$

ARANHA, 7, 8, 9

Arrowsmith, 6

\section{B}

BALAKRISHNAN, 13

BARABASI, 13, 17, 18

BATTISTA e OUTROS, 39, 40

BEATTY e SMITH, 2

BERRY e LINOFF, 8

Biblioteca Karl A. Boedecker, 7, 132

bibliotecas, 7

BOLLOBÁS, 13

BUSSAB, MIAZAKI e ANDRADE, 8

C

CABENA e OUTROS, 6

CARSON e OUTROS, 7

CLUNG e GRAHAM, 13

coesão, 10, 14

colaboradores potenciais, 6

collaborative filtering, 3, 134

cooperação indireta, 15

COX e COX, 20, 21, 23, 25, 26

D

data mart de transações, 7

data mining, 126

detecção de fraudes, 6

difusão de inovações, 15

distância temática, 9

E

escalabilidade de algoritmos, 9, 12 escalonamento multdimensional, 20

escalonamento multidimensional, 10

espaço temático, 10, 11

\section{F}

filtro colaborativo, 3, 5, 6, 8, 10

filtro de conteúdo, 4

filtro informativo, 3, 4, 5, 6

formação de subgrupos especializados, 8

G

GLADWELL, 16

GOOD, SCHAFER e OUTROS, 3

grafos, 13

GRAHAM E NESETRIL, 13

GRANOVETTER, 15, 17

\section{H}

HAIR, TATHAM e OUTROS, 8

HANN, 6

\section{I}

identificação de assuntos significativos, 8

information filtering, 3

information retrieval, 3

J

JENSEN, 6

JOHNSON e WICHERN, 8

$\mathbf{K}$

KAUTZ, SELMAN e SHAH, 6

KNOKE e KUKLINSKY, 14

$\mathbf{L}$

LARGE, 2

Lawrence e Giles, 17

livraria virtual, 9,18

\section{M}

matriz de co-ocorrências, 9 
MIDGLEY, 2

MILLER, 7

Movie Lens, 19

\section{$\mathbf{N}$}

NEWMAN e STAELIN, 2

\section{$\mathbf{P}$}

padrão de navegação, 6

PAYTON, 6

PEPPERS e ROGERS, 7

período de latência, 6

Personalized Television, 19

procura de empregos, 15

$\mathbf{R}$

$\mathrm{R}, 79$

RAMO, 18

recuperação de informação, 3

Redes, 13

relevância de um item, 5

relevância localizada, 3

ROGERS, 15, 16
S

SANTOS, 7

SCHWARTZ e WOOD, 6, 8, 14

sistema de recomendações, 7, 8, 9, 18, 19

sistemas de recomendações, 18

SKIENA, 40, 56, 126, 136

SMYTH e COTTER, 4, 19

subgrafo, 14

subgrupos especializados, 8, 9, 10

SWANSON e SMALHEISER, 6

\section{$\mathbf{T}$}

teoria dos grafos, 10, 13, 15

TRUDEAU, 13

vizinhança, 10,14

\section{W}

WASSERMAN e FAUST, 14

WASSERMAN e GALASKEWICZ, 14

WATTS, 14

WILSON, 13

WURMAN, 2 